\title{
Gender-based Violence in Bougainville: Stories of Change
}

\section{Viktoria Degerman}

$$
2014
$$

A thesis submitted to Victoria University of Wellington in partial fulfilment of the requirements for the degree of Masters in Development Studies

School of Geography, Environment and Earth Sciences Victoria University of Wellington 


\section{Abstract}

Gender-based violence throughout Papua New Guinea is a well documented concern across disciplines. Within the field of development, gender-based violence is not only seen as a human rights breach, but it is widely accepted that violence exacerbates poverty, and that poverty exacerbates violence. Women are particularly affected by this cyclic nature of violence. Despite numerous initiatives from development actors, the Papua New Guinean government and local agencies, the rate of violence has not shifted in the past two decades (Ganster-Breidler, 2010). Similarly, in Bougainville, an autonomous region of Papua New Guinea, reports state that the rate of violence against women is extremely high. A United Nations study from 2013 showed that over 60 per cent of Bougainville men surveyed had committed rape at some point in their lives, and that physical violence was equally prevalent (Fulu et al., 2013).

In response to these worrisome reports, I began to wonder what can be done to address gender-based violence. What has been successful in the past and what can we learn from those who have firsthand experience of intimate partner violence?

The research addressed these types of problems through the use of 18 interviews conducted with men and women; including former perpetrators of intimate partner violence and survivors. The study was further strengthened by my observations from working at Buka Family Support Centre, a service in Bougainville that cares for survivors of gender-based violence.

I frame this research within feminist and poststructural ways of knowing. It is influenced by a four-tiered conceptual model that considers external and internal influences on individual actions. The analysis was inspired by Foucault's discourse analysis (Foucault, 1979, 1984) and I pay special attention to dominant and discriminatory discourses and the resistance to these.

In summary, this study offers intimate and detailed stories of change. It reveals that the participants primarily referred to positive change as an absence of physical violence and not necessarily other forms of gender-based violence. The study also shows that the survivors' 
resisted violence throughout the abusive period, and those who eventually chose to divorce only did so because of concerns over safety.

The stories are anchored to lived experiences, and the conclusion and recommendations that flow from this qualitative study contribute to knowledge of what works when trying to end violence within an intimate partnership in Bougainville. 


\section{Acknowledgments}

A heartfelt thank you to the 18 Bougainville men and women who generously shared their time and experiences with me. I will long remember the stories told; of sadness, of fear, of hope and of bravery. Without you, this thesis could not have happened.

To my supervisor Sara Kindon, for your encouraging words, for helping me to stay on track, and for always being able to place ideas in a context. Your way of viewing and articulating the world is inspiring.

To Sister Essah Barnabas at Buka Family Support Centre, my former work colleague and friend. Your guidance made it all so much easier. Your laughter and dedication to the cause made my day for an entire year.

To Buka General Hospital, in particular Dr Imako for supporting me and my research and for always beginning our conversations with a joke.

To all of those women in Buka who work tirelessly to improve gender relationships. Your dedication and ability to keep going is nothing less than inspirational.

To all of the VSA volunteers and other friends in Bougainville who refreshingly just got on with things.

To all of my proofreaders who helped me from afar: Anna, Kirsten, Lorraine and Chris. Thank you so much for your time, effort and feedback. Reading about gender-based violence in your spare time is not everyone's cup of tea. I truly appreciate it.

To my family back home in Sweden, for always being there and for always believing in what I do.

Also, thank you to the New Zealand Aid Programme who financially supported my field work.

And Mark. For going to Big C, for the late-night coffees and for always being happy to help. 


\section{List of Acronyms}

ABG Autonomous Bougainville Government

Al Appreciative Inquiry

ARoB Autonomous Region of Bougainville

BGH Buka General Hospital

BPA Bougainville Peace Agreement

BPA Beijing Declaration and Platform for Action

BRA Bougainville Revolutionary Army

CEDAW Convention on the Elimination of all Forms of Discrimination against Women

CEO Chief Executive Officer

CoE Council of Elders

CSO Civil Society Organisations

DA Discourse Analysis

DFAT (Australian Government) Department of Foreign Affairs and Trade

DV Domestic Violence

EIGE European Institute for Gender Equality

FSC Family Support Centre

FSV Family and Sexual Violence

FSVAC Family and Sexual Violence Action Committee

GBV Gender Based Violence

HEC Human Ethics Committee

HIV Human Immunodeficiency Virus

IPV Intimate Partner Violence

KRA Key Result Area

LNWDA Leitana Nehan Women's Development Agency

MDG Millennium Development Goal

MSF Médecins Sans Frontières

NBHRC North Bougainville Human Rights Committee

NGO Non-Government Organisation

NRT Non-Representational Theory

ODA Official Development Assistance

ODW Office for Development of Women

OECD Organization for Economic Cooperation and Development

PGK Papua New Guinea Kina (currency)

PIFS Pacific Island Forum Secretariat

PNG Papua New Guinea

PNGDF Papua New Guinea Defence Force

PPA Pacific Platform for Action

PPP Public Private Partnerships

RPPA Revised Pacific Platform for Action

SRHR Sexual and Reproductive Health an d Rights

STI Sexually Transmitted Infection

UDHR Universal Declaration of Human Rights

UN United Nations

UNDP United Nations Development Programme 
UNICEF United Nations Children's Fund

VAW Violence Against Women

VSA Volunteer Services Abroad

WHO World Health Organization 


\section{Table of Contents}

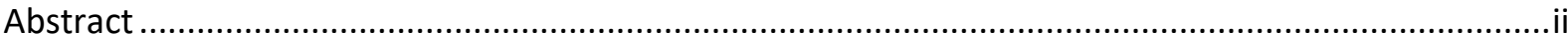

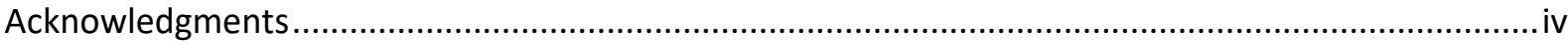

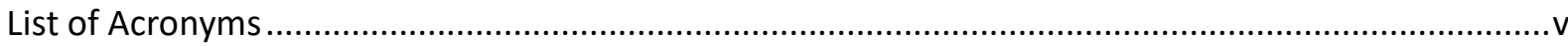

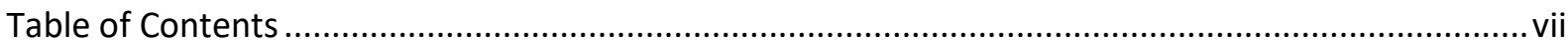

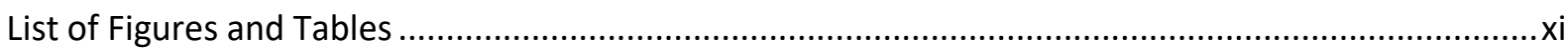

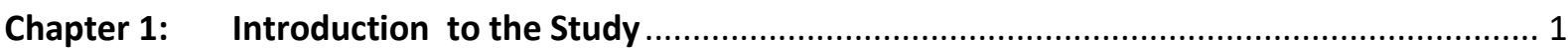

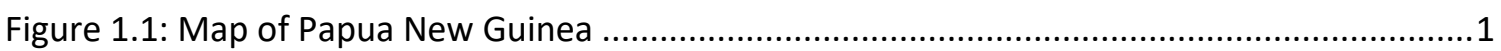

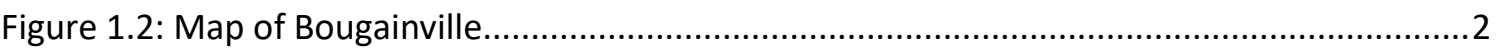

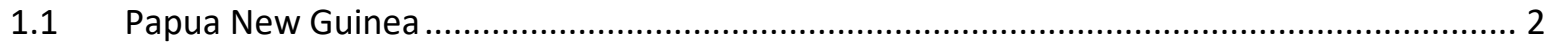

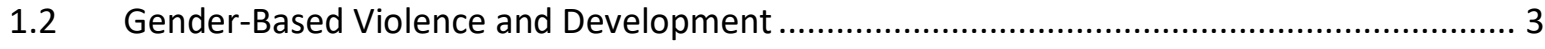

1.3 Commitments to Address Gender-Based Violence in PNG ................................................ 4

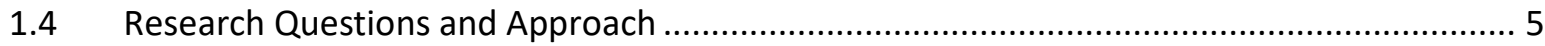

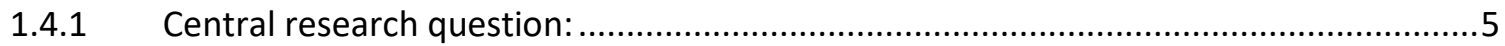

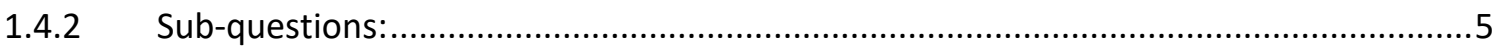

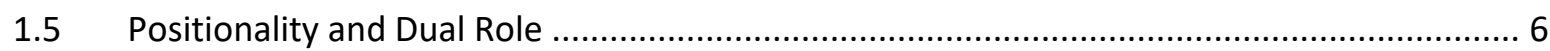

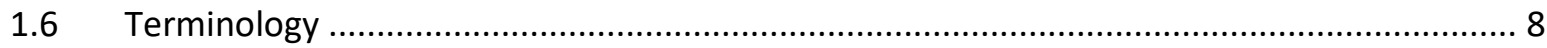

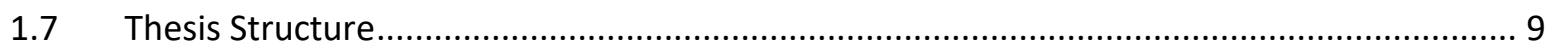

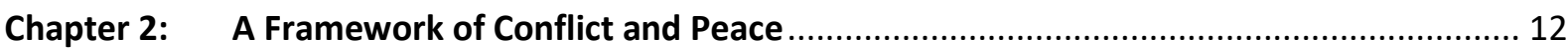

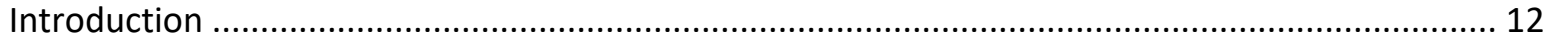

2.1 Conceptual Framework to Understanding Gender-Based Violence ................................... 12

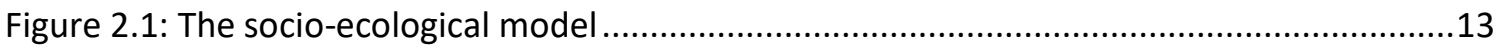

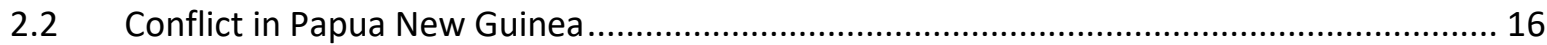

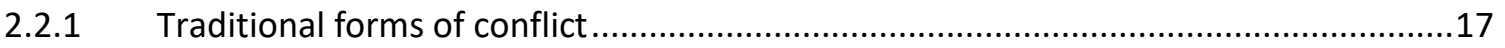

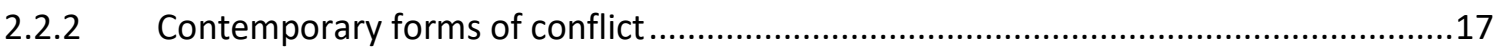

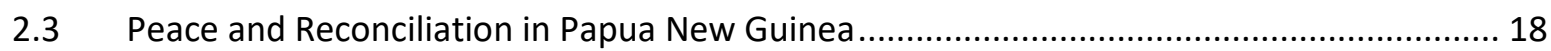

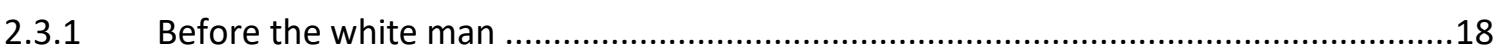

2.3.2 The Westminster System and Customary Law.........................................................

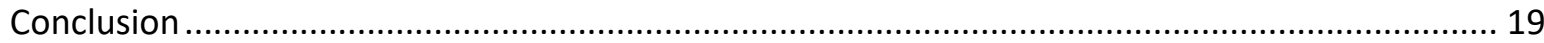

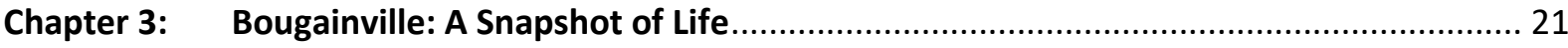

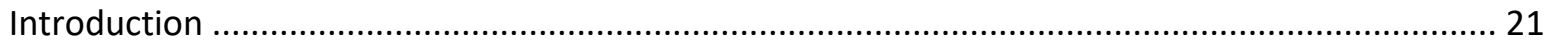

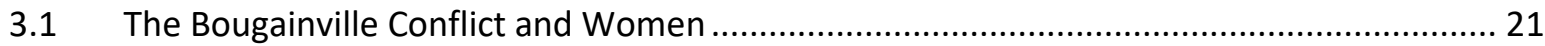

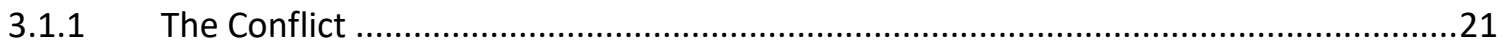

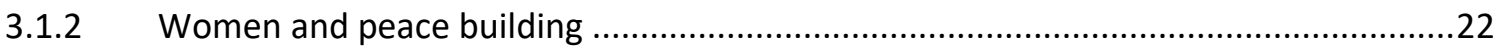




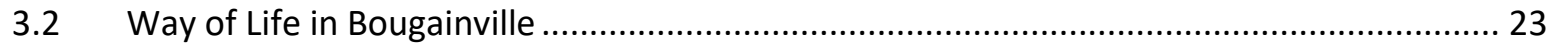

3.2.1 The Autonomous Bougainville Government and Council of Elders .............................23

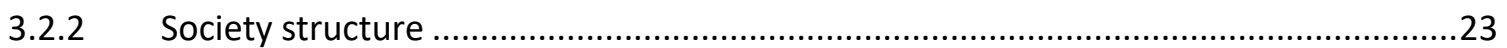

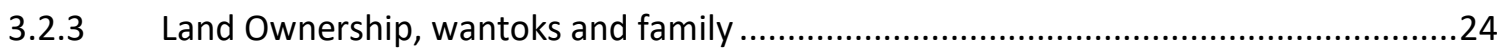

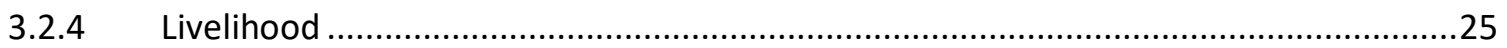

3.2.5 Health, including sexual and reproductive health and rights (SRHR) ..........................25

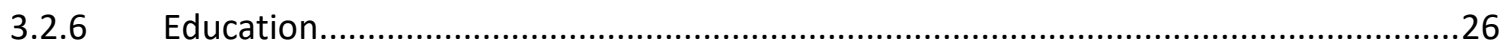

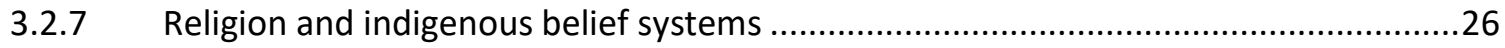

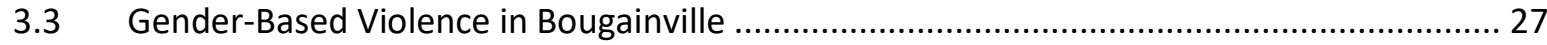

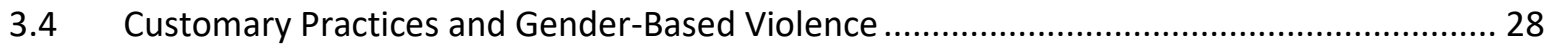

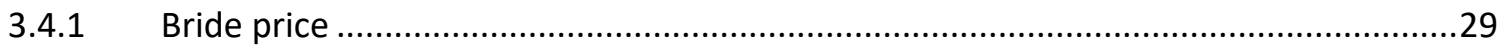

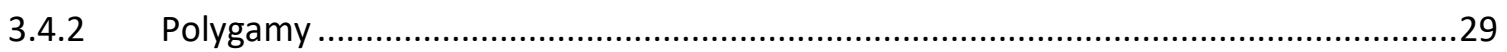

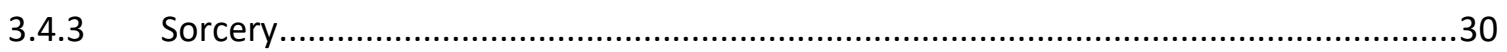

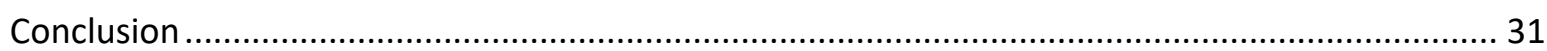

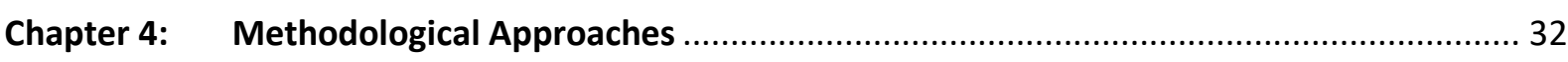

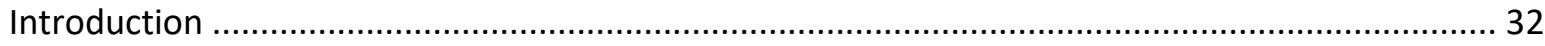

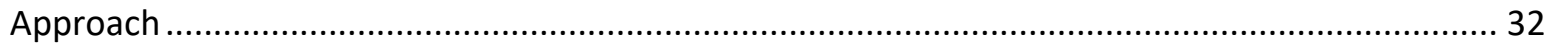

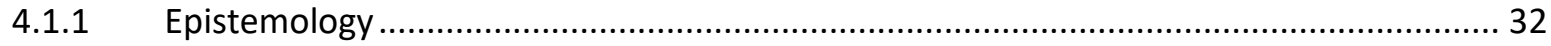

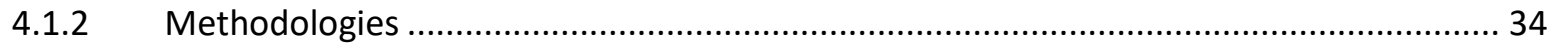

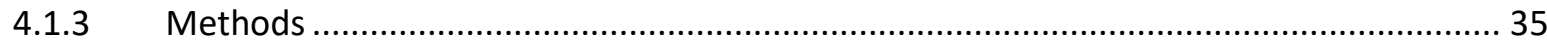

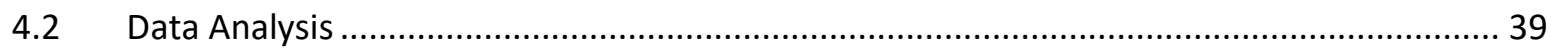

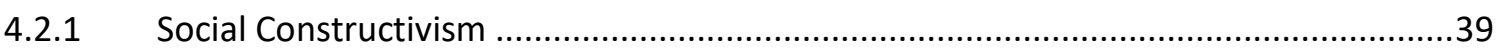

4.2.2 What is a discourse analysis inspired by Foucault? ....................................................

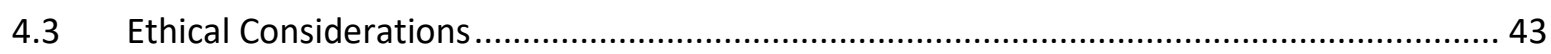

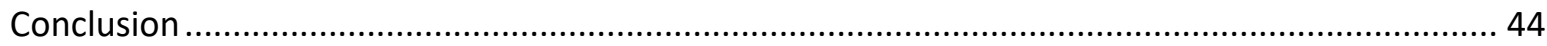

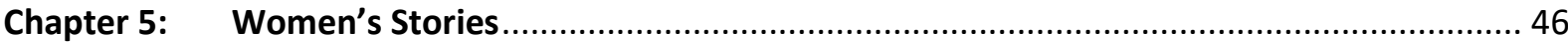

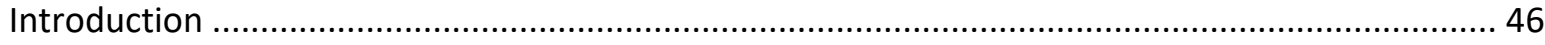

Table 5.1: Demographics of the female participants .................................................................

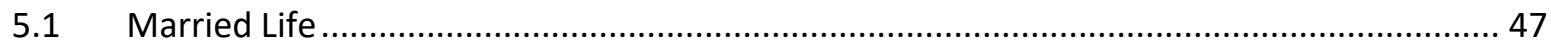

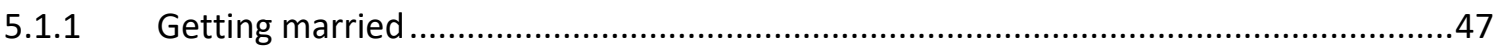

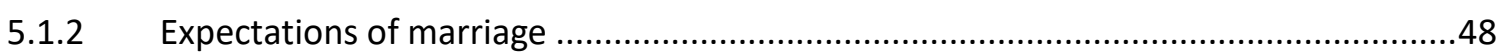

5.1.3 Expectations of a woman in marriage; by self and others ...........................................50

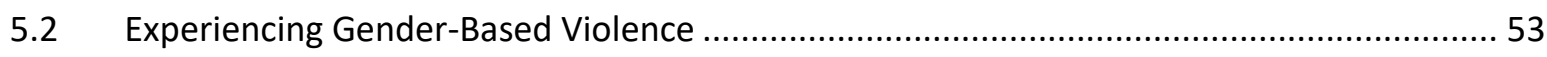

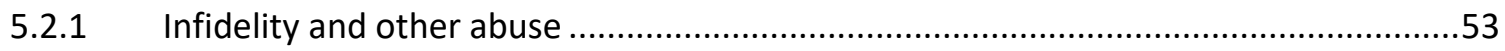




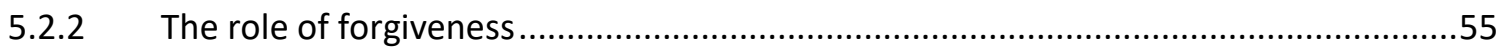

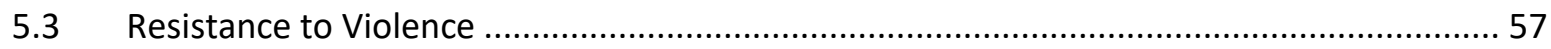

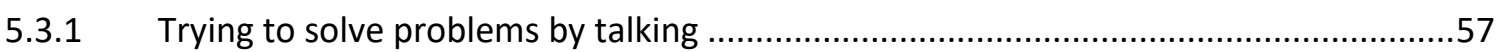

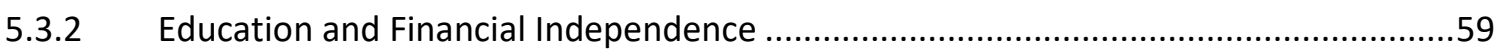

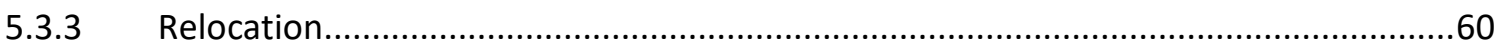

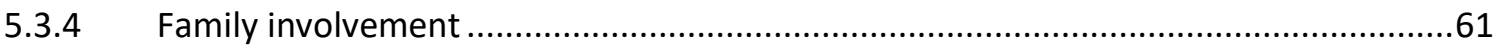

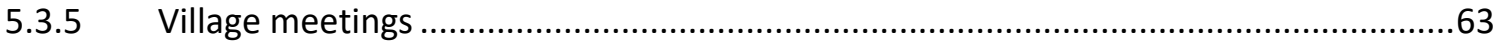

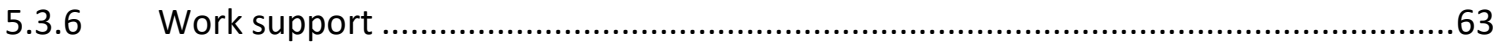

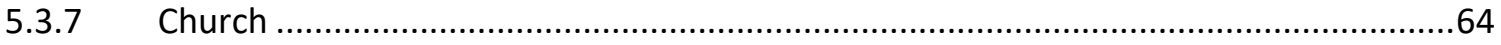

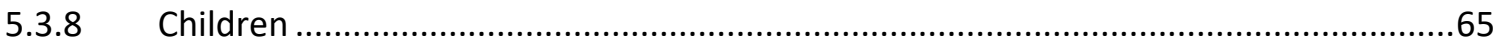

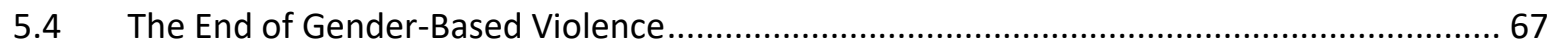

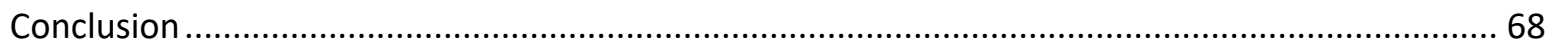

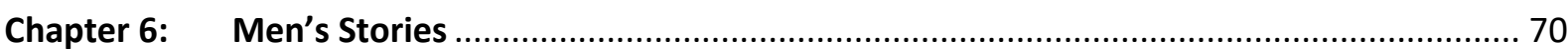

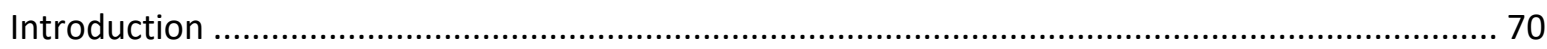

Table 6.1: Demographics of the male participants ....................................................................

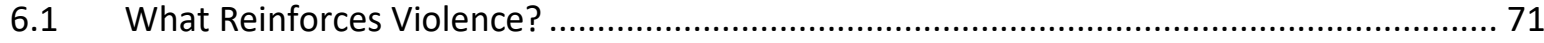

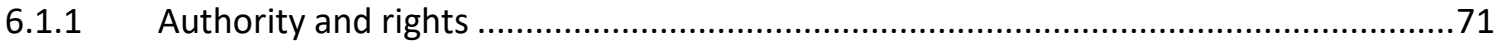

6.1.2 Male expectations influenced by alcohol and peers...............................................73

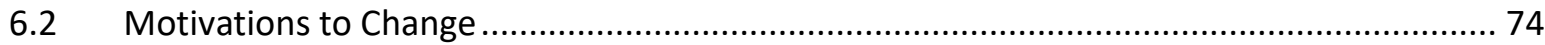

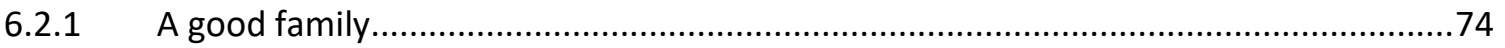

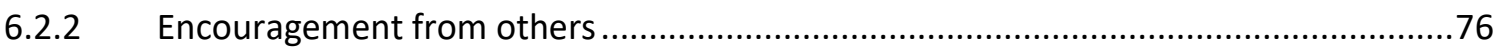

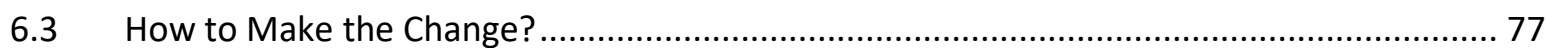

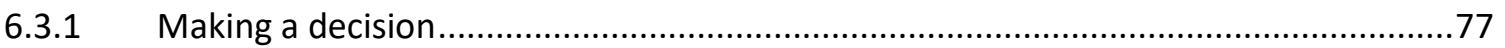

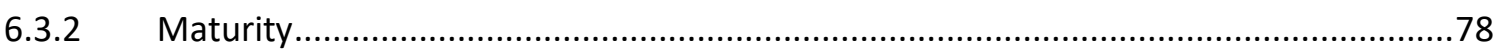

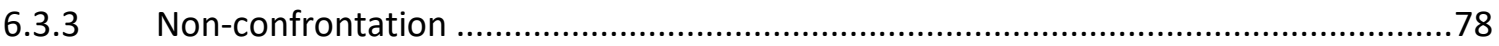

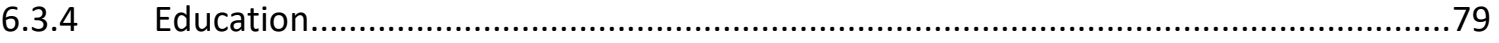

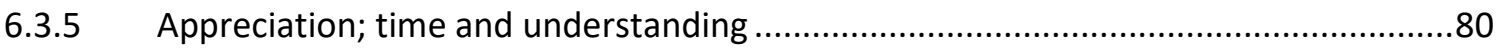

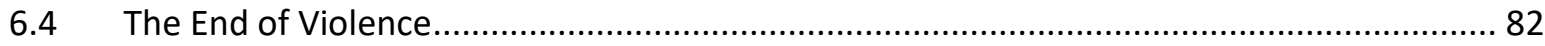

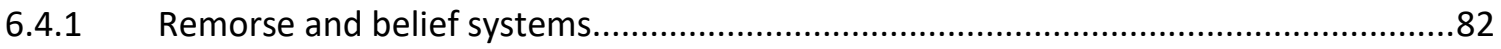

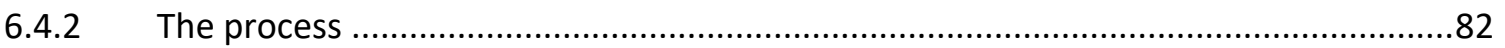

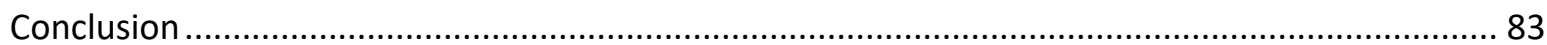

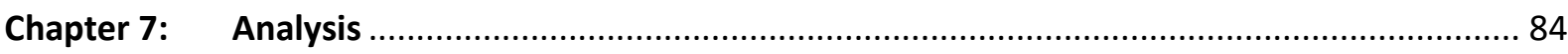

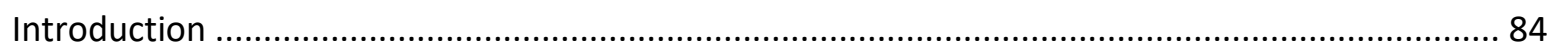

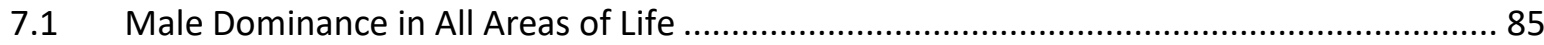




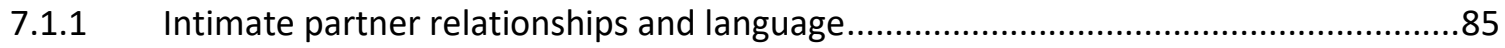

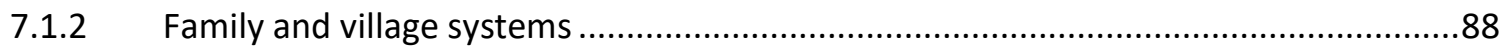

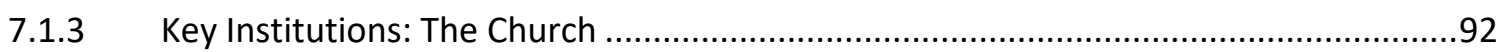

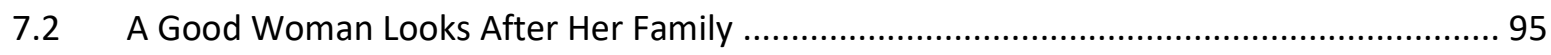

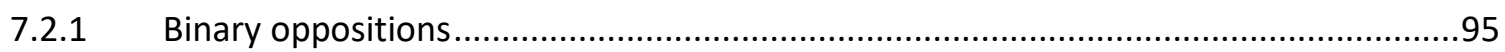

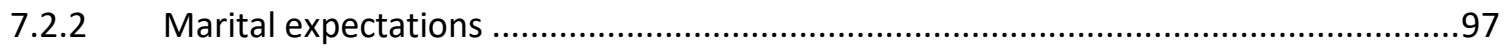

7.2.3 Key Institutions: The Police and Child Protection ....................................................100

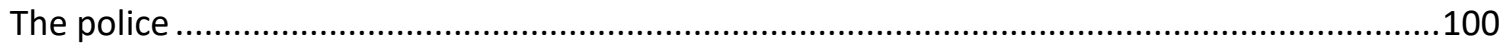

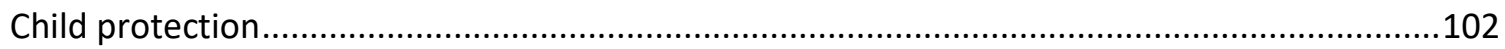

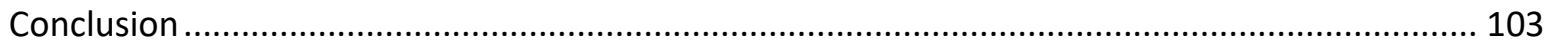

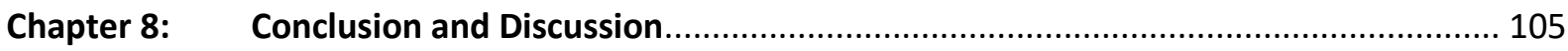

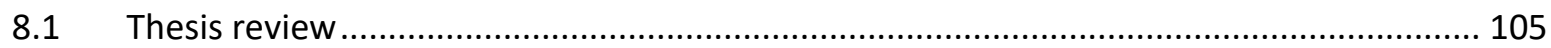

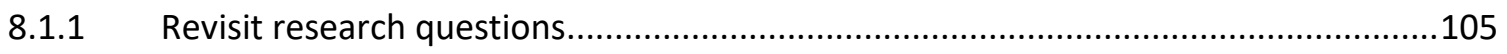

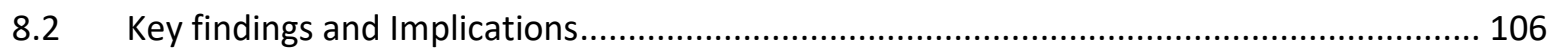

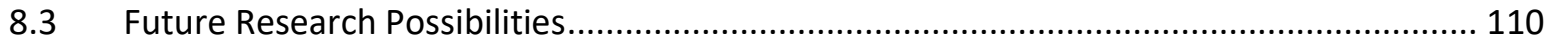

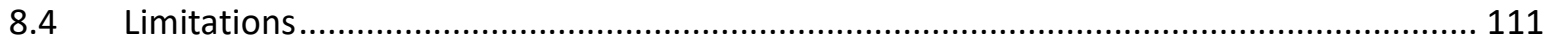

8.5 Value

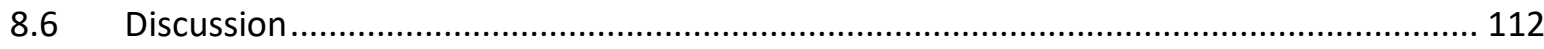

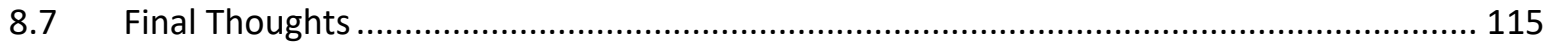

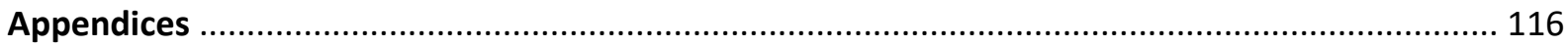

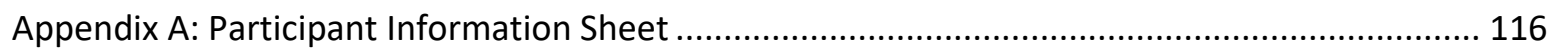

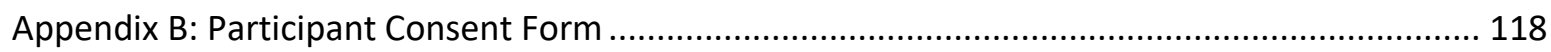

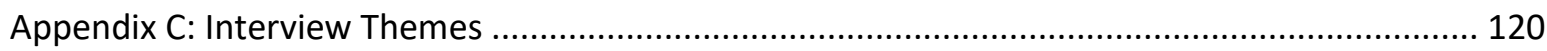

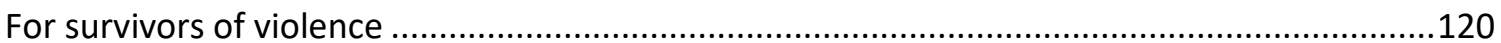

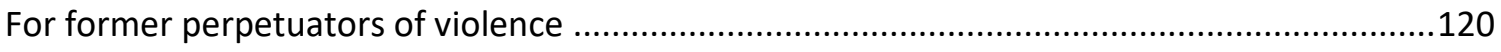

Appendix D: Interview Questions (for one email-based interview) ........................................... 121

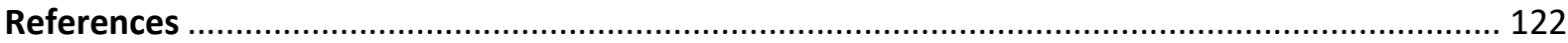




\section{List of Figures and Tables}

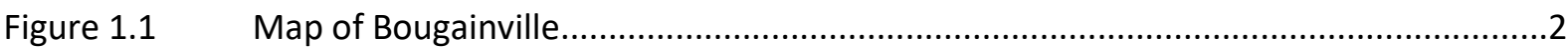

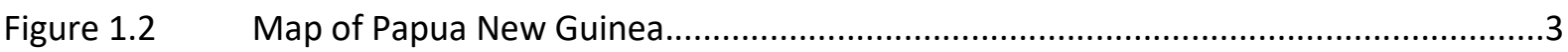

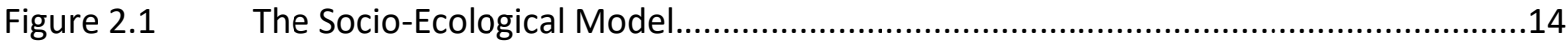

Table 5.1 Demographics of the female participants................................................................

Table 6.1: Demographics of the male participants.............................................................. 


\section{Chapter 1: Introduction to the Study}

This study aims to shed light on the enabling and restricting discourses that are linked to the perpetuation and resistance of gender-based violence (GBV) in Bougainville, Papua New Guinea (PNG) (Figure 1.1).

\section{Figure 1.1: Map of Papua New Guinea}

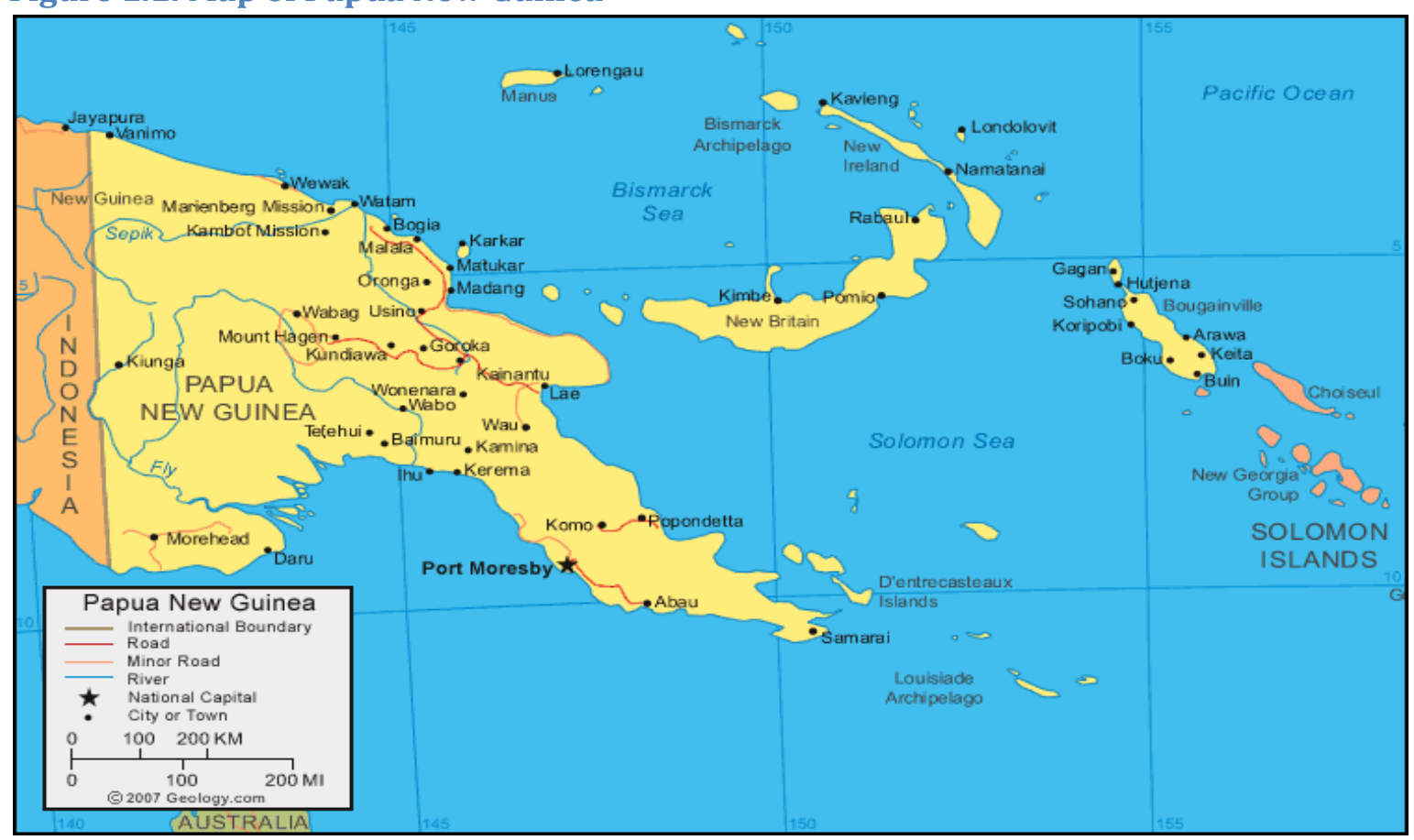

(Geology, 2008)

A 2013 study by the United Nations (UN) confirmed what many already knew, that men's use of violence in Bougainville, including sexual violence, is common. The study showed that life time prevalence of physical violence against a partner was 62 per cent, whilst 59 per cent of every partnered man admitted to perpetuating sexual violence at some point in their lives. Also, rape of non-partners was high at 40 per cent (Fulu et al., 2013). Despite conflicting responses to the UN report (Momis, 2013), my observations from having lived in Bougainville for three years is that gender-based violence is an enormous problem that causes immeasurable suffering to many women and girls.

The Autonomous Region of Bougainville (ARoB or just Bougainville, Figure 1.2) is a province of Papua New Guinea. Located 1,000 kilometres, or a two hour flight from the national capital of Port Moresby, it is the most remote province of PNG. Bougainville (with a landmass slightly larger than the NZ district of Gisborne) is made up of the raised coral island 
of Buka, the large mountainous Bougainville Island and a number of smaller islands and atolls (Goodland, 2012; Kay \& Russell, 2013). Whilst Bougainville is politically tied to PNG, the cultural tie to the Solomon Islands is strong and trade between the two is common (Swain, 2005).

\section{Figure 1.2: Map of Bougainville}

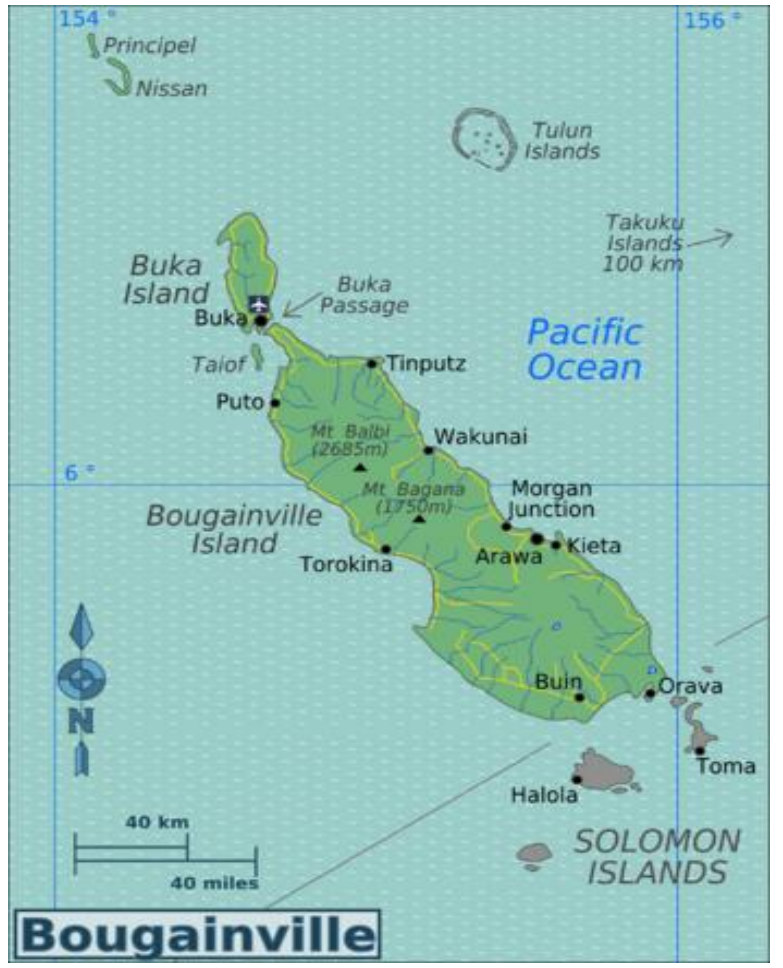

("Map of Bougainville ", 2010)

\subsection{Papua New Guinea}

Papua New Guinea is located in the South Western Pacific Ocean and shares a border with Indonesia on the island of New Guinea. The approximately seven million peoples of PNG are known for their cultural diversity, and the vast majority of people live a traditional lifestyle, ${ }^{1}$ mainly as subsistence farmers (UN Data, 2014). PNG has reported strong economic growth over the past decade, mainly due to resource extraction, however it is a generally accepted notion that the distribution of wealth does not benefit the greater populace (Pollard, 2014). Because of geographical inaccessibility, many Papua New Guineans live in areas secluded from other villages, which may begin to explain the 800 plus languages spoken within the nation. PNG's populous highland provinces are covered in rain forest whilst other provinces host large wetland areas surrounding natural river systems and a long coastline. There are

\footnotetext{
${ }^{1}$ In this context a traditional lifestyle refers to a life revolving around fishing and/or subsistence agriculture. The family is the basic social unit and the family belongs to a clan. Chiefs and other elders are village leaders and are central to decision making.
} 
also approximately 600 islands surrounding the mainland (WHO, 2012). Bougainville Island is one of them.

\subsection{Gender-Based Violence and Development}

Gender-based violence is a major public health issue and causes immeasurable suffering for individuals, families and communities throughout the world. It is an area of concern not only for aid-receiving nations, but for every nation. In a recent study spanning the European Region, the results revealed that one quarter of women living in Europe will experience some form of physical and/or sexual violence by an intimate partner at some point in their lives (WHO, 2013). This shows that the problem is not tied to particular countries, but that GBV pollutes human wellbeing regardless of nationality.

Gender-based violence, a human rights breach, is linked to widespread poverty and a hindrance to economic growth, which is the focus of much Official Development Assistance (ODA) today. ${ }^{2}$ Although attempts are made at quantifying GBV in terms of direct costs (e.g. legal services, medical expenses) and indirect costs (e.g. loss of productivity, loss of earnings and tax revenue), it is often difficult to produce accurate data in dollar terms.

This thesis, whilst recognising the link between poverty and gender inequality, approaches gender-based violence as a severe human rights breach, worthy of attention on its own merits, and not primarily due to its economic detriment. My approach echoes a United Nations think piece report from 2012 which states: "economic growth, where accompanied by significant inequalities, environmental degradation, repression, and structural indignities, is neither sustainable in the long term, nor morally acceptable in the immediate term" (United Nations, 2012, p. 4).

Whilst gender-based violence is a problem everywhere, rates of violence in PNG are amongst the highest in the world (Amnesty International, 2014b). Oxfam has described the situation for women in PNG as living in a "war zone" (2014, p. 1) referring to the extent of physical and sexual violence against women and girls.

\footnotetext{
2 "DAC is the Development Assistance Committee of the OECD. The DAC provides guidelines on what types of assistance can be defined as official development assistance (ODA). The DAC definition of ODA is defined as those financial flows to developing countries and to multilateral institutions for developing countries which are administered with the promotion of economic development and welfare of developing countries as its main objective"(NZ NZ Aid Programme, 2012, p. 4).
} 


\subsection{Commitments to Address Gender-Based Violence in PNG}

PNG has committed to a number of international and domestic goals to address genderbased violence, but so far with little effect. In an attempt to explain why progress has been slow, the Government stated:

Efforts to address family and sexual violence within government have been slow because of policy makers' reluctance to acknowledge domestic and other forms of gender-based violence as public matters, and to understand the dynamics and consequences of family and sexual violence. There has been little coverage on these issues or their human rights implications. The overall approach to genderbased violence issues has been unstructured and uncoordinated, with little communication and coordination between agencies and no existing network to link agencies working on similar issues around the country (PNG Government, 2009, p. 18).

In 1995 PNG ratified the Committee on the Elimination of Discrimination against Women (CEDAW), an international bill of rights for women that defines what constitutes discrimination against women and which outlines an agenda for national action (United Nations, 1979 para. 1). The same year PNG also attended the fourth World Conference on Women in Beijing where the Beijing Declaration and Platform for Action (BPA) was established. A year previously, in 1994, the PNG Government had endorsed the Pacific Platform for Action (PPA) which focused on advancing gender equality and women's empowerment in the Pacific Region. In 2004, the Revised Pacific Platform for Action (RPPA) was developed to identify regional issues concerned with mechanisms to promote the advancement of women (Secretariat of the Pacific Community, n.d., p. 1).

The Millennium Development Goal (MDG) 3 aims to "promote gender equality and empower women" (United Nations, 2013). PNG, as one of 189 member states of the United Nations has committed to achieving the eight MDGs. Reports do however suggest that it is unlikely that PNG will reach any of the goals despite progress in some areas (PIFS, 2013; PNG Government, 2004).

Domestically, Papua New Guinea has ascribed to several visions and goals to tackle genderbased violence which the Government has called "an impediment to effective progress" (PNG Government, 2010b, p. 95). Vision 2050 is the highest level strategic plan that provides a framework for addressing socio-economic development and to which all other domestic 
plans must align (National Strategic Plan Taskforce, 2009, p. xiv). In presenting Vision 2050 in late 2009, the Government made explicit their desire for a long term approach to development, owned by the people and executed through the different government layers, ${ }^{3}$ and through Public Private Partnerships (PPP), ${ }^{4}$ Civil Society Organisations (CSO) ${ }^{5}$ and other community actors (National Strategic Plan Taskforce, 2009).

In addition, in September 2013, the Papua New Guinean Parliament passed the Family Protection Bill. It was the first step towards reducing violence against women in the home supported by legislation. With the passing of this Bill domestic violence is now criminalised and gives legislative backing for interim protection orders. It also allows for neighbours, relatives and so forth to report domestic violence. Up until the passing of this Bill, the reporting was the domain of the abused person. This legislative change is an important decision to show that domestic violence must not be treated as a household issue any longer (Islands Business, 2013).

\subsection{Research Questions and Approach}

\subsubsection{Central research question:}

What methods support positive change to those intimate-partner relationships in Bougainville previously affected by gender-based violence?

\subsubsection{Sub-questions:}

What were the experiences of the male and female participants as former perpetrators and survivors of violence?

How can the participants' experiences of gender-based violence help inform policy development and improved professional practice?

The purpose of the study is to learn about what methods worked for a number of men and women in Bougainville when moving to a life free from intimate partner violence. At no point do I believe that the participants' stories of positive change can or should attempt to be replicated as a blueprint for how change must happen. By drawing from the experiences of those with detailed personal knowledge about the circumstances surrounding this shift,

\footnotetext{
${ }^{3}$ National, Provincial and Local Governments.

4 "Public-Private Partnerships (PPPs) are long term agreements between a government and a private partner whereby the private partner delivers and funds public services using a capital asset" (OECD, n.d.-a).

5 "CSOs can be defined to include all non-market and non-state organisations outside of the family in which people organise themselves to pursue shared interests in the public domain" (OECD, n.d.-b).
} 
the findings are anchored to the circumstances of a total of 18 Bougainville men and women.

Thirteen of these participants were survivors of gender-based violence, where as five were former perpetrators. Although not part of the research criteria, it turned out that all survivors who came forward were women, whilst the former perpetrators were all men.

In this research I am particularly interested in the workings of resistance to dominant discourses and ideas that reinforce gender inequalities. By placing the participants' experiences within a feminist poststructural framework, I hope to contribute to the knowledge of what works when addressing gender-based violence within a partnership in Bougainville.

The study was influenced by Talanoa, a Pacific-research approach that encourages stories to be told in a conversational style which allows the participants to speak about their experiences in ways that suit them. As such, all interviews, except one, were unstructured in style and only governed by themes (Appendix C), as opposed to a structured question/answer format. Given the sensitive nature of the topic, unstructured interviews are also suitable as it allows for more flexibility for both researcher and participants (Fletcher, Parkhill, Fa'afoi, \& Morton, 2006).

This study is also informed by observations and in addition I have chosen to draw from media clippings gathered over the course of one year as these provide an insight to current issues.

\subsection{Positionality and Dual Role}

In 2009 I started a two-year Volunteer Services Abroad (VSA) assignment, based in Bougainville. That assignment entailed supporting local teachers to set up a counselling office at a high school on Buka Island. Later, in April 2013 I accepted a one-year VSA assignment, also based in Bougainville. My job title was Family Support Centre adviser and I was assigned to help establish a centre that offers medical and psychosocial support for survivors of GBV at Buka General Hospital (BGH).

It is not necessary to outline the intricate details of my VSA assignment, although it is important to understand the general picture of this role and the relationship I had with members of the community as they helped shape this study. 
In November 2013 Buka FSC officially opened, and local women and girls started to arrive in a steady stream. Their concerns were many, often including distress over their husbands' multiple marriages, and their experiences of rape, incest and violence. The perpetrators were nearly always known to them. Whilst my colleagues provided the frontline support, I worked on developing protocols for the running of the service and I occasionally helped with face-to-face counselling.

In addition, we presented our work at national conferences, networked with other FSCs around PNG, spoke out on radio and at events, we ran workshops at schools and at the hospital and together with the North Bougainville Human Rights Committee (NBHRC) we arranged and participated in human rights activities such as the 16-Days of Activism and the PNG Human Rights Film Festival, and more besides.

The FSC is also part of a larger network of local and international organisations working against gender-based violence from different angles. Included in this network are representatives from the police, courts, child protection and local and international nongovernment organisations (NGOs).

When summarising a year-long assignment in one paragraph it is easy to make it sound neat and structured, progressive and satisfying, but in reality it was often ambiguous and personally challenging. It was a year that I was forced to deeply reflect on my own value system. For example, why did I feel angry in the face of, what I considered to be, injustices? The answers are few, yet I learnt much about myself and about the realities of gender-based violence in PNG. My previous training and experience of working as a family counsellor assisted me with both self-care and with addressing the topic sensitively.

In line with feminist poststructuralism I believe that the truth developed from this thesis is relational and subjective, and that the best way to generate some form of honesty is by the practice of reflexivity. To me, this first meant recognising my personal values and preferences, and then critically examining how they affected the study. It also meant attending to my dual positions within the field.

Alongside my position with VSA was the fieldwork undertaken for this research, which I carried out part-time. I arrived at Bougainville and BGH with an idea of what to include in my study, however the ethics-approval was still a long way off. Since I had spent two years in 
Bougainville previously, I knew a little of what to expect and I believed that the final preparations would best be arranged whilst there, and this turned out to be correct. Focusing on GBV seemed appropriate given my professional role and interest. After consulting with my Bougainville colleagues, including the CEO, about the scope and support for this research, I made some amendments to gain ethics-committee approval and soon after I began interviews.

It was important for me to keep the research and the VSA role separate and I persisted in explaining this difference when meeting with participants and with those professionals who had helped with their recruitment. Making sure the interviews were arranged differently to client-appointments, ${ }^{6}$ and held during lunch time instead of during working hours, all helped to further separate the research from the VSA role.

\subsection{Terminology}

In this thesis I have chosen to primarily use the term gender-based violence (GBV) when referring to an act of violence against a person on the basis of gender, although the term Violence Against Women (VAW) is often used as well. ${ }^{7}$ This does not mean that every act of violence against a woman is GBV or that men and boys are excluded from the definition; rather it points towards the fact that women are overrepresented in violence statistics worldwide (Fulu et al., 2013).

VAW is defined by the UN Declaration on the Elimination of Violence against Women (1993) as:

Any act of gender-based violence that results in, or is likely to result in, physical, sexual or psychological harm or suffering to women, including threats of such acts, coercion or arbitrary deprivation of liberty, whether occurring in public or in private life. $^{8}$ (UN, 1996, p. 1)

I have adopted this definition, but included "economic harm or suffering" (EIGE, 2014, para. 3) because the study location experiences high unemployment and limited government-run

\footnotetext{
${ }^{6}$ E.g. by the participants contacting me directly instead of through the hospital reception.

7 Although primarily using the term GBV in this thesis, I do occasionally use the term VAW because all of the participants that had experienced domestic violence were women. Other terms to describe GBV (and VAW) include intimate-partner violence (IPV) which is domestic violence (DV) against a current or former partner (EIGE, 2014).

${ }^{8} \mathrm{GBV}$ also includes trafficking, forced prostitution, forced sterilization, female infanticide and more. For more information see EIGE (2014).
} 
social services, two factors that I believe render people more dependent on those who earn a cash income.

Understanding the difference between gender and sex is important to any study interested in gendered perspectives and analysis. Sex refers to a person's biological characteristics, whilst gender refers to the socially constructed roles that impact on people (WHO, 2014b). Male and female, which I often refer to in this study fit within the category of sex, whilst masculine and feminine are constructed according to the place and time of the person and thus relate to gender. Understanding how various forms of discrimination that positions one gender or sex as inferior to the other, is part of the complex web of understanding genderbased violence (WHO, 2014c). ${ }^{9}$

Throughout this study I refer to the men and women in the interviews as either participants or interviewees. I am aware of the power-imbalanced connotation associated with those terms, however this is not my intention, rather, it is a way to describe those who generously shared their knowledge and time with me within the bounds of research. Also, I use the word survivor to describe a person who used to experience intimate partner violence, but at the time of the interview the experience had ceased. I also use former perpetrators to describe a person who used to inflict some form of violence against an intimate partner, but who has chosen not to do so any longer. I am conscious of the assumptions and conclusions that are easy to draw from those value-laden terms, however in this research it is strictly a way to describe the participant's purpose for taking part in this research.

\subsection{Thesis Structure}

Following this introduction, in Chapter 2, I present a framework which helps to conceptualise GBV. The framework includes four interlinked tiers and helps us to understand how various factors in peoples' lives have influence. Chapter 2 and Chapter 3, in particular, form a context to the study and therefore are important to the findings presented in later chapters. Following the conceptual framework in Chapter 2, I examine traditional and contemporary forms of conflict before tracing the process from traditional to contemporary methods of peace making.

\footnotetext{
${ }^{9}$ For example, gendered-expectations in marriage that position the wife as inferior is a form of discrimination that I will address in this thesis.
} 
In Chapter 3 the gaze turns to Bougainville. To begin with I discuss the Bougainville Crisis which caused severe social and political upheaval and whose aftermath has been a focus of international aid agencies since. Then, I give an outline of the make-up of Bougainville society such as the structure of the Government, the education system, belief systems and more. After this, I analyse gender-based violence and the number of customary practices that have been widely criticised for having negative impact on gender-relationships.

Chapter 4 explores what it means to align with a feminist poststructural epistemology by considering issues such as objectivity, knowledge and truth, as well as the feminist cornerstone of reflexivity. As in the other chapters, I interweave research-specific information with my personal experiences and observations to deepen the study. I also elaborate on the role of ethnography and appreciative inquiry, as tools that help position myself and frame my questions. In this chapter I also address the theoretical basis for the analysis which primarily draws from the work of Foucault and the practice of discourse analysis (Foucault, 1979, 1980, 1984). I also explore the methods used to gather data including details of the recruitment of the participants and the actual interview process. To wrap up Chapter 4 I raise a number of ethical considerations concerning this study, as well as the limitations and value of carrying out this project.

In Chapters 5 and 6 I present the voices of the participants. These two chapters tell the stories as elicited from the interviews. Chapter 5 is concerned with the 13 female participants and follows the marriage itself, the women's experience of gender-based violence and later their resistance and the end of violence. Chapter 6 follows the same format and explores the stories of the five male participants. Embedded in their stories are ideas that perpetuate gender inequality, but also factors such as motivations to change, the process of change and again, the end of violence.

Chapter 7 examines the participants' stories and identifies the dominant discourses that enabled and resisted the perpetuation of gender-based violence. In drawing from the work of Foucault, intercepted with a feminist critique, I explore the links to, and influence of, language, family systems and key institutions on the participants.

In the final chapter I condense the entire study into key points. From these key points I refer to a number of implications and recommendations that I hope can be of benefit to those 
GBV professionals in Bougainville who work tirelessly to address this human rights breach. I also hope that the key findings can help inform the policy and practice of institutions here in New Zealand that have an interest in addressing GBV, particularly in the wider Pacific. As in the case of much research, this work has also generated a number of other research possibilities, and in the concluding chapter I will highlight some of the possible future areas for research. 


\section{Chapter 2: A Framework of Conflict and Peace}

\section{Introduction}

To begin this chapter, I present a conceptual model that explains causes of violence and therefore possible entry points for interventions. This model is a framework to understand how various influences, from personal to societal, have an effect on a person. Then, I specifically focus on historical and contemporary forms of conflict and peace as these create a foundation for understanding the wider context of violence and positive change. I will show that the people of PNG already had a well developed system to deal with conflict in ways that fitted with their history, before the arrival of the white man. Reconciliation processes were, and continue to be, a valued way of solving problems.

\subsection{Conceptual Framework to Understanding Gender-Based Violence}

The socio-ecological framework conceptualises violence against women as a complex and multilayered occurrence that encompass individual circumstances, relationships and family, community and societal factors (US Government, 2013). ${ }^{10}$ It includes, yet stretches further than, an analysis of male dominance and gender hierarchy, to include a discussion of the interplay of the different tiers of the framework. In this part I discuss and give examples of how it fits in to the Bougainville context, by drawing from personal experiences and literature. Figure 2.1 shows how the multiple layers of the framework fit together.

\footnotetext{
${ }^{10}$ The socio-ecological framework is sometimes referred to as the ecological framework/model and I will use both (Fulu et al., 2013).
} 


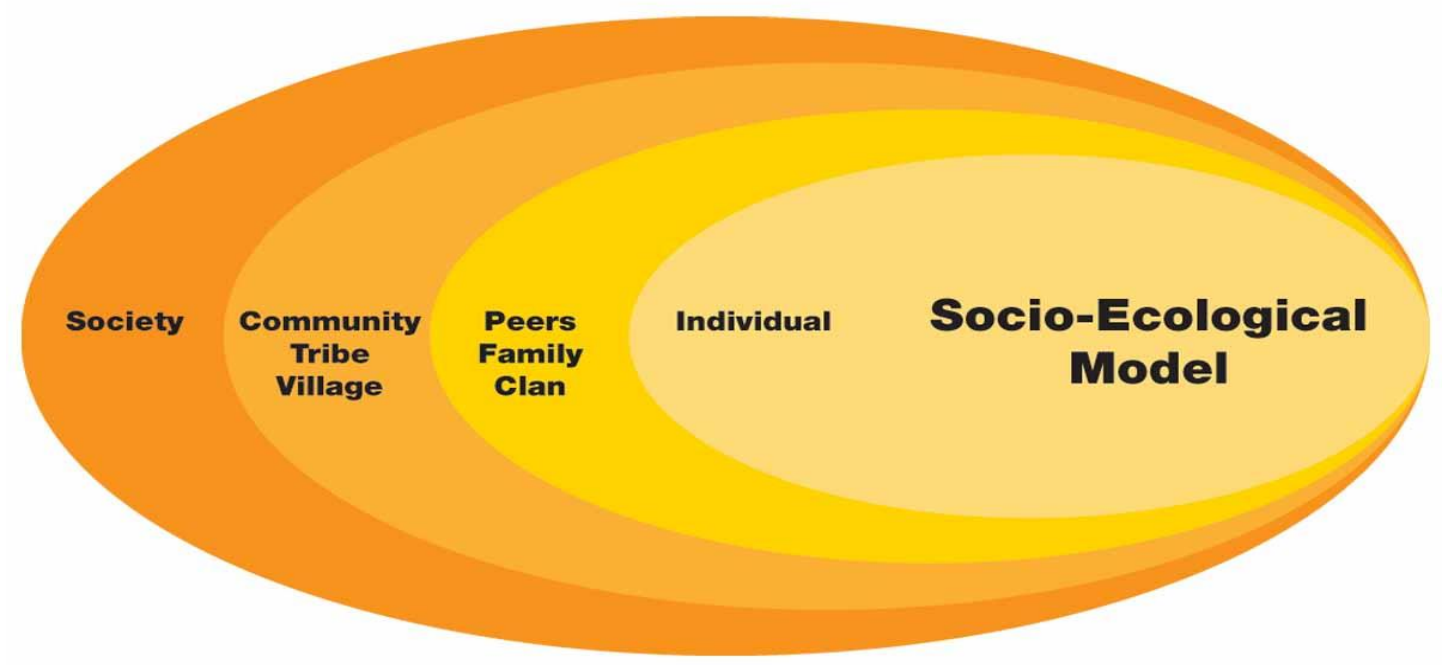

Figure 2.1: The socio-ecological model

(Connect, 2014)

The innermost circle illustrates the biological and personal background that each and every person brings to a relationship (GUIDE, 2005). To effectively address violence against women, interventions need to target all of the layers in the framework.

Studies have shown that childhood abuse is strongly linked to men's perpetuations of violence against women (Fulu et al., 2013). In one study on Bougainville, 86 per cent of men reported childhood emotional abuse or neglect, 67 per cent reported physical abuse and over half the men reported having witnessed abuse of their mothers. At the same time, the study reported that 61.9 per cent of men had used physical violence against a woman at some point in their life and 59.1 per cent admitted to having perpetuated sexual violence (Fulu et al., 2013).

Another influencing factor that consistently has been linked to violence against women is the misuse of alcohol and drugs (Heise, 1998). Several studies have confirmed the harmful effects of alcohol misuse whilst also linking it with effects of the Bougainville Conflict (see Chapter 3) (Boege, 2013; Weiner, McLeod, \& Yala, 2002). In one study from 2013, 35.4 per cent of Bougainville men reported alcohol related problems (Fulu et al., 2013). Psychological stressors such as traumatic experiences, lower level education, unemployment, and food security issues also impact on men's readiness to use violence against women, and in Bougainville 40 per cent of men surveyed reported high to very high levels of depressive symptoms, and 30.9 per cent of men are unemployed. In addition to the trauma ensuing 
childhood neglect and abuse, the effect of the Bougainville civil war has resulted in posttraumatic stress which are yet to be fully addressed. ${ }^{11}$

The second level of influence on a perpetrator is his family and his relationships. For example, having peers who hit their wives if they disobey or who accept violence as a form of solving problems is likely to reinforce a man's gender unequal attitudes which supports intimate partner violence. Having several sexual partners is also linked with the increased likelihood of violence against women (Fulu et al., 2013).

In contrast, effective parenting skills have positive effects on child development. In light of this knowledge and after requests from staff at BGH I conducted a parenting course with staff from BGH. The participants, all mothers, consistently asked if not a stricter and more punitive parenting approach was the best way to teach children good behaviour. The participants were new to the idea of positive reinforcement but recognised that their own upbringing influenced their opinion on punitive parenting including physical discipline.

The third tier of influence on the perpetuation of violence against women is related to a person's community. In this context, a community refers to a place where "social relationships occur" (WHO, 2014a, para. 4) and those communities that accept subordination of women have an effect on those who live there. The attitudes of a community are in turn influenced by the broader society which makes the connections between the tiers clear. The primary community in Bougainville is the village. If members of the village frequently beat their wives, whilst others turn a blind eye, this is likely to suggest that wife beating is accepted, or at the very least nothing that concerns others. The opposite is also true; if a community stands up against violence then this signals disapproval. Whilst living in Buka, my village took such a stance: after a night of listening to my female neighbour being severely beaten, I was informed by the village chief that the couple would be "spoken to" as abusive behaviours were not tolerated. One week later, after one warning and another fight, the couple was asked to move away.

The church is another type of community. A majority of Bougainvilleans are Catholics and the Catholic Church in Bougainville is very active. The church generally encourages "an ethos

\footnotetext{
${ }^{11}$ A mental health steering group based in Buka General Hospital aimed at addressing post-conflict trauma was established in early 2014. At present, there is only one trained and practicing mental health nurse in Bougainville.
} 
of care and compassion, and a desire to maintain harmonious relations within the community" which promotes wellbeing (Eves, 2012, p. 10). In contrast, the Catholic Church leaves little room for gender equality as it mainly ascribes to a traditional model of the man as head of the family. A happy family is considered a family that is married, and not divorced. For a woman who is experiencing abuse, this limits her options (GUIDE, 2005).

During my years in Bougainville I often purchased the local newspaper which frequently reported on stories such as murder and rape, and ended with a discussion on whether the village would hand in the culprit to the police or not (usually based on if they perceived that the raped/murdered person deserved it or not). This suggests an enormous power of the village to decide on what a good act is, and what is bad, not to mention the inactivity of law enforcement agencies.

Finally, the fourth tier of influence is broader society which has the power to develop norms and acceptance or non-acceptance of violence against women (Krug, Mercy, Dahlberg, \& Zwi, 2002, p. 1086). The following excerpt is taken from the national newspaper The Post Courier. It illustrates marital expectations which are reinforced and strengthened by the weight of the law:

A woman appeared before Number Two Village Court last week after her husband summoned her for burning his fingers while cooking for himself. The husband,identified as Jeremiah from Mapowa area, told the Village Court that his wife had left him and stayed in her village for five years and he was tired of cooking for himself.

The father of four grown-up children told the eight bench magistrates, which includes a woman, that he burnt his finger a couple of weeks ago while cooking his evening meal and he summoned his wife as what she did as a wife was not fair. "It is her responsibility as a wife and mother to prepare the family's meals", the husband said. "I have been doing it for the last four years and to go to the extreme of burning my fingers I thought the law should deal with this".

The wife agreed that she had been living in her own village for the last four years but said that "the reason why I went back to my place is not solved yet and that is why I am still here".

She said she will return when her husband has addressed their primary problems. 
The Number Two Village court magistrates who presided over the case urged the woman to return to her husband and children as it is not proper for a married woman to stay in her own village for that long. (The Post Courier, May 20th, 2013)

I discussed this article with a number of female colleagues in Bougainville who all noted the inequality of the ruling, yet no one was particularly surprised, suggesting that this type of ruling is nothing new and perhaps expected. Although many men (and women) reject violence and men choose to express masculinity in peaceful ways, the overall acceptance of women's compliance, from both genders, reinforces the societal norm of male superiority (US Government, 2013).

Although variation exists within every society on what it means to be a man, in a 2013 Bougainville survey, nine out of ten men and women believed that to be a man you need to be tough (Fulu et al., 2013). Masculine toughness and strength are associated with physical fights, sexual violence and dominance over others which takes many forms and expressions (Greig, Basnyat, \& Lang, n.d.). In addition, post-conflict societies are often "plagued by violence long after formal declaration of peace" (Stuart \& Barnett, 2012, p. 34) including forms of violence that extend beyond intimate partner relationships. While gender inequality, power over women and aggressive forms of masculinity can be understood as root causes of violence against women, the individual, family and community level factors all play a part (Fulu et al., 2013, p. 6).

\subsection{Conflict in Papua New Guinea}

At the end of the 19th Century, different parts of PNG were separately colonised by Germany and the United Kingdom before the country as a whole was given a League of Nations Mandate and administrated by Australia. These European powers took little notice of the social and political structures present within the ethnically and linguistically diverse region, and partitioned PNG's territorial borders as they saw fit (Dinnen, 2001). Traditional PNG societal structure lacked central political organisation, present in Europe at that time, but was made up of thousands of small yet functional and independent tribal groups, well suited to the diverse ethnic and linguistic society. Identity was linked to a person's kin and 
wantoks $^{12}$ and allegiances were tied to the local community. National identity was an unfamiliar concept. With an acute risk of oversimplifying the historical account of the development of the Nation State of PNG, it is safe to suggest that the political organisation imposed on PNG fitted poorly with existing structures and norms (Weiner et al., 2002). PNG gained its independence from Australia in 1975 (Smith, 1987).

\subsubsection{Traditional forms of conflict}

Traditionally, conflict in PNG was caused by "competition over the ownership, access and use of resources, particularly land, women and pigs" (Weiner et al., 2002, p. 7). One's identity was formed by social relationships and resources, in particular land. Reilly (2008) expands the argument by referring to studies on analysis of ethnicities, and states that "ethnic identities were both a salient feature of traditional society and a reaction to colonialism, modernisation and independence" (p. 15). Although scarce resources sometimes inflamed conflicts, Banks (2008) argues that "most clashes were centred on the creation, maintenance and restoration of networks of social relationships, all of which fed in the construction of individual and group identity" (p. 27). Conflict was never fully resolved, only temporarily settled, and therefore likely to form a basis for future conflict (Banks, 2008).

\subsubsection{Contemporary forms of conflict}

Today, PNG makes international headlines for all the wrong reasons, mainly relating to violence-be it muggings of tourists, conflict around the mining industry, sorcery, or violence against women. In this section I highlight the complexity of these conflicts.

In a discussion paper analysing conflict in the modern-day Highlands region, Weiner (2002) provides a context for rules and order. He states that "a good deal of contestation in PNG public life is precisely because the notion that there is a society consciously governed by a set of rules is not what orders people's social encounters" (p. 4). This does not mean that social life is free from rules and conventions; quite the opposite. Rules are made and followed within a particular community, not driven by national legislation.

Maintaining law and order is a well-publicised challenge for PNG. National institutional shortcomings are evident in their limited capacity to maintain public order and deliver public

\footnotetext{
${ }^{12}$ Wantok refers to those people who speak your language (one talk), essentially those in your clan (Nanau, 2011).
} 
services (Dinnen, 2001). I recall several inter-tribal fights from my time in Bougainville; causing disruptions to pupils' ability to attend school, others resulting in road blocks, and multiple instances of entire villages being burnt down. As far as I am aware, no arrests have been made in any of these cases and if the problems have been settled, that would have happened locally.

\subsection{Peace and Reconciliation in Papua New Guinea}

Before the arrival of the colonial masters, PNG had a history of successful conflict resolution processes that protected the peace of villages. This section examines the impact of the Westminster legal system imposed on Papua New Guineans, and the extent to which Custom Law is still active. Understanding how problems used to be solved, and the relatively rapid changes to how the society is run today, assists in locating current methods that people draw from when trying to affect positive change.

\subsubsection{Before the white man}

Before the arrival of the colonial powers, people had been living in villages and small communities as hunters, farmers and fishermen, and life had not changed dramatically for thousands of years. These communities were governed by effective local justice systems that valued social contracts, forbidding actions such as murder, stealing, and adultery (Howley, 2004). The ruling body was the village big-man and his council who were selected because of their skills in the community and "persuasive powers to gain cooperation" (Howley, 2004, p. 74). Although there is some discussion about how big-men came into their leadership, it is generally argued that the position was "earned" and not inherited (Weiner et al., 2002, p. 7), and linked to what the leader could provide for his tribe, for example, performance during warfare, the provisions of feasts, and ability to negotiate peace.

Communities strived for effective big-men who would guide them through times when rules were broken or when social obligations were unfulfilled. ${ }^{13}$ When this happened, village people would get together and discuss what wrongs had been made, and what rules had been broken. Restorative justice and consensus were valued higher than punishment. The offender(s) would eventually be expected to speak, apologise, and offer a gift to the offended party. After this, forgiveness would generally be offered and the community would

\footnotetext{
${ }^{13}$ E.g. respect for elders, the acceptance of social obligations, and the maintenance of community relationships (Howley, 2004).
} 
return to normal (Howley, 2004). Clearly this is a snap-shot account of the process of village justice, and it is not to deny that retribution occurred and could be swift and severe, or that big-men occasionally took advantage of their powers.

\subsubsection{The Westminster System and Customary Law}

Despite vocal disapproval by the PNG elite and those favouring customary legal processes, the British Westminster legal system was adopted in 1975 when PNG became independent from Australia (Howley, 2004, 2005a; Jacobs, 2012). However, Village Courts ${ }^{14}$ were established shortly prior to independence for the purpose of dealing with customary matters in villages and gave some form of power back to the people (Howley, 2005b). Whilst Village Courts have had some success, mainly due to customary appropriateness, neither are they without critique. Slatter states that utilising a restorative justice process, including forgiveness for sexual abuse and rape, can be inappropriate and "not deliver justice to female victims" (2012, p. 1), and which occasionally result in the woman victim dropping the charges under pressure from a male dominated Village Court.

Customary reconciliation processes are common and reconciliation is supported by all levels of the society including CSOs and Government (Braithwaite, 2010). Still, reconciliation is only effective if all sides agree to participate and communicate openly. Again, in the case of rape and sexual violence, the survivor may not feel safe or even know who the perpetrator is, nor may she want to face the offender or offer forgiveness. One study on Bougainville showed that a majority of men perpetuating rape did not experience any consequences, including feelings of guilt or negative social consequences (Fulu et al., 2013).

\section{Conclusion}

This chapter has outlined the four tiers of the conceptual framework. It showed how the perpetuation of GBV springs from complex and interlinked influences and therefore any attempt at finding solutions must reflect these tiers. To understand people's behaviours of today, we must first understand their background. This is particularly so in PNG where many people still live a traditional lifestyle governed by customary belief systems despite the Government's push towards Western systems such as the Westminster. This chapter has

\footnotetext{
${ }^{14}$ Village courts deal with approximately 80 per cent of all legal complaints and the focus is on mediating minor crimes. Shame plays an important part in addressing a crime. Being shamed in front of your community is powerful, and in Melanesian custom, this should be accompanied with forgiveness during a reconciliation process and considered a win-win (Howley, 2005b).
} 
also shown that some efforts have been made to incorporate customary responses to conflict resolution, including for family matters, yet these efforts continue to have varying effects. 


\section{Chapter 3: Bougainville: A Snapshot of Life}

\section{Introduction}

In this chapter I will look deeper into Bougainville, briefly covering its recent history. No discussion of Bougainville is complete without references to the Bougainville Conflict, a civil war between the province and the PNG army that led to the creation of Bougainville as an autonomous region. I look at all the major services and systems that influence the daily lives of Bougainvilleans. Then, I turn to gender-based violence (GBV) followed by a discussion on some of the customary practises that have come under fire for hindering gender equality. This chapter continues to draw on the conceptual framework, showing how various aspects of life influence people and their choices.

\subsection{The Bougainville Conflict and Women}

I have chosen to include information about the Conflict because of the enormous impact it had on Bougainville, not least on women. Although many people get on with life, there are still unresolved issues that continue to impact on people. The Conflict fits within all tiers of the conceptual model; it has influence on individuals, on families, communities and ultimately the entire fabric of society.

\subsubsection{The Conflict}

The cause of the Bougainville Conflict (the Conflict) was centred on the once largest copper mine in the world, Panguna Mine, in Central Bougainville (Regan, 1998). The people of Bougainville expressed concerns over the few benefits and growing social change they were experiencing from the mine. They saw that only the owners were reaping the mine's economic benefits, whilst environmentally degrading the area. After ongoing disruptions the mine's production came to a halt in 1989 as the Bougainville Revolutionary Army (BRA) was formed by local leaders from Panguna and thus ensued a 10-year long civil war.

The story of the Conflict is long and messy, and providing a synopsis is most certainly oversimplifying a war that had devastating effects on both men and women. What began as a fight against PNG Government forces, ended with a destructive fight amongst Bougainvilleans themselves (Boege, 2009; Reddy, 2008). According to one civil society organisation, more than 1000 incidents of rape were committed, often in front of family and community members and many of them resulting in horrific internal injuries (Hakena, 2002). Other forms of violence, including domestic physical violence, also increased during this 
time. This corresponds with Pillay and Turshen (2001) who state that: "there is clear evidence that, for women, the end of war time violence sees the beginning of an increase in gender based violence" (as cited in Morriss, 2006, p. 3).

It is estimated that one tenth of the population - 10,000 to 20,000 people - died or were injured whilst one third were displaced after hundreds of villages were burnt down. A majority of those who died were civilians (DFAT, 2014; Hakena, 2002). All of the participants were youth or young adults during the time of the Conflict.

After the 1998 ceasefire and following talks in New Zealand, the Bougainville Peace Agreement (BPA) was signed in 2001. The BPA provides a platform for the Autonomous Bougainville Government ( $A B G$ ) to operate under the Bougainville Constitution (established in 2004). The first Bougainville president was elected in 2005 and today, in 2014, the third president of the $A B G, M r$ John Momis, leads the region.

\subsubsection{Women and peace building}

In Bougainville, women were, and continue to be, instrumental to peace building (Conciliation Resources, 2002). During the Conflict for example, women took risks when providing medicine and clothes to those suffering; ${ }^{15}$ they organised grassroots movements and marched against rape and the inactions of the police; they put pressure on men to seek peace; and they represented women in peace negotiations overseas (Hakena, 2002).

Today, despite limited funding, women's groups are still leaders in advancing gender equality in Bougainville. Justice and peace are not limited to formal organisations however, but also take place at village level, often initiated by dedicated and educated women. Churches also play an active role in promoting and advancing social relationships and peace. Sr. Lorraine Garasu, the head of the Sisters of Nazareth Rehabilitation Centre, encourages such groups and does not believe that a lack of funds has to hinder effective work, quite the opposite. In an informal conversation with myself, Sr Lorraine explained that "a reliance on money limits people's initiatives and people fail to take ownership of what the group is trying to achieve" (L. Garasu, personal communication, November 10, 2014).

\footnotetext{
${ }^{15}$ For example, mother's travelling in and out of Bougainville used to smuggle medicine in their baskets concealed with babies soiled nappies, feminine hygiene articles and underwear which PNG soldiers were reluctant to inspect as it was believed to cause premature ageing or bad luck (Hakena, Ninnes, \& Jenkins, 2006).
} 


\subsection{Way of Life in Bougainville}

Bougainville is a diverse region with diverse traditions. Someone once said to me that Bougainville is more like several regions, rather than only one, based on the many differences in language, custom and identity that exist. In an attempt to paint a picture of the institutions and processes that have influence on most Bougainvilleans, I devote this part to a broad and brief outline of society. There are of course many deviations to a typical life in Bougainville. Nevertheless I begin with an overview of the functions of the governing body, the Autonomous Bougainville Government $(A B G)$, before highlighting more local processes such as the Council of Elders (COE). Then, I present a number of elements that I have noted that impact on people, such as the interweaving of language and identity. Together, all of these sub-sections are connected, via people, to form a context of what it is like being a man or woman, boy or girl, living in Bougainville.

\subsubsection{The Autonomous Bougainville Government and Council of Elders}

Bougainville has an estimated population of over 230,000 divided into 13 districts and 33 constituencies. Buka is the main town of the populous northern region and since the Conflict has been the administrative centre for Bougainville (Bougainville Inward Investment Bureau, 2013).

The Bougainville House of Representatives, Bougainville's Parliament, has members from all 33 constituencies as well as three allocated seats for ex-combatants (BRA) and three for women.

Whilst the $A B G$ is the highest level governance institution in Bougainville, the region is split into 41 CoEs that make up local level government. These Councils are mostly comprised of people who share customs and language and live in proximity to one another (Boege, 2013, p. 19). The CoEs are meant to represent and assist the people throughout the region, hence addressing gender-based violence and other issues ought to be of interest to them (Boege, 2013). With the introduction of Western systems of governance, women's representation has decreased and although more women are represented in local level government than national level, overall numbers remain low (CLGFP, 2013).

\subsubsection{Society structure}

People in Bougainville belong to a tribe/clan. Clan members generally speak the same language and have an overall leader; the Paramount Chief. Clans also have other chiefs who 
have particular responsibilities to the people in their area, yet are themselves responsible to the Paramount Chief. Women can also be chiefs and although this is rare, are respected as such. Chiefs have a central role in their village, such as solving disputes, although some of their powers are weakening as a consequence of a changing society and the impact of the Conflict (Boege, 2009).

\subsubsection{Land Ownership, wantoks and family}

Bougainville is mostly a matrilineal society. This means that Bougainville women are the land title holders, that land is inherited through the mother's side and a person's lineage can be traced through a matrilineal ancestry (Pearson, 2010). Despite colonial influences and war, this customary tradition has remained and is of great importance and pride to Bougainvilleans. Approximately 97 per cent of land is customary owned and thus women hold a customary powerful position (Sirivi \& Havini, 2004). In my experience, however, in particular when working informally with an eco-tourism group in central Bougainville, the men in the village were the ones making the vast majority of decisions about the activities on the land, and during the dozen or more meetings, which I attended, women were rarely present.

One cannot speak of Bougainville without considering the wantok system [one-talk] which broadly refers to a group of people who speak the same language-tok ples [language]. There are approximately 20 languages in Bougainville. Nanau explains that "it [the wantok system] is an identity concept at the macro level and a social capital concept at the micro and family levels particularly in rural areas" (2011, p. 31), however; the term is used liberally by Bougainvilleans who often refer to all white people in the region as people from the same wantok. There are commonly accepted expectations associated with the wantok system such as the importance of looking after each other, no matter what (Nanau, 2011).

As in many other Pacific Nations, family can mean a number of people who either have blood ties or some other close relationship to the person speaking. Family members often live in separate dwellings, but on the same piece of land. Husband and wife generally stay together, although this has changed since pre-colonial times when couples were living separately (Jolly, Stewart, \& Brewer, 2012). 


\subsubsection{Livelihood}

At least 80 per cent of Bougainville's population live in rural areas with only basic infrastructure (World Vision, 2014). River crossings are frequent on mainland Bougainville and many areas are only accessible by foot or boat. The major economic activity in Bougainville is agriculture. The majority of Bougainvilleans are subsistence farmers with 14 per cent also selling their produce at local markets to generate a small income (World Vision, 2014). The production of coconut and cocoa provide an income for 43.7 per cent and 69.5 per cent of households respectively (National Research Institute, 2010). Apart from agricultural activities, people run and work in small businesses such as trade stores and food bars, while others are employed by the public service (Ipp, 2013).

\subsubsection{Health, including sexual and reproductive health and rights (SRHR)}

Health indicators have not improved in PNG over the past ten years, and both women and children in particular have been dying from treatable causes (PNG Government, 2010a). There is a single hospital in Bougainville and a number of smaller health centres and aid posts scattered throughout the islands. Buka General Hospital, where I was working, employs approximately 200 staff, yet they are severely understaffed. For many rural people, health centres and aid posts are their primary location for help although these are often poorly supplied and under-resourced (PNG Government, 2010b).

Despite PNG reporting the highest level of maternal mortality in the Asia-Pacific Region (National Department of Health, 2009), access to maternal health services has improved in Bougainville since the only other obstetrics and gynaecology facility outside of Buka opened in Central Bougainville in 2013. Dr Joe Vilosi, the resident doctor, pointed out that "twenty eight maternal deaths per year were recorded, but now it has been reduced to six" (Vilosi, 2014, para.6), and that awareness raising regarding family and reproductive health is underway. $^{16}$

In my experience, from having female friends in Bougainville, family planning is a sensitive topic and not easy to bring up with husbands who often believe it is the woman's responsibility to avoid pregnancy. This belief, coupled with not being able to refuse sex with

\footnotetext{
${ }^{16}$ The annual number of female deaths per 100000 live births for any cause related to pregnancy was 230 in 2010 in PNG (UNICEF, 2013).
} 
their husbands and a strong religious faith, makes it challenging to control the timing, number and spacing of children (Orkii, 2013).

\subsubsection{Education}

Many children missed out on the right to an education during the ten year Conflict. Many parents were inventive and provided home schooling if possible, but despite attempts at bringing affected people back to school, there are still a large number of people, now in their 20s and 30s, who have very limited education.

Achieving universal primary education ${ }^{17}$ is one of the eight Millennium Development Goals (United Nations, 2000) and although PNG will not reach this target by 2015, there has been an increase in enrolment for both sexes. Education has not only been hailed as a tool to aid economic prosperity, but it is generally accepted that education, both formal and informal, helps bridge gender inequalities (Thomson, 2012).

There have been numerous programmes aimed at raising awareness of human rights and gender equality, targeting health workers and youth among others. Yet, the general acceptance of male dominance is still widespread and those living away from radio reception and urban influences rarely receive messages on rights and equality (Fulu et al., 2013).

Whilst working at the FSC I noted that the majority of women who referred themselves to us were women with some form of education, generally higher than primary school. Those who had minimal or no education were mostly referred from other organisations such as the police, or from within the hospital. This corresponds with a Pacific Island Forum Secretariat (PIFS) report which states that "more highly educated women make more effective use of health services for themselves and their children, have better sexual and reproductive health outcomes, and lower rates of STIs and HIV" (PIFS, 2013, p. 31).

\subsubsection{Religion and indigenous belief systems}

In 1901, alongside the colonial administration, the first Christian Mission in Bougainville was established. The Roman Catholic Church has been the most influential, but the Anglican, Evangelical Lutheran and a number of minor churches are also operating (Regan, 2002). For many, involvement with the church is a central activity in life.

\footnotetext{
${ }^{17}$ In PNG this equates to nine years (three years elementary schooling and six years primary schooling) (PNG Government, 2009).
} 
Many Bougainvilleans additionally embrace indigenous traditions and spirituality. For the outsider it can be difficult to grasp how two seemingly contradictory belief-systems work together, but in Bougainville, people often believe in both. Spiritual beliefs are unique to each region and some involve lengthy initiation processes into manhood and similar, whilst other spiritual practices are part of daily life.

\subsection{Gender-Based Violence in Bougainville}

In a United Nations 2013 multi-country report on men and violence in the Asia-Pacific Region, Bougainville (PNG) exceeded all other participating countries on levels of violence, including sexual violence (Fulu et al., 2013).

This report found that:

- 62 per cent of the Bougainvillean men surveyed (who are currently or have been in a relationship) reported that they had perpetrated rape against a female intimate partner at some point in their lifetime;

- 41 per cent of Bougainvillean men surveyed reported that they had raped a female non-partner at some point in their lifetime;

- 25 per cent of Bougainvillean men surveyed reported that they had raped someone in the past year (Fulu et al., 2013)

Of the 530 Bougainvillean men who reported having raped a woman, the most commonly reported motivation for rape was "sexual entitlement". The second most common motivation for rape was "entertainment purposes".

Physical and emotional violence are also common:

- 62 per cent of Bougainvillean men surveyed reported having perpetuated physical violence against a female partner at some point in their lifetime;

- 57 per cent of Bougainvillean men surveyed reported an act of emotional violence (Fulu et al., 2013).

It must be noted that the Bougainvillean men who participated in the study also reported high levels of being the victim of physical, emotional, and sexual abuse before the age of 18 and also of witnessing their mothers being abused. 
The findings of the study were published in September 2013, but were then denied by the Bougainville President John Momis. In an interview on Radio New Zealand President Momis responded to the report by saying:

Bougainville is a small community, you know, being a matrilineal society. And we, the leaders, would have found out a long time ago if what they reported was true. None of us, including myself [sic]. If it is true that one out of every five people interviewed was a rapist, then you are saying that one fifth of the population is rapists [sic]. That's totally bloody untrue. (Momis, 2013, para. 6)

Another study on GBV in PNG, by Ganster-Breidler (2010), also confirmed that GBV is common. However, what is interesting from the Ganster-Breidler study is that the women interviewed also held strong beliefs on what it meant to be "a good wife": 77 per cent of respondents said that if a husband had proof of her infidelity, violence was justified; 77 per cent of women also felt that if she disobeyed her husband, violence would be justified. The third most common reason for perceptions of justified violence was if the man suspected that the woman had been unfaithful. Another reason for justified violence included refusal of sex (52 per cent).

The UN multi-country study confirms that there are set expectations on the role of women. For example, of the Bougainville women surveyed, 83 per cent believed that a woman's most important role is to take care of her home and cook for her family and 72 per cent of women believed that a woman should obey her husband. These opinions, however, are contrary to the view of 94.5 per cent of women surveyed, who believed that people should be treated the same whether they are male or female ( 87 per cent of men also agreed), suggesting a gap between the abstract idea of gender equality and the actual and specific norms and practices.

\subsection{Customary Practices and Gender-Based Violence}

A number of international human rights groups, and local people, have raised concerns that some customary practices in Bougainville undermine women and impact negatively on the entire region (Amnesty International, 2006a; Kopi, 2010). In light of this, it is necessary to look closer at those customs that have been critiqued, and in doing so, I recall the words of the Director for the Medical Services at BGH, a Bougainvillean man, who during a workshop on women's rights stood up and said: 
We shouldn't be scared of change, change happens all the time. I think of my bubu [grandparent]. When he was young, girls weren't sent to school much. They stayed at home to look after their family. They all had many children early. Now we send our girls to school all the time. My wife went to school. This is a change in custom, and it is good. (Dr B. Matanu, personal communication, November 21, 2013)

\subsubsection{Bride price}

The common practice of paying bride price for a wife has come under fire from both within and outside of PNG. Paying bride price is the responsibility of the family of the groom, with the traditional currency being shell money and pigs, but today cash is often expected as well (Amnesty International, 2006a). Expectations of having to pay for a bride reinforce the stereotyping of women as commodities and contribute towards the ongoing discrimination of women and girls in all aspects of their lives (Bre, 2006).

This ownership claim corresponds with the 2013 UN multi-country report, which shows sexual entitlement as the major motivator for both partner and non-partner rape. This also fits with some of the stories from women who attended the Family Support Centre, where I worked. Many of them repeated a common saying that their husbands' had used when being abusive: "I bought you; you did not buy me".

\subsubsection{Polygamy}

The practice of polygamy, the choice for men to marry more than one wife, is endorsed by PNG legislation. The Marriage Act of 1963 recognises religious ceremonies as well as customary weddings and allows for those customs that recognise polygamy (Jessep, 1992).

Having several sexual partners is linked to an increase in violence against women as noted in the second tier of the conceptual model. Also, women are increasingly being charged for violence against another wife (or wives), whereas men are rarely imprisoned for sexual violence or any crime against their wives (Dinnen \& Thompson, 2004). In PNG, wives in polygamous marriages are often referred to as numbers: number one, number two and so forth, suggesting an impersonal relationship to the wife. Whilst living in Bougainville, I had many conversations with number one wives, whose husband had taken other wives. They told me that their husband mainly returns for sex or food. The majority of these women were saddened and humiliated, but felt they had no choice; as he would otherwise either beat them or abandon them altogether. Dinnen and Thompson (2004) confirm that 
polygamy places an "enormous strain on women who are fighting to maintain their dignity at the same time as providing for their children" (p. 11).

Despite international disapproval (Amnesty International, 2006b), the PNG Community Development Minister Loujaya Kouza has explained that the Government does not intend to review the part of legislation relevant to multiple marriages, indicating continued acceptance of polygamy at the highest level (Islands Business, 2013).

\subsubsection{Sorcery}

In PNG, newspapers regularly report on sorcery, mainly concerning stories of torture and death (Zocca, 2010). The New Zealand media also reports on sorcery in PNG. In the last year for example, Radio New Zealand featured these headlines:

PNG sorcery-related killings described as 'silent epidemic' (Radio New Zealand, 2013);

Six people have been hacked to death in a sorcery-related attack in Papua New Guinea's Madang province, including two children (Radio New Zealand, 2014b);

Bougainville police detain woman accused of using black magic (Radio New Zealand, 2014a).

Sorcery, also referred to as witchcraft, is a ubiquitous belief system still present throughout PNG today. Although some people have discarded this practice altogether, many are still reluctant to doubt its powers. Different provinces in PNG have different belief systems regarding who controls sorcery practices and for what ends, good or bad. As an excuse for unexplained misfortune, sorcery accusations, which Dinnen (2001, p. 15) calls a form of "social control" (2001, p. 15), are made to those most vulnerable, such as "women, widows without male kin, elderly people and people who are resented or envied (most often independent or progressive women)" (Oxfam, n.d., para. 6).

While I was working in Bougainville, we had several women at BGH being treated for sorcery related cuts and abrasions. I also interviewed a young single mother who had fled her village because of sorcery allegations against her, initially thinking she would fit the criteria for this study. The NBHRC estimates that at least 40 people, mainly women, have been attacked over sorcery allegations during the past four years in Bougainville alone (Evenhuis, 2013). 
However, with the repealing of the 1971 Sorcery Act in 2013, which protected those accused of violent crime if their victim was an alleged sorcerer, some progress has been made. Amnesty International approved of this action, saying that PNG has now "taken one step forward in protecting women from violence" (Amnesty International, 2013, para. 4). The head of the Family and Sexual Violence Committee (PNG), Ume Wainetti, was also pleased that the government had taken action on sorcery, which often masks domestic violence (Kua, 2013).

\section{Conclusion}

Bougainville society is experiencing rapid change. From the impact of colonisation to the devastating effects of the Conflict, people and services continue to suffer. Although aspects of life are improving, such as SRHR and the education system, positive change is slow. On the contrary, women leaders in Bougainville have a history of peace and reconciliation and continue to drive positive change to their best ability. This chapter has shown that women and girls are marginalised in all facets of society and that gender unequal attitudes are normalised and therefore internalised. Gender-based violence rates are very high and supported by customary practices that privilege men. 


\section{Chapter 4: Methodological Approaches}

\section{Introduction}

This chapter provides the design framework for answering my central research question:

What methods support positive change to those intimate-partner relationships in Bougainville previously affected by gender-based violence?

I begin by considering how poststructural feminist epistemology creates a framework for conducting and thinking about this study. I pay special attention to the discussions around knowledge and truth and the feminist concern of objectivity (Gavey, 1989). The thread of feminist epistemology continues into the methodology section, joined by ethnographic influences and non-representational theory (NRT), as well as the strength-based questioning of appreciative inquiry (AI).

Next, I elaborate on the fieldwork methods used in particular the role of unstructured interviews, observations, a field diary and newspaper clippings.

To analyse the findings I draw from the work of Foucault $(1979,1980,1984)$ and in particular his work on discourse analysis, but using a feminist approach throughout. I will also elaborate on some of the major ethical dilemmas I faced, and the ways in which I navigated them.

\section{Approach}

\subsubsection{Epistemology}

Harding (1988) has briefly defined epistemology as "a theory of knowledge" (p. 3), which Moss (2001) has added to by stating that it is "knowledge associated with doing and approaching research" (p. 2).

Feminist epistemologies, in turn, critically consider the role of gender and how it is, or should be, linked to the production of knowledge. They notice and point out "ways in which dominant conceptions and practices of knowledge attribution, acquisition, and justification systematically disadvantage women and other subordinated groups" (Anderson, 2012 para. 1). In other words, feminist researchers believe that the way knowledge and truth are generated within a traditional research paradigm fails to recognise hierarchies of power, 
thereby serving the interests of those groups already in control of what is considered to be worth knowing (Anderson, 2012).

My study primarily aligns with a poststructural feminist epistemology. Poststructural feminism shares values with other types of feminisms, such as concerns over a perceived objectivity, a need for "consciousness raising" (Gavey, 1989, p. 462) and a rejection of totalising theories (Anderson, 2012). However, poststructural feminism also diverges from some forms of feminism. In particular, it rejects the idea that people have a fixed identity, and as such are stuck in their epistemological reality.

Objectivity is considered something to cherish and strive for in traditional scientific research. The validity and reliability of such studies are often dependent on the scientist's illustrated objectivity, as though the process was free from the effects of external influences (Hesse-Biber, 2012). Those influenced by poststructural feminist epistemologies have a different way of viewing objectivity in relation to the production of knowledge. Gavey (1989) explains it by saying:

Poststructuralist theory rejects the possibility of absolute truth and objectivity as feminists have observed [that the] dominant conceptions of reality and truth in patriarchal Western society have tended to be male constructions which reflect and perpetuate male power interests. Feminists' explorations of our own realities, as women, have tended to produce different truths, thus casting suspicion on the idea of one reality and one truth. (p. 462)

Haraway labels "feminist objectivity" as "situated knowledges" (Haraway, 1988, p. 581). This means that knowledge and truth are always partial (i.e. situated), and that objectivity should be considered relational and subjective, always located within a web of power hierarchies and imbalances.

Feminist objectivity is best understood when connected to a specific context. As such I must make explicit the importance of reflexivity to the process of this work. The practice of reflexivity has been elaborated on by many academics and feminist researchers (for example Cassell \& Symon, 2004; Hesse-Biber, 2012; Silverman, 2006), and refers to a researcher's critical ability to recognise that their values, belief systems, biases, assumptions, social background and so forth affect their world-view and practice (HesseBiber, 2012). 
Hesse-Biber (2012) expands the critical reflection beyond a concern for gender by explaining:

Multiple feminist lenses wake us up to layers of sexist, racist, homophobic and colonialists' points of view. Some lenses provide radical insights to knowledge building that upend traditional epistemologies and methodologies, offering more complex understandings and solutions toward reclaiming subjugated knowledge. (p. 4)

When choosing an epistemological approach to this thesis, I was aware that the people I would be interviewing were likely to think about violence, power structures and equality differently to me, and I first wondered if we would be able to understand each other. However, every research project contains a degree of differing backgrounds and I soon realised that this does not need to limit the trustworthiness and reliability of the findings.

\subsubsection{Methodologies}

Methodology encapsulates the researcher's overall approach, or as Harding defines it: "a theory of how research is done or should proceed" $(1988$, p. 3).

Ethnography, a methodology within anthropology, has been prominent in shaping this crosscultural study. Fetterman explains that "ethnography is about telling a credible, rigorous and authentic story" $(2010$, p. 1) which I aimed for by first trying to establish a genuine rapport with each person that I interviewed by sharing some stories ${ }^{18}$ about myself and by answering questions. Herbert (2000), describes how ethnography can be used as a vehicle for unique insights into peoples' lives:

Ethnography provides unreplicable insight into the processes and meanings that sustain and motivate social groups. These processes and meanings vary across space, and are central to the construction and transformation of landscapes; they are both place-bound and place-making. (2000, p. 550)

So how does ethnography make a contribution to development studies? The benefits are numerous:

Ethnography can shine a light on areas usually unexplored during research. By paying special attention to what happens outside of the narrow focus of concern, ethnography helps provide an understanding of how particular (development) events unfold and why particular commitments work, or do not work. Ethnography can also help capture the emotion of what

\footnotetext{
${ }^{18}$ The word 'stori' [story] is used in PNG to mean any personal tale involving one's life.
} 
is said (and not said) which provides insights into what is important to a person or a group of people. In addition, ethnography can help bridge any gap between what is said and what is acted upon. For example, if there is no or little local ownership of a development-initiative, ethnographical observation can help to enrich the understanding of why this may be so.

Non-representational theory, which has been anchored in human geography since the 1990s, also provided value. Developed by Nigel Thrift in collaboration with colleagues from around the United Kingdom (Gregory, Johnston, Pratt, Watts, \& Whatmore, 2011; Thrift, 2008) NRT focuses on the practices and events that often go un-noted in research. Instead of solely informing the research question by interpretations and/or representations from conventional research methods, NRT looks to culturally bound, often mundane, everyday events, to learn about a topic. As such, NRT has also helped shape the observations informing this research.

These observations alongside the approximately 25 hours of interviews, constituted nearly 2000 hours I spent at the FSC working alongside local professionals well versed in the complexities of gender-based violence (GBV) in Bougainville.

Finally, it is also necessary to comment on the impact of Appreciative Inquiry (AI) on my work. Al has often been used in organisational settings and in community psychology in efforts to yield better results. Instead of focusing on a problem definition as a starting point for change, Al begins with what works (Boyd \& Bright, 2007). Cooperrider and Whitney (2005, p. viii) explain that appreciative inquiry is "a process that starts with strengths" and it is this strength-focused entry point that I was motivated by. Having used aspects of Al whilst practising counselling I was familiar with the benefits of the questions - and answers - it promoted (Boyd \& Bright, 2007).

\subsubsection{Methods}

Harding describes methods as "techniques for gathering evidence" (1987, p. 2), whilst also explaining that the term method is often used as a universal term for epistemology, methodology and method, causing confusion. There is no one method that is specifically designed for feminist, ethnographic or appreciative inquiry, rather, researchers use a range of means to arrive at their destination. More importantly is that the chosen methods can 
help answer the central research question and that it is consistent with the ideology of the chosen epistemology and methodology (Jayaratne \& Stewart, 2008).

\section{Who did the research target?}

I wanted to speak with men and women who had experience of intimate partner, GBV violence. I was interested in hearing from both those responsible for the violence and from the survivors. I had ambitiously hoped to interview as many men as women, but I soon realised that this was not realistic given the sensitive nature of the topic, combined with a limited timeframe, and so I settled for five male participants, and thirteen female participants. To reduce the risk of harm in recalling past events, I asked that participants had been living free from violence for a minimum of one year. I also asked for the interviews to be held in English as my ability to ask questions in Pidgin is limited. I wanted to speak with adults only, partly because it was unlikely that youth would have fitted the above criteria and partly because I envisioned that the ethical university process would be smoother if I focused on those 18 years and older.

\section{How did I recruit my participants?}

Victoria University's Human Ethics Committee (HEC) initially voiced stern concern for my recruitment process. I had hoped to advertise the project on notice boards around Buka Town and perhaps on radio if the notice board option failed to yield results. However, the HEC wrote back advising me to reconsider this approach. I was horrified to learn they feared my initial approach was "culturally insensitive" (A. Kirkman, personal communication, August 3,2013 ) as I believed the respect and understanding I had developed for Bougainville culture was a strongpoint of mine. Having said this, I listened to their suggestions and as such primarily used a "snowball approach" (A. Kirkman, personal communication, August 3, 2013) to recruit participants, a way of working that proved successful. The first people I interviewed were staff at $\mathrm{BGH}$ which spread to people they recommended. When the snowball came to a halt, I approached peers from the local network of professionals concerned with GBV. They, in turn, gave my number to people they thought would be suitable, some of whom ended up contacting me to arrange an interview.

\section{Who did I speak with and how did it happen?}

The BGH was supportive of my research, and encouraged me to draw from the FSCcoordinator's local knowledge. I took advantage of this suggestion and often spoke to her about my approach and occasional frustration with finding suitable interviewees. She was 
also available to speak with any participant who might want counselling. I referred two of the participants to her for further support as they wanted to talk more about their stori.

With respect for Talanoa, a Pacific approach "to allow important stories to be told" (Fletcher et al., 2006, p. 36) I was guided to choose unstructured interviews as the primary data collection method. Vaioleti explains how to interview the Talanoa way:

An open technique is employed, where the precise nature of questions has not been determined in advance, but will depend on the way in which the Talanoa develops. The Talanoa will end when it loses its malie [sic] or starts to revisit areas covered already, since then it is probable that no more new points will be added to those that have been co-constructed. It is a respectful, reciprocating interaction. Talanoa is a good conversation: one listens to the other. When to speak and what one says depend upon what the other has to say. $(2006$, p. 26)

In this way I also hoped that the inherent power imbalance between me as a researcher and the participant would be levelled out somewhat, which felt ethically right. One interview was carried out through email correspondence as the participant was living in another province at the time. I had already known this man for several years, and despite needing to structure the questions (Appendix D), our writing was conversational and non-judgemental.

In the end I conducted 18 interviews: 13 with women and 5 with men and I was very grateful to all of those who came forward. Given that Buka Island is small, and the GBV network even smaller, approximately half of those I interviewed I had met previously. This situation raised various ethical concerns which I will discuss later in this chapter.

Whilst speaking with those men who had perpetrated violence against their partner, I was impressed with their admission and description of past wrong-doings and how they had chosen to change. I tried to create conversations that did not interchange the abuse with the participant's total identity, thus rendering them bad. Nor did I intend to suggest that the participants were all good as a result of their positive changes. Instead I wanted to highlight the complexities of life and change.

The majority of interviews took place at the Family Support Centre, in a private room. Most were held during the lunch hour, but occasionally we met during the weekend. Other interviews took place at the participant's workplace. One conversation was held outside, under a large mango tree. All informants were given information letters (Appendix A) and 
consent forms (Appendix B), which they read and signed. In the information letter, which I had handed out prior to the interview where possible, I asked that the interviews be held in English. One participant however, only spoke Pidgin English, which I understand well, so we proceeded anyway. The communication was made easier by the participant agreeing to the questions being asked in English which he understood well. In this chapter, when I refer to this Pidgin/English interview, I first present his exact words, and then my interpretation in square brackets after. Other participants regularly slotted in English Pidgin words throughout the conversation, as is common in Bougainville.

I had not requested a time limit to the interviews. ${ }^{19}$ Rather, encouraged by Talanoa methods and by the style of conversation common in Bougainville, the interview was brought to an end when we started to repeat ourselves, or we felt that the subject had been exhausted. Most interviews reached this stage after one to one and a half hours.

I voice recorded ten of the eighteen interviews, which I transcribed soon after. I kept these transcripts on my password protected laptop. Six interviewees did not want to be voice recorded, one interview was impromptu and I was underprepared, and one person responded to questions using email. For those who were not voice recorded, I took detailed notes as soon as the interview had finished, also noting down quotes. Later, I typed up full notes and the originals were destroyed. Although I offered all participants to meet again, to see if they were happy with their contribution or if they would like to make any changes, this offer was not taken up. One person did however want a copy of the voice recording which I burnt onto a CD and dropped off at her work.

For those who travelled to see me, I reimbursed their travel costs. For all participants, except for the one I corresponded with through emails, I either gave a small food allowance or we shared some food that I had prepared.

\section{Observations and experiences}

Whilst working at the FSC I observed, whilst also being a part of, the daily hospital activities. These observations included noting comments made at meetings, discussions flowing from workshops and the language people used when describing clients. These observations

\footnotetext{
${ }^{19}$ Although I had indicated that it may take around one hour, in particular if people only had a short time such as during their lunch break.
} 
deepened the analysis of this study and provided an insight into discourses that govern behaviours in ways that would not have been possible if I had only relied on interviews.

As I was a member of staff at the FSC my contributions are not exempt from scrutiny either and although I recognise the difficulty in assessing one's own performance, I valued the process of examining my own thoughts and responses to what I had observed.

Initially I used a field diary noting down my observations, however; the diary soon started to encompass my personal, philosophical and often emotional responses to some of the frustrations and injustices I observed at work. As such, in this study I only draw from the diary if and where relevant, acknowledging that it is a piece of writing that reflects not just my field work process but my entire experience in Bougainville.

\section{Collecting secondary material}

To better understand the context in which the participants lived, and to take the pulse of Bougainville, I collected a number of local newspaper articles and local and international radio interviews relevant to GBV. They assisted me in situating the participants' comments and stories within my analysis. Yin (2003) highlights the need for the researcher to use multiple sources of evidence such as local documents, as it will have real advantages to the depth of the study.

\subsection{Data Analysis}

The primary and secondary sources of data were analysed using a Foucauldian-inspired discourse analysis with a special focus on gender. Foucault has been described as a "discourse-theorist" (Jørgensen \& Phillips, 2002, p. 63) and a "post-theorist" (Graham, 2005, p. 4). However, he is more often cited in relation to his post-structural discussions on language, space and the knowledge/power paradigm, as embedded in discourse (McEwan, 2008; Mills, 2007; Sawicki, 1991).

\subsubsection{Social Constructivism}

Discourse analysis fits within the wider frame of social constructivism. To be able to understand the former, it is important to create a context. Social constructivism is an "umbrella term for a range of new theories about culture and society, (and) discourse analysis is just one among several social constructionist approaches" (Jørgensen \& Phillips, 2002, p. 4). Practised across disciplines, a social constructionist perspective rejects 
essentialism, ${ }^{20}$ whilst privileging the use of language as a tool for understanding human behaviour and experience (Burr, 1995). Language however, does not only describe one's social world; it also constructs it.

In an attempt to simplify a description of the diverse field of social constructivism as it relates to discourse analysis, Burr lists four commonalities in the production of knowledge (1995, as seen in Jorgensen \& Phillips, 2002, p. 5):

- A critical approach to taken-for-granted knowledge ('common sense') Knowledge should not be treated as an objective truth

- Historical and cultural specificity Our worldviews and identities are time and historically bound and the way we understand the world is based on this context

- Link between knowledge and social processes Social processes and interactions create and maintain our understanding of the world

- Link between knowledge and social action

Our understanding of the social world leads to our social actions, which means that the social construction of knowledge has real social consequences.

Critics argue that knowledge - and identity - constructions have few restrictions and rules. Although this may be so in theory, in reality specific situations do place restrictions on identities, which often make them inflexible in particular contexts (Jørgensen \& Phillips, 2002).

\subsubsection{What is a discourse analysis inspired by Foucault?}

Since there is no Foucauldian-model per se, I refer to my discourse analysis as inspired by Foucault, as this also allows for multiple post-structural doors to remain open. I draw particularly from the work of Linda $\operatorname{Graham}^{21}$ (2005; 2008) as well as Jørgensen and Phillips (2002).

Discourse analysis (DA), most basically, is an analysis of language patterns that form part of, and contribute to, the construction of our reality. It is an interpretative approach used across disciplines, including psychology, education and research (Willig \& Stainton-Rogers, 2007). A critical research project such as this thesis aims to analyse power relations and offer a

\footnotetext{
${ }^{20}$ It refers to a belief system that believes that people and things have fixed characteristics and identities regardless of context.

${ }^{21}$ In relation to Foucault, she calls this type of definition-avoidance "informed by Foucault" and

"Foucauldianistic" (Graham, 2005, p. 3).
} 
critique "with an eye on the possibilities for social change" (Graham, 2005, p. 2), through a shift in dominant discourses (Sawicki, 1991) that may result from the process and findings.

As such, DA is not solely an intellectual approach keeping academics stimulated; it also has the ability to influence action by altering changes in discourse.

Cheryl McEwan defines discourse as:

The ensemble of social practices through which the world is made meaningful. It is not confined to words and pictures, but encompasses their material effects... Discourses always provide partial, situated knowledges. They are embedded in power relations but are always open to contestation...[they] determine what is possible to say, the criteria of truth. (McEwan, 2008, p. 121)

Discourses contribute to the construction of:

- Social identities;

- Social relations, and;

- Systems of knowledge and meaning.

(Jørgensen \& Phillips, 2002, p. 167)

What is considered right, normal and correct is decided by discourse. What subjects [people] do and think is influenced by discourse, and no one is exempt.

Foucault's contribution to the understanding of the workings of power has been profound. For many, Foucault's name is equated with the power/knowledge paradigm about which he has written extensively (Foucault, 1979, 1984; Jørgensen \& Phillips, 2002). Power and knowledge are inextricably interlinked as nothing exists outside of power. No relationship is exempt from the influence of power.

Power is responsible both for creating our social world and for the particular ways in which the world is formed and can be talked about, ruling out alternative ways of being and talking. Power is thus both a productive and a constraining force. (Jørgensen \& Phillips, 2002, p. 14)

With respect to knowledge, the link to power and discourse is distinct. Discourses influence our understanding of the world and of our identity, and are communicated through relationships and social institutions (Gaventa, 2003). Humans can access and be part of the production of knowledge (and discourse), which means that discourse can be affected by 
those who are involved (Gaventa \& Cornwall, 2001). This has further implications for truth, which Foucault asserts can never be universal or absolute. Instead, truth is always subjective, whether expressed by an individual person or through the functions of a larger group, or an institution (Gaventa, 2003, para. 4).

Another distinct feature of Foucault's analysis of power, is his recognition that power is not only a negative and coercive force, but can also be positive and inclusive. Being able to exercise power over one's own life does not mean that other's power is reduced or limited. Again, power does not belong to anybody according to Foucault; it is not a zero-sum relationship (Gaventa \& Cornwall, 2001).

What makes power hold good, what makes it accepted, is simply the fact that it does not only weigh on us as a force to say no, but that it traverses and produces things, it induces pleasure, forms knowledge, produces discourse. It needs to be considered as a productive network which runs through the whole social body, much more than as a negative instance whose function is repression. (Foucault, 1980, p. 119, as cited in Jørgensen \& Phillips, 2002, p. 13)

A central concern for feminists across all disciplines is power; in particular women's subordination through structures endorsing power inequalities (Hartsock, 1990). In this study, DA compliments my preference for using a feminist epistemology in that it allowed me to listen out for words and expressions suggesting power imbalances in relation to gender. In practice, I asked particular questions that were influenced by DA. For example, when interviewing the male participants, I asked questions such as "was it possible for people around you to challenge the violence?", and to the women I asked questions such as "what was particularly helpful to make change happen?". The answers to these types of questions provided valuable insights into those discourses that were governing peoples' lives and decisions. I identified discourses by listening to repetitive and/or strong statements that included references to gender although some of the participants explicitly referred to the assumed superiority of men. In contrast, I also listened out for counter discourses; ideas, practices and forms of resistance that contradicted those dominant, repetitive discourses. For example, when several of the female participants said that they valued the children's safety over their marriages, the counter discourse of children's safety resisted the hegemonic idea of male dominance. 


\subsection{Ethical Considerations}

Ethical approval for this study was granted on 17th October 2013, approximately six months after my initial application. During this six month period, the university's ethical application process had changed which delayed it further, but of more importance were the concerns the HEC had for my vulnerability during this study. They were mostly concerned about my apparent lack of local support, so after some major revisions, in which I formalised the support the BGH was offering, and my method of recruiting participants was improved; I received the HEC stamp of approval.

Ethical research is of course much more than a PDF attached to an email. The word ethics is related to the Greek word ethos which means character (Hesse-Biber, 2012, p. 17) and this resonates with me as I like to think of ethics as an enduring practice, just as "character" implies an enduring attitude. I hope that my ethical reflections on the entire process are apparent in each chapter as they play an important role in every step of the research.

The dual role which I described in the introduction chapter and earlier in this chapter, caused most of my ethically-related sleeplessness. Most people in the local community of Buka knew me as working at the FSC as this was how I introduced myself. My role as a researcher mainly surfaced during conversations with the FSC-coordinator, when I was looking to recruit participants, and during the actual interview. I was concerned about my dual role because I was not sure how easily participants would be able to distinguish between them. Despite my best efforts I wondered if I was being clear enough about my research role, to enable potential participants to make an informed choice about engaging in an interview. I was concerned that a lack of transparency may have extended the inherent power-gap between me as a researcher and the eventual participants. As a result, I asked the FSC-coordinator for guidance and she assured me that I did not need to worry, and that it would be enough for me to explain the details of my research role as I approached participants and when speaking to those who helped me to get the snowball rolling. Explaining my dual role at all instances was likely to cause confusion for people.

Satisfied with the fact that I was not likely to cause harm by a lack of transparency, another ethical concern surfaced. This time it was linked with the connection I already had with half of those women and men I was to interview. Some people I knew through work, others were friends of friends. Did they say yes because they felt obliged to me or to my friends? I found 
a peculiar comfort in accepting that there were no right ways of addressing these dilemmas, and that most research is affected by dilemmas which the researcher herself must decide how to approach (Hesse-Biber, 2012). I decided to confirm the commitment of those I knew already, upholding the universal principles of "honesty, justice and respect" (Miller, Mauthner, Birch, \& Jessop, 2012, p. 20). I explained my concern in ways I thought would resonate with Bougainvilleans: tentatively, leaving space for a yes or a no answer, and by expressing my happiness for our ongoing relationship no matter their answer. Despite opening space for this conversation, and for an easy withdrawal, all of those I asked were happy to talk to me. I appreciate that the researcher has more freedom than the researched in terms of leaving the context of the topic (Fonow \& Cook, 1991), but I also think it is important to trust the participant's own decision to take part, or not.

I felt pangs of ethical uncertainty about interviewing men, as I believed that the best people to interview women were women, hence maybe I, as a woman, would not be suited to interview men. And how could I feel a connection - important to feminist research - with men who used to be abusive? In addressing this I felt reassured that most of the male participants already knew me from my first assignment in Bougainville or from my work at FSC, hence their abusive past was only a part of our association.

It was not only the difference in sex that concerned me; I am also unmarried, I have no children and I am a European. None of the participants related to a similar background. Will they think that I am a phony do-gooder or worse, taking pity on them? The questions were many and straight-forward answers were few. Sometimes I felt the need to confirm that I was a suitable person to carry out this type of research and speaking with my supervisor and resorting to texts on feminist reflexivity all helped. Feminist research is encouraging of differences if it comes with reflection and it is the ways of navigating and handling our differences that are important.

\section{Conclusion}

Feminist epistemology run through the entire thesis, and in this chapter I have given accounts of how the various parts to the research process were influenced by feminist epistemology, in particular post-structural feminism. My methodological preferences align with a post-structural framework, as do the many aspects of discourse analysis which I discussed here. Whilst recognising that the ethical process of research is continuous and not 
limited to a particular section, I pointed out some of the more challenging ethical dilemmas I faced and how I overcame these. 


\section{Chapter 5: Women's Stories}

\section{Introduction}

In this chapter I present the key themes from the interviews with the 13 female participants, supported by my observations from working at the Family Support Centre. Eight of these women were voice recorded and the interviews were later transcribed by myself, while I took detailed notes of the remaining five interviews (four of those did not want to be voice recorded, and the last interview was arranged impromptu and I was underprepared).

To begin with I look at the context of marriage. What were the women's circumstances and expectations? Then, I present the women's voices in relation to the violence they had been subjected to. Following this, I consider the role of resistance. None of the women were passive recipients of violence, but opposed it in many ways, and over a long time. Finally, I reflect on the end of violence, the non-linear process of getting there, and the different meanings they shared about what the end of violence entailed.

All female participants were either born in Bougainville, or had lived in Bougainville for an extended period of time. Some of them were, or still are, married to men from other provinces in PNG, although most men also consider Bougainville home. Three of the women have been married twice, with both marriages being affected by violence. Approximately half of the women's families were paid some form of bride price and two marriages were arranged by the parents.

In Table 5.1, I illustrate some basic demographics of the female participants that I refer to throughout this chapter. 
Table 5.1: Demographics of the female participants

\begin{tabular}{|l|l|}
\hline Age range & $32-55$ years \\
\hline Children & Between 1 and 7 \\
\hline $\begin{array}{l}\text { Still married to formerly } \\
\text { abusive partner }\end{array}$ & 4 \\
\hline $\begin{array}{l}\text { Still married, but separated } \\
\text { from formerly abusive partner }\end{array}$ & 2 \\
\hline $\begin{array}{l}\text { Divorced from formerly } \\
\text { abusive partner }\end{array}$ & 7 \\
\hline Median length of marriage (still married) & 16 years \\
\hline Median length of marriage* (before separation or divorce) & 13 years \\
\hline $\begin{array}{l}\text { Median age at time of marriage (for both married and } \\
\text { divorced)* }\end{array}$ & 23 years \\
\hline
\end{tabular}

*For those women who had been married more than once, I have drawn from the relationship to which they primarily referred.

\subsection{Married Life}

\subsubsection{Getting married}

Some years back, a friend from Buka asked if we could talk. Curious as to what had prompted her unusually formal request we sat down. She told me that she had just found out that she was pregnant. Under many other circumstances I would have congratulated her, followed by questions of due date and so on, but not that time. The week prior she had told me that she wanted to break up with her boyfriend, that he was controlling and jealous. Now, one week later and pregnant, she said that they were getting married as requested by their parents and would soon move in together. She was 20 years old.

From the interviews with the women in my study, I understand that Bougainvillean women marry for many different reasons. Two of the 13 women said that their marriage was arranged. One of these was Mary, whose marriage was an arrangement based on repayment and rights to land. Mary's uncle had married her future husband's sister, so she was deemed an "appropriate exchange". For Barbara, the other arranged marriage, the wedding was forced on her by her future husband's family. At gunpoint, the uncle of her husband-to-be 
approached Barbara's family to say "if the two of you don't allow your daughter to marry this boy, we are going to shoot your daughter". Barbara continued to explain "I am the only girl in the family and what could they have done?"

Although Barbara resented the marriage, he "could sometimes be a good husband" and she laughed when she explained that "I had to try and make this love grow. And he was young, very handsome, but not someone who you can love". Barbara later explained that "during the Crisis there were many women who were like me. They married against their will".

The Bougainville Conflict, as discussed in Chapter 3, impacted severely on both men and women. However, it was only the female participants who spoke of the negative impact on them and their marriages.

It was not part of my question guide to ask for the details of getting married, I was more interested in the transition from gender-based violence to violence-free living. However, as the interviews progressed I began to understand that details about the women's marriages and the hopes connected with them could be helpful to form a context for what would follow. As such, for six of the thirteen interviews, I explicitly asked if the women had been pregnant at the time of marriage. Four women said yes whilst the other two said no. For the remaining seven women, I am unsure, although twelve out of the thirteen women had delivered a child within one year of the wedding day. ${ }^{22}$

Some of the women's families had been given bride price for their daughter. In a matter-offact way Agnes explained that the bride price for her was 700 Kina in the early 1990s (approximately \$340 NZ). Although Barbara's marriage was forced, bride price was still important to her, as expressed in her disappointment; she explained:

A woman came with a mimis [necklace] that they use in Buin (the south part of Bougainville) for bride price. In Buka we would use one or two metres, but the mother of this guy she came with a very short one. Worth only 100 Kina...it is like an engagement, so this is not right.

\subsubsection{Expectations of marriage}

As a friend, I have attended a number of church weddings in Bougainville, and also one customary engagement. Unsure what to expect, I attended these events with open eyes.

\footnotetext{
${ }^{22}$ I do not have data on the date of birth for the 13th woman's children.
} 
Although sharing many similarities to weddings I am familiar with, ${ }^{23}$ I noticed a stark contrast to the tone of the celebrations in Bougainville. Instead of speaking of the joys of marriage, the focus was on how "marriage is hard", as repeatedly mentioned by the pastor. He also reminded the grooms that they will now "have to stop running around with other people (women)". In effect, he reinforced the need for commitment and fidelity almost as if he was warning the newlywed couple.

All of the women in the study had either opinions of what they were hoping for in a marriage, or of what they did not want to see in the marriage. Some of these reflections were centred on the expected role of the husband.

Three of the women referred to their husbands as points of safety. In recalling her husband's abuse, Barbara said that "he was supposed to be my security, but it was the opposite". Helen, who had married during the Crisis, said that she had been looking for "protection". Ten years after that marriage ended, Helen remarried but then separated again because of her second husband's infidelity and abuse. Still, at the time of the interview, Helen was hoping that her second husband would come back "to look after the family".

Several other women referred to their husband's size and strength, including Mary. In response to asking her if it would be possible to live without a husband in her village, she said:

That would not be good because we need a husband to do hard work for us like building houses and other hard work that a woman can't do...l leave most for him. He can climb fruit trees, build the house when it is bagarap [broken]...going out fishing and cut firewood.

Several women explained that financial support from a husband was important. Deborah reflected on the first four years of her marriage which were "good". She said "he never left the family and never went out drinking or socialising. Every time he got money he would come and give me everything, his whole pay packet". Irene echoed this sentiment by referring to her husband in the early days of marriage as "a good man who took me shopping and gave me money". Although Irene later spoke of her husband's extramarital affairs and other forms of abuse, she was reluctant to criticize him. She said "he would

\footnotetext{
${ }^{23}$ The weddings I am familiar with are traditional Swedish and New Zealand weddings, both civil and church.
} 
spend time with us... he talks nicely to us, but when he goes out he comes back in the morning. He just go and sleep. But he made sure that we were happy, that we had food".

Other women made it clear what they wanted from a husband, by saying what they did not get. Linda for example, a woman in her $30 \mathrm{~s}$, who has ended two violent relationships, reflected on what it was like to be young and live in an abusive relationship. She had wondered "is this how it is going to be for me, is this married life? Is this what I am supposed to get out of it? I had no idea you see, was sex supposed to be like this?"

Kirsten, a woman in her 40s and divorced, reflected on what she would like in a potential future relationship:

Two of the most important things that I am looking out for now is, one; my children, and two; alcohol \& womanizing. I mean, a man can drink, but not so heavily that he starts womanizing. And also, I would like a man who understands who I am, what kind of person I am.

Both Esther and Florence said that they had wished that their husbands were more involved in family life. Esther, on reflecting on her husband's lack of interest in the family said "I had a marriage that never existed...we never did family-things like going to church, going shopping, visiting people, or cooking. He was never there it was just me and the kids".

Florence, who is still married, said that she used to joke around with the extended family when they went to the garden by saying "I don't think I have a husband, my husband is already dead" [laughter]. Later in the interview Florence happily exclaimed that things have now changed "now he will be the first one to wake up and cook our breakfast. Good I say, I will relax and sleep".

\subsubsection{Expectations of a woman in marriage; by self and others}

When I asked women at the FSC about their expectations of marriage, they often answered tentatively about what they could do for their husband and children, and rarely about any reciprocal benefits.

What it means to be a good wife is a bold theme throughout the texts. The welfare office and the police were described as agents reinforcing the discourse that a good wife is a woman who stays with her husband, no matter what. 
For Linda, trying to gain custody of her son continues to be difficult, and she expressed disappointment at how "the system" privileges her former husband, despite all the abuse he has put them through.

L: They [the welfare office] tried to mediate with my ex about the custody of my son, but he didn't want to have anything to do with it. It wasn't getting anywhere. And when I came here [to Bougainville], the same thing happened. The same obstacles with child welfare. There was a guy who worked there... he said that maybe I wanted to get back with my ex, that maybe we should mediate. I said "don't you get what I am saying, I don't want to be with this guy".

V: $\quad$ So you started the process in Moresby but it kept on going until you moved here to Bougainville?

L: $\quad$ That's right. So then I took the issue with the Public Solicitor and I've been waiting for the last two years.

V: Do you know what the holdup is now?

L: $\quad$ No. I've been waiting patiently for two years and at the end of last year I decided to go and check again. And I asked them "what is the latest?" They had been tidying up and cleaning the place and they found my papers somewhere. And it had nothing on it. It hasn't even been registered with the courts.

Linda also experienced the (in-) actions by the police as privileging her second abusive partner. Linda explains what happened when she agreed to meet him at a public restaurant to confirm that their relationship was truly over. She explained:

We went to have lunch...this is not the first time he beat me, just the worst time. We started talking and he asked if I was really sure that I wanted to end it. And I said that I was sure. And that was it, he couldn't accept it....The ladies who were looking after the place came out running saying "stop, stop". And then some police officers who were coming for lunch walked past. By that time he was kicking me in my ribs on the floor. I just got up when I saw these two police officers and I ran to them and I said "Help me, this guy is beating me!" And they asked "Man bilong yu?" [is this your husband?]. I said "No!" Then he ran out to say to them that "Em meri bilong mi!" [it is my woman!].

For Linda, trying to make positive changes in her life was made more difficult by the authorities who should be helping her. Yet it was not only government departments that caused the women in this study suffering; the church was a double-edged sword which I will explain later in this chapter. 
Although a majority of women had some family support, other family members prompted the women to stay in their abusive relationship. Both Jennifer and Barbara spoke of the "shame" the family would feel if the marriage ended in divorce. Barbara explained that the lack of support she had received from her mother had caused a rift in their relationship. She said "Mum is somebody who complains a lot... she is ready to just throw stones. She said that I married that guy and I should tell my husband to come back". Deborah said that her family had called her "mad" for wanting to separate from her husband even though he had made her sister pregnant and then suggested that he should marry her too.

Although these are predominantly examples of external pressures on women of what a good wife ought to be and do, some women also explained how these expectations had become internalised. At the FSC, several women clients told me that they had never wanted to refuse their husband sex. In fact, many women jokingly said that it is much easier to allow their husbands' to slip antap long mi [have sex with me] than face the consequences of saying no. In late 2013 , these stories were placed in a context for me. As I was walking through the maternity ward where a dozen or more women had just delivered children, a respected doctor in his 50s, reminded the women of spreading out the birth of their children, yet at the same time to never refuse their husband sex, because if you do "He will bring home disease to you, and that is not good".

So, what actions are considered good for a wife, apart from loyalty and not resisting sex? In answering this, Jennifer said that "I would never swear" (although she "occasionally called him names"), and to make sure that he was safe she would "ask him to drink at home", otherwise he might "get into a fight with people and they would kill him". Florence also asked her husband to drink at home for his own safety.

Four women explicitly said that their husbands had been angry with them when challenging their whereabouts. Helen said that her husband "called me bad names when I went to check what he was doing outside at 5.30 in the morning...and I knew he was with this woman". Esther's husband had called her "a jealous woman" for asking about his affair.

It is also appropriate to consider what constitutes bad behaviour for a wife, as these points towards what is expected. In trying to get over the separation from her husband, Deborah had occasionally "partied". She explained, "I had not tasted alcohol, even after I got married, 
but when I went through problems my sisters encouraged me to go out with them...I wasn't used to it but they told me to have one bottle. It helped". Also, Irene said that out of loneliness and "frustration" over her husband's "women friends" she had "started smoking and texting friends", behaviours she later wished she could undo because of her husband's retribution. Florence, who has been working at a health care facility for over a decade, articulated the expectations from "some men" of their wives, she said:

Even though she brings in the money he still expects her to do the household duties like looking after the children, cooking, and bathing the children. Some of the men here in PNG they don't know how to bathe the children, they don't know how to cuddle the children. They just come and impregnate their wives and then they go and stay far away until the child is big. When they are grown up, they will come back. Hard work!

\subsection{Experiencing Gender-Based Violence}

\subsubsection{Infidelity and other abuse}

Abuse took many forms, including: a bruised face; broken bones cuts; sexual violations, rape; psychological torment; financial deprivation; infidelity. My colleague and I conducted a survey in 2013 at the BGH into the extent of intimate partner violence amongst staff. Over 50 per cent of the staff participated (approximately 100 persons), and 90 per cent of nurses (all women, except one) said they had experienced abuse in the home at some point during the previous year.

Many of the women interviewed for this study initially approached me to tell their story about their husband's past infidelity. First, I was a little reluctant to include these women in the study as I was unsure if they fit with the study preferences. However, I soon changed my mind. Not only is adultery and enticement ${ }^{24}$ illegal in $\mathrm{PNG}^{25}$ for many people it causes immense and lasting psychological suffering. The suffering is not only linked to the matrimonial betrayal, but also to the lack of options available to many women. In the interviews with the women who spoke of their husband's infidelity, I learnt that they had all also suffered physical abuse, and some suffered sexual, financial and other forms of psychological abuse.

\footnotetext{
24 "A person commits enticement when he persuades or attempts to persuade the spouse of another person to commit an act of adultery whether or not the contemplated act of adultery is committed" (Adultery and Enticement Act, 1988, p. 1).

${ }^{25}$ Adultery and Enticement Act, 1988.
} 
Twelve of the thirteen women explained that alongside various forms of abuse, their husband had also had an extramarital affair. For nine of these twelve women the physical abuse had started about the same time as his infidelity. Kirsten said that when her husband started to sleep away from home for two or three nights per week he told her he was "just sleeping in the office and drinking with friends". Kirsten, knowing that her husband was lying, decided to quit work to spend more time at home, hoping that it would change his behaviour, which it did not. "I had a terrible time in my life" she said.

For Helen, her husband's infidelity was also hard to deal with. Not only had he been beating her throughout her pregnancy, but later he had an affair with his brother's wife which had forced him to flee the village for fear of family retribution. When we spoke, Helen's husband was still hiding, something she did not approve of; she wanted her "hubby to come home" so they could sort out their problems.

Gertrude, who was living with her husband and their three children, said that "the affairs were worse (than the physical abuse) and I don't think I could stay if it would happen again". In an attempt to overcome her husband's betrayal they were both attending counselling at the time of the interview, which she said was useful.

For Linda, her safety was jeopardized as a result of her partner's extramarital affair. She explained:

I started to have confrontations with this other lady, before and even after I had our baby...at one stage she wanted to kill me with a knife so he came and took me from campus and brought me to the most remote village in the highlands...I stayed there for a couple of days until it was safe.

Other forms of violence, such as sexual violence, were also reported. Four women explicitly said that their husband had raped them during the marriage. Another two women implicitly suggested that this may have occurred although I chose not to ask any further questions. Kirsten, at the very end of the interview, recalled her husband's sexual violence:

I didn't want to sleep with him, so he committed rape. It was really terrible. Because he was womanizing I didn't want to sleep with him. It bothered my mind and totally put me off. So he raped me instead. He felt that it was his right. He said that I was seeing someone else because I didn't want to sleep with him. He blamed me. 


\subsubsection{The role of forgiveness}

Forgiveness is a permeating theme in the findings: expectations to forgive an abusive partner, hopes that forgiveness will set things right and forgiveness as part of reconciliation.

Although I aspired to listen and learn from my colleagues at the Family Support Centre, at one point in my work I rejected a suggestion to forgive. My closest colleague and I had been dealing with a number of building contractors who were working on the FSC building. The job, when completed, was of an incredibly poor standard, partly because of misappropriation, it was delayed by over one year and on top of that they were frequently intimidating us when we met. I felt that we were treated unfairly. After completion of the building, my colleague, with a heart more forgiving than mine, suggested that we should invite the contractors for the opening party so that "we can ask for forgiveness for not getting on during the building phase". This got me thinking. Asking for forgiveness although we were taken advantage of? Asking for forgiveness when they had shown no sign of remorse? For me, this was unreasonable and not something I could do.

This story, although centred on my subjectivity, indicates that forgiveness holds power in Bougainville and that perhaps it is an expected medium to be able to move on. Through the interviews, the women in this study helped me to understand more about the discourse of forgiveness.

Irene said that when her husband admitted to having extramarital affairs she had responded with forgiveness. She said:

At the time I was involved with the church so I wanted to forgive him. I used to forgive him very easily. At first I used to be very angry and say some nasty things, and not talk to him...then as I was going to church, I decided to start forgiving him. Twice when he told me I said "it is okay". He told me he would not do it again, he would not go out again. But he did.

Later in the interview, Irene apologetically told me how she had started to go out with friends, one man in particular, as her relationship with her husband was deteriorating. When her husband, "a Christian and church leader", had asked her about this he had promised her that "I will not beat you...I will forgive you for anything". Because of her faith and hope that telling the truth would set the relationship right she "confessed", believing "marriage was more important than anything". Her husband however did not forgive; instead he beat her severely and continued to psychologically taunt her until their separation. 
Jennifer's husband used to apologise for his temper, she said "he used to say that he was so sorry for what he did to me and that his problem was his temper and that he wanted to deal with it, but that is was hard for him". Jennifer, in efforts to save the family forgave him many times.

Florence's husband also used to apologise and although she was sceptical of his genuineness back then she now feels more assured that he really meant it. Until this day, many years since the violence ended, he still says that he is "really sorry for having hit you". An apology, she accepts.

For Esther, forgiveness looked different. To be able to "move on" and not grieve her husband's infidelity any longer, she decided to call his new wife to say that she wanted to "forgive her" for what she had done. This apology laid the foundation for a friendship between the two women which has lasted longer than her former husband's marriage to this woman.

Forgiveness also played a part in Mary's reconciliation with her estranged husband, as the excerpt below shows.

V: When your husband then came back to the village, I understand it took some time before he came to stay with you again.

M: Yes it took maybe a year. We stayed apart. Then my brother talked about it and we had to reconcile.

V: So who was involved in the reconciliation?

M: My husband and his family and me and my family.

V: And what is the custom at this point, what do you do?

M: We talked about it and decided to forgive each other. We shook hands.

V: What was that like for you, to forgive?

M: It was a little hard. Is that ok? I had to accept it because it wouldn't work out otherwise. Later in the conversation I asked what had become of their marriage after the family reconciliation process and Mary said that life had gotten better, "we live happily now...we work together and share family work". But as we were wrapping up the interview Mary explained that despite the apology she still "sometimes recalls his past activities", but when 
she brings it up he asks her to "forget about the past and that today is today". Encouraged by her reflection on the effectiveness of the reconciliation, I asked her if she thought she would ever fully forgive her husband, and she said "yes I think that day will come".

\subsection{Resistance to Violence}

All of the women in this study had utilised a number of different approaches for trying to safeguard themselves and their children against their husband's abuse. What is apparent is that some of the findings were expressions of a double-edged sword; one approach could be both a hindrance and a help.

\subsubsection{Trying to solve problems by talking}

Talking to a husband may seem like a sound first step in trying to encourage change, yet it seems to have had the least effect. Nevertheless, all but one of the women tried to speak to their husbands to ask them to stop.

For Cecilia however, who married after overwhelming expectations from her family, was not safe to raise her concerns with her husband. The first time they met he had raped her, but Cecilia, under pressure from her family, had hoped that married life would get better. During their many years of marriage he had continued to beat her and the children, with several attempts at killing both her and their children.

Cecilia who had been living free from violence for over ten years at the time of the interview was the only woman in this study who did not try to speak to her husband. In fact, she said that "no one tried to speak to him, because he was so violent, everyone was scared". Instead, she avoided (resisted) his violence by working long hours, visiting her siblings who provided some support, and she attended counselling. The divorce was the initiative of her husband who "jumped on the last boat out of here during the Crisis", leaving her and the children behind. Today, Cecilia is "relieved" that he moved and she said that if he ever would try to come back her children will "kill him".

The remaining 12 women all tried various ways of speaking to their husbands. Invariably, all partners either refused to talk about the problems, blamed the abuse on their wives or blamed the abuse on external influences, in particular alcohol. After several years of trying to speak to their husbands, alongside other means of influence, three of the men had eventually accepted some of the responsibility for their abuse. 
Kirsten said that she had tried to speak to her husband many times over the years, but "the only time he talks is when he has been drinking and when he is sober he never wants to talk...which made things worse". Also, Linda spoke to her first partner many times over four years, yet his constant "lies and manipulation" made her feel as though there was "no way out" and her talking made little difference. She even contemplated suicide. Jennifer said that when she had spoken to her husband he had either blamed the abuse on a relationship Jennifer had with a male friend or on alcohol, not willing to take any responsibility until some years later.

Three women in the study had first attempted to solve problems by peaceful means, they had later responded to their husbands' unwillingness to change with either threats or actual violence. One example is Florence whose husband was abusive after drinking alcohol and had had an extramarital affair. Florence said that she was "sick of his behaviour". I asked her how she had dealt with these problems.

F: $\quad$ At that time he treated me very well. He said "sorry, sorry". I used to threaten him and tell him to buy me a ticket so I can go home "I don't want to stay here". I had to chase him. I said "if you go drinking again I will kill you" [laughter].

V: $\quad$ Oh hard on hard?

F: $\quad$ One time there was this messenger who carried messages to and fro between that woman and my husband. This was one of his cousins. And I said "you are the cause of my husband's relationship with this woman, you set it up", and then I had to punch that man. I punched him on his eye and he had a big spilt that was bleeding [laughing].

V: What happened then?

F: $\quad$ He wanted to retaliate, but my other brothers'-in-law they said “don't touch our tambu [relative]".

V: $\quad$ And did this clear it up or?

F: Well later, I got the cousin and my husband together and I said "you know why I hit you". I wanted our family to be strong and not have problems.

Later on in the conversation with Florence, who was born in another Province, she said "I find these Buka-men easy to talk too actually". In a friendly challenge to her praise of Bougainville men I then said that I believe many women find it difficult to speak to their 
abusive husbands, to which Florence answered "It is about your approach to them... they have a lot of respect here".

For the other two women who had used violence or sent family members to threaten the husband, both marriages ended in divorce.

\subsubsection{Education and Financial Independence}

All of the women in this study had received an education. Only one woman had a basic level of education in the form of elementary and primary school, whereas five women had completed high school; and the remaining seven had graduated from some form of tertiary education.

At the time of the interviews, all women were in employment, from senior positions in large organisations to grass-root level work. Many women were continuing to up-skill through their employer. At the time of the violence ten out of thirteen women were working, two women were in a transition from school to work and one woman was looking for work (which she eventually found).

Four out of the six women who initiated divorce from their husbands said that finances were important for them. These women explicitly spoke of how money, or the lack of it, made a difference to their ability to leave.

Esther said that she stayed married a little longer than she had wanted because of a promotion at work. She said that "financial progress was important", referring to being able to provide more "stability for the children" after the separation. Kirsten was intermittently working during the abuse and when she was offered a job in a location several hours away, she jumped at the opportunity, "I decided to take the kids with me and then I left".

Both Kirsten and Esther reflected on the financial situation for many young women and girls who fall pregnant outside of wedlock and who become dependent on others for money. Kirsten elaborated on what it is like:

I feel for them. I mean, now when I have a regular income and my life is like this....well, they depend on their husband for an income. So they have to continue to live with their pain and to suffer. For some women though, possibly out of frustration, they just go and end up with some other men and then fall pregnant again. And the problem keeps going. I think that these women who have gone through some pain, if they use their heads properly, they can see what is good for 
them. Don't just go from man to man and have another baby, and then the dads are leaving them again, this is no good. They need to be more responsible for themselves and for the children they have already got.

Esther supported this belief by saying that "life is hell" if you have to support yourself and a child without an education. She said "where will they [these women] work...all they do is work in the garden and make copra".

When I asked Linda if it was important to have an education and access to money when she had decided to leave she said:

My desire to leave was greater than to think about how I should survive. The most important thing was to get out at that time, to survive a little bit, and then continue to survive afterwards. I didn't really depend on the [university] degree that much. Even when I went back to Moresby I was cooking food and selling to make a bit of money to survive.

Only one of the women who is still married mentioned the issue of money. Mary "had sent" her husband to Rabaul [in another province] so he could work and make money to send home to her and the children. He failed to send any money and instead Mary had to find work and arranged for a childminder for the children.

\subsubsection{Relocation}

Work flexibility proved important to several of the women in this study. Four of the women who divorced their husbands found their employers' encouragement to consider relocation helpful. These women were not coerced into relocating, but they implied that employers had knowledge of the poor law-enforcement system and the likelihood of continued abuse, hence suggestions of relocation.

This approach to escaping violence is consistent with my experience of working at the Family Support Centre. Not only clients, but also abused staff, at the BGH were occasionally encouraged by managers to consider relocating, usually to somewhere they had a form of support network.

Unsurprisingly, such a move does not hold the perpetrator responsible, instead it may reinforce the belief that the woman is somehow to blame. I recall one incident at BGH where both husband and wife were working in different departments. After subjecting her to very 
severe violence she first fled to a safe house and then was encouraged to move away from Bougainville. Her husband, on the other hand, remained working and living in Bougainville.

Both Esther's manager and work colleagues had confronted her husband which made her feel supported. In spite of this her manager had suggested to Esther that she may want to consider relocating "as he will never change". For Esther, the natural step was to move back home to Bougainville. For many women, such as for Linda, it can be a relief to not live near the abuser. Linda explained “since my love and feelings had totally been diminished I didn't wanted to stay anywhere near him. I wanted to get as far away as possible from him".

\subsubsection{Family involvement}

Support from family members is a resolute theme in this thesis and all women shared stories of their families' concern, or lack of, for their wellbeing. All of the six women who divorced their husbands, thus ending the violence, had significant support from at least one family member.

Barbara had asked her father to stay with her and her husband "so he could see the abuse with his own eyes". After some months he had asked if she "was ready to leave this man", to which she responded positively. After this, Barbara moved to her parents' village and her father explained to her brothers the reasons for her separation. This gesture was important to Barbara in order to minimise shame for the family. She explained: "in my custom, brothers' feel ashamed when their sister leaves a husband".

Linda had called her mother as soon as the physical violence started, saying "the first time my husband beat me I called my mum who got on the first flight". Later on in the relationship, Linda's father and younger brother had also responded to her distress.

My brother has been trying to stand up for me, and I appreciate that...he tries to speak on my behalf, like when I ran away with my son, there was a time when my ex had come back...and he wanted to take my son away... my brother and my dad confronted him.

The level of support that Esther received from her sister at the time of the separation was essential for her to be able to deal with the abuse and subsequent divorce. Her sister had been used to Esther showing up with a "smashed-up face" and welcomed her and the children into the house. 
Various forms of financial, practical and/or emotional family support were spoken about by all women who had escaped the violence by divorce. Also, three of these women recalled reflective questions by family members that made the women think about their lives. Kirsten's aunt had asked "what kind of life are you living?" and "do you want to live this kind of life?" which in turn had motivated her to take the next step, to move out of temporary housing and seek more suitable help. For Deborah, her brother was the only one in the family that showed support, for which she expressed deep gratitude. By being asked to "make a life-time decision" based on what she and the children deserved, Deborah gained the strength to leave her husband. For Linda, it was her mother who asked a simple yet pertinent question that stuck with her, "is this the kind of life you want, a man who has two women?" This gentle yet challenging question, coupled with support from her employer and other family members, empowered Linda to escape.

The remaining seven women, who did not choose divorce, consistently reported less involvement from their families.

Florence lived with her children and husband in a different province to her own and chose not to tell her five brothers about the abuse. Florence differed from the other women who were still married or separated, in that she felt assured that her family would help her out if she needed it. This appears to have created a sense of confidence in her.

If we were in my home town and my brothers knew that he was abusing me they would hit him... They would have come. And I didn't want to spoil this relationship. I wanted to deal with it myself, I wanted to find my own solutions to my problems.

Jennifer explained that her family had known about the abuse but advised her to "try and talk to him in a more civilised way, sit down and talk about it...to spend time with the kids". Jennifer's husband's family on the other hand had stepped in to "talk to him and advise him", something custom did not allow her family to initiate. In asking Jennifer if anyone ever suggested that they may benefit from living apart for a while, she said that "no one ever suggested that. Not even my family. They wanted us to try and work it out".

Neither Helen nor Gertrude received support from their families. Helen, who is currently separated from her husband, said that her mother had encouraged her to get back with him 
again, something Helen also hoped for. For Gertrude, who is still married, her parents support was minimal as they "see my husband as their son". Both women were attending counselling at the time of the interview and felt strengthened by it.

Mary, whose marriage was arranged, said that her family had strongly disagreed to a separation. Instead her brother had arranged for reconciliation with her husband, with which Mary ultimately expressed satisfaction.

\subsubsection{Village meetings}

Three women had taken part in village meetings hoping to find a solution to their problems. These meetings took place in their villages around Buka Island and were initiated by either chiefs or the woman's parents.

The people who attended the village meeting for Agnes expressed their conflicting opinions on what she ought to do; stay or leave. Agnes' mother "who felt sorry for him" wanted her to stay whereas some others said that leaving may be the best. At some point after the meeting Agnes left her abusive husband for good.

The end of Barbara's relationship with her abusive husband was signified by a village meeting with several chiefs. Although her husband had showed remorse and been crying, the chiefs approved their separation which laid a path for a life free of violence. In response to her husband's final pleas, Barbara said the time had come when she could not give him "any more chances".

For Helen, the village meeting was called by the chiefs to "try and straighten things out" but had a poor outcome. Although her husband had earlier admitted to the infidelity with his brother's wife, he later denied it in front of the chiefs. The mistress, who had also attended, denied it as well and the blame for the marriage problems was placed on Helen. At present, they are separated.

\subsubsection{Work support}

Although addressed briefly in the section titled relocation, it is necessary to further explain the importance of work support as an enabler of change, as raised by several women in this study. 
In addition to an employer's flexibility in supporting relocations, emotional support and guidance were also reported as helpful. Where there was an absence of support from an employer, the participants did not raise it as a concern or as something they wished they had received.

Four women, two still married and two divorced, specifically pointed out the importance of their employer's interest in their lives as a contributing factor to making change. Jennifer was thankful to both work colleagues and her manager who had been instrumental to her husband's positive change. One of their neighbours, also a senior work colleague to them both, used to come over with his wife, offering advice. Instead of confronting the abusive behaviour as Jennifer said she used to do, she said they were "not telling him off in his face, but being respectful...[they said] for him to drink this [finish his alcohol] and then sleep". In response to the question of what their support meant to Jennifer she said "this is why I like that community so much, they are so caring about other peoples' problems, they don't just sit back, but they took action."

Both Linda and Esther felt that their employers had taken on a guidance role which helped in clarifying their thoughts without having to worry about what would happen to their work if it was affected by the abuse.

In contrast to the appreciated involvement from colleagues was the push from Kirsten's manager for her to attend counselling with her husband. Kirsten did not want to meet with her husband for counselling but felt obliged to follow her manager's request. Her husband failed to show up.

\subsubsection{Church}

The influence of the church was noted by seven of the women, although only Jennifer and Irene explicitly referred to the church as being a major influence in their lives. Both of those women were still married, although one is currently separated. In the interviews they articulated the complications of holding a strong faith whilst also living with violence.

Jennifer, a woman with three children, explained that she had not involved the church in their problems, yet there were clear expectations on her to stay with her husband since both of them were "devout Catholics". However, living according to her faith whilst also trying to protect herself and her children was difficult and it made her feel "stuck": 
I am a Catholic and in the Catholic Church marriage is for life. All these doctrines and laws set by the church really holds you accountable to marriage and in a modern world...well between the modern world and the church, I got really stuck. I went through so many horrible experiences. He even attempted to rape me.

Irene, whose Christian belief in forgiveness resulted in her separation, later told a story of how she had tried to run away from her violent husband to seek help from a pastor. Irene explained, "the pastor came out with his boys [the pastor's sons] and they were talking to him [her husband], but my husband scolded them, and in front of them he beat me up. The pastor and the boys then turned around and left me". For Irene, the church was thus a double-edged sword.

Florence, in reflecting on the balance between human rights and the church said:

\begin{abstract}
A lot of men here still don't understand what human rights are. And you know what, in the colonial days, when the Missionaries came, a lot of people have tuned in to the Bible. Believing in what the Bible says, but there are some teachings in the Bible that whoever is interpreting the Bible is misinterpreting it...making women subservient.
\end{abstract}

The remaining women referred to prayer as a source of strength, and to the church as a moral guide which encouraged "role modelling". It is unclear if any of these women attended church service with any regularity, or at all, yet prayer in particular had helped them to gather strength whilst living with the abuse.

\title{
5.3.8 Children
}

All women in this study shared stories about their children. The interviews did not include questions about violence directed to the children, and it is unclear to what extent the children were affected. What is clear however is that many women knew that the children could be adversely affected by the abuse they were at the hands of, and this was a major worry for them. This also contributed to some women's decision to end the relationship.

All women in this study went to extraordinary lengths to care for their children. All of them were the primary caregiver of their children, being responsible for paying for school, medicine, food and clothes and so forth.

Deborah and Esther both worried what would happen to the children if their husbands killed them, a thought that was so prevalent that it aided them in the separation process. Agnes, 
whose two children are in their 20s now, recalled the abuse her mother received at the hands of her father, and wanted something different for her own children. Several times during the interview she repeated the importance of a "healthy family", a family without violence. Kirsten was driven by rights; the rights to a safe life for her and to a safe upbringing for her children. In considering if she would remarry one day, Kirsten remained open to the idea only if her children would also be treated well.

Opposing this, some women felt that their husband was a "good father" and that his care for the children transcended the abuse he directed towards her. Although I did not consistently ask what a "good father" meant, the women who referred to their husbands as such spoke of his involvement in the children's lives. Florence said: "He created swings and toys and he liked to stay with them and play with them. When they grew up he made a basketball hoop for them to play with". Irene said that he was good because "he gave the kids money and talked nicely to them", whilst Agnes acknowledged that her former husband was a good father, although she constantly had to "make excuses" for him for failing in his responsibilities.

This corresponds with my experience at the FSC where many clients believed that children need their father, no matter what. Although these clients often know that it is illegal for a husband to abuse his wife, few are as aware of the detriment effects on the children for witnessing such behaviour. Deborah, who left her abusive and unfaithful husband still experienced guilt for taking such a decision. She said “maybe it wasn't the right decision as I abused my children for leaving their father". To complicate matters further, it is not uncommon that fathers remove all forms of support from their children in a separation, which many women take into account before making such a decision.

The six women who are still married or separated also spoke of their love for their children, with one woman saying that her husband is even better than her at looking after them because of her long working hours. None of these women spoke of their concern for the children's future as a result of their father's abuse, although Jennifer had found solace in her neighbours prompting of "being mindful" about arguments in front of the children. Jennifer, who is still married, said that "spending time as a family", going to the beach and having fun had strengthened their bond and contributed to decline of her husband's abuse. 


\subsection{The End of Gender-Based Violence}

In embarking on this research, I thought I would find tidier answers to my research question. I thought that people would either be in a relationship affected by some form of violence or they would not; however painful either situation may be. I thought that living free from abuse would always be the preferred situation by those previously affected by it. This research has shown that such beliefs are not represented by the findings in this study. The methods of change are many, yet they are also complex and often contradictory. For some women, a particular combination of methods may be useful, whereas other women find different support systems helpful.

The process of moving away from violence was long for everyone. No one spoke of their husband changing from one day to the next. Equally, deciding to leave the abusive relationship was a decision that took time. After the decision was made, once again, it often took time before a woman found a suitable place to live with her children. Mostly, she moved out of their home, whilst he stayed. For the women who went through divorce, several of them felt shocked at the outcome of their marriage. Kirsten explained that "I never thought that I would leave him or find another man. I thought we would live together as a good family...but then, his behaviour started to change". The process towards divorce was tainted by many attempts at giving the relationship another try, although these eventually failed.

None of the women who divorced, expressed joy at this decision. The weight of guilt for removing the children from their fathers was often balanced against the need to protect everyone's safety. Two of the women told stories of how this was made more difficult because of their children's pleading demands of going back to their father.

For the women who stayed, and for those separated at the time of the interview, the end of violence was more complex than for those who endured the process of divorce. These six women all confirmed that they had been living free from violence for a minimum of one year, yet some of their answers to my questions concerned me. At the beginning of the interviews I reminded them of what GBV was, as outlined in the Information Letter, giving them an option to withdraw if they wished. But no one did. 
I asked Jennifer about the ways her husband now deals with frustrations, and pleased with his progress she said that "he hardly ever gets aggressive. He has come to a point when he tries to understand and tries to listen. He tries to listen before he reacts". Equally, Gertrude said that her husband "has calmed down somewhat, and matured a little", yet she would consider leaving him if he did not improve even more. Helen, who is separated from her husband, expressed what I understood to be more of a concern for his abandonment, than for the abuse he had put her through. She was hoping that he would return to "tell them the truth" about the affairs he had had, and this would hopefully set things right. Also Irene, who had been separated for one year, wanted her husband "to make a decision" about whether he wanted to stay with her and the children, or not. Many of the women's stories affected me personally, not least Irene's as she gave many examples of her husband's continuous psychological tormenting. In carefully suggesting that his current behaviour does not sound fair, Irene acknowledged that this was probably so, yet she remained hopeful for positive change. Her husband, not physically violent any longer, had been a "wonderful husband" in their early days of marriage, and this was still a fond memory for Irene. I left the interview puzzled by the definition of GBV and about my rights, or lack of, to define other people's experience. If Irene did not consider his words abusive, then who was I, as a researcher, to tell her differently?

The definition of GBV for those who are still married appeared more fluid than for those who had left. The end of violence was a process that some women, for a multitude of reasons, achieved by staying and trying to influence their husband's behaviour. Other women, after many attempts at influencing positive change, decided that staying with their husband would be worse for themselves and the children, than leaving could ever be.

\section{Conclusion}

The four tiers of the conceptual framework were indirectly addressed in this chapter. The women's stories showed how all tiers had elements of both constraint and support for positive change, although discourses privileging men were dominant throughout. Institutions were not exempt from societal norms and expectations even when a particular institution was mandated to offer support. This chapter has further illustrated how the women in this study consistently rejected the violence and how they drew from personal and professional networks that were understanding of their situation. It was clear that some 
of the women felt empowered by knowing their rights (see Chapter 1 for more on rights), whilst other women prioritised the marriage over their right to live free from violence. 


\section{Chapter 6: Men's Stories}

\section{Introduction}

In this chapter, I present key themes from the interviews with the five male participants. Two of these interviews were voice recorded and transcribed by me soon after. During another two interviews I only took detailed written notes (as requested by them) and with the fifth participant, I corresponded via email, because he was living in another province at the time.

When presenting the key themes, I first share the male participants' ideas and practices that reinforced violence. Then I introduce their motivations for wanting to end the use of violence in their intimate partner relationships. This is then followed by stories of what actually helped in the process of shifting their marriages away from violence. I conclude the chapter with participants' ideas about the non-linear process of ending violence.

In Table 6.1, I illustrate some basic demographics of the male participants that I refer to throughout this chapter.

All men were either born in Bougainville or had lived in Bougainville for several years. They had all only been married once. Four of the men had married by own choice, whilst one of the men had his future wife "picked" for him by his father, based on how his future wife "worked in the house". She had been 16 years old when chosen. One of the men reported that his family had paid bride price for his wife; over 2,000 PNG Kina (approximately $\$ 1,000$ NZD), two pigs and shell money, ${ }^{26}$ whilst the others did not report bride price payments.

\footnotetext{
${ }^{26}$ Small shells are strung together to form a necklace, often several metres long. These hold monetary value and are often used in customary weddings.
} 
Table 6.1: Demographics of the male participants

\begin{tabular}{|l|l|}
\hline Age range & $33-58$ years \\
\hline Children & Between $2-5$ \\
\hline Marital status & $\begin{array}{l}4 \text { men are still married to the wife who was } \\
\text { previously affected by his abuse } \\
1 \text { man has been a widow since } 2013\end{array}$ \\
\hline Median marriage length & 23 years \\
\hline Median age of marriage for the men & 22 years \\
\hline
\end{tabular}

\subsection{What Reinforces Violence?}

\subsubsection{Authority and rights}

The men in this study were not asked what reinforced their violence, yet their stories gave both explicit and implicit (through the words and phrases used, and through what was not said but implied) accounts of what it had been like living in their worlds at the time of the abuse.

David, a father of five adult children who still lived with his wife at the time of the interview, said that "Bougainville men are groomed to be authoritarian" and trying to break from this grooming can be very difficult. David, who was outspoken about the horrors of genderbased violence (GBV), said that he was regularly challenged by other men who believed that it was their right to behave as they liked within their marriage and that outsiders ought not to challenge this right. Cedric, a father of four adult children, and a recent widow, did not comment on if and how his life had been affected by this authoritarian grooming, yet his clearly expressed actions as a newlywed man suggest that he had been thoroughly affected. Cedric explained "when I was young and had just married, I did not want my wife to go to high school, so she did not go". Cedric's decision to not allow his young bride an education had ongoing effects that further marginalised her. He said that her lack of an education meant that she could not "correct him" for his abuse and that he did not find it appropriate for her to "tell him how to behave". "Today...", Cedric said, "... would have made a different decision and allowed her to go". 
When I asked Bart, a father of two who lived with his wife, if any senior community members, such as a chief or a pastor, had tried to interrupt the fights with his wife; he explained that it would not have been easy to do so:

Mi nogat chief long ples bin lukim mi, bin kross wantaim mi. Mi ting em i hard tumas bikos...olegta man i relatives bilong mi...ol i pilim shame long toktok long mi.

[No chief in the village came to see me, or was angry with me. I think it would be very difficult for them to do so because they were all relatives of mine and they would feel ashamed if they had to come and talk to me.]

Bart's explanation of the complexities involved in people speaking out reminded me of a male relative of a female client of the Family Support Centre. This middle-aged man, whose niece had been raped by a young man from their village, felt unable to report the crime to the police because the village was not his by birth. Complaining about someone in his village by marriage was considered customarily inappropriate and he felt awfully stuck.

The outcome of silence often has as great an effect as speaking out, although the latter may seem more difficult. For Bart, it was not only the collective community's inaction that silently endorsed his behaviour. During Bart's elaboration of how the violence had begun, an unspoken right reserved for men only, was embedded in his language. His story went like this:

When Bart returned to Bougainville after living in another province for one year, he heard "stories" about his wife, stories about infidelity or having male "friends". Although his wife continually denied these stories Bart had lost all trust in her and two years of extreme physical and psychological violence followed. Bart explained how it started:

Mi no belivim em, mi nogat big trust long em. Taim dispela stori kamap na mi harim planti kain kain ting ting, that's why mi start long paitim em.

[I did not believe her, I had no trust in her. When this story came out and I heard all kinds of theories...that's why I started beating her.]

Bart, driven by a fear that his wife had been unfaithful, felt that he had the right to demand "the truth". He continually questioned and beat her. Although Bart himself acknowledged the physical abuse he put her through, he did not recognise any psychological torment although this was clearly evident in his stories. 
At the FSC, staff frequently met with men who believed it was their right to place demands on their wives, something women cannot do without being frowned upon. This male privilege seemed so normal that it appeared to be an unspoken right based on gender; another form of discrimination against women that continued to reinforce inequalities.

David, although outspoken against GBV, implicitly pointed out his privileged role in the family by using phrases such as "I allowed my wife to do women-things" and that he did not like it when "she hassled him" about his abuse, or that he realised that he did not "need to be suspicious".

Although there were many areas of influence on men that reinforced violence, some expectations also helped to create positive changes. For example, Eric, a father of three children and married, said that after his family moved to his province of birth, he felt obliged to "look after the family", and take on more responsibility for their wellbeing. He said that the expectation on him to provide for his family helped him to want to change.

\subsubsection{Male expectations influenced by alcohol and peers}

The five men in this study all told stories about the influence of alcohol and negative friendships on their lives and relationships. Drinking alcohol in excess with friends had contributed to the abuse all of the men had put their wives through. From my experience, alcohol continues to be a problem, and it is also used as an excuse for a variety of poor behaviour that can follows its consumption.

Albert, a father of five children and married, spoke about "influences that encouraged quarrels" with his wife, and specifically referred to "workmates" and "alcohol" as contributing factors. Despite "always dreaming of being a good father and husband", he repeatedly drank heavily with friends which often led to fights with his disapproving wife when he eventually got home. Bart, Cedric, David and Eric all told personalised versions of heavy drinking with friends, and intimate-partner violence, often the two were linked, but not always. Cedric said that his behaviour "did not feel good, but it was hard to resist" whilst David said that "not seeing his friends was hard, but necessary to stop drinking". Bart, whose friends were aware of the abuse that ensued after a drinking session, said "em samting bilong yutupela" [that's your thing], and opted not to get involved. 
It is difficult to paint an accurate picture of the complexities of alcohol consumption in Bougainville. Generally, all forms of alcohol consumption are negatively perceived, (although there are signs this may be shifting in some layers of society) and even I, as a foreigner, preferred to hide the bottle of wine I purchased for the weekend, by stuffing it far down in my bag and ignoring obnoxious comments from other customers (almost exclusively men). Occasionally, female-clients of the FSC whispered stories of how they "partied" in the weekends, and local social media forums were disgusted at the (rare) sight of "drunken girls" in town. As an avid morning-runner, I avoided the weekend runs as I knew that groups of drunken men occupied the normally safe streets, and their unpredictability frightened me. The concept of a "social drink" ${ }^{27}$ (or even three) is unfamiliar; if you drink, you are expected to finish what is there, which often equates to an excess.

I recall the story of a woman who attended a course on child development which the FSC facilitated. She said:

When a man drinks one beer - he is okay. Two beers and it is like drinking the blood of a dog - he pisses everywhere. The third beer is like he is drinking the blood of monkey - he jumps around and can't sit still. The fourth beer is like he is drinking the blood of a pig - he rolls around in the dirt and snuffles in the mud. After five beers, it is like he has drunk the blood of a lion - he roar and breaks everything inside and out. (Anonymous, personal communication, March 24, 2014)

\subsection{Motivations to Change}

In order to make changes, there needs to be a motivation for doing so. People who stop smoking might do so to save money or improve their health. Someone who changes employment may need a pay rise, or want to live closer to work, and so forth. I think that the motivations of a person tell us something about what is important to him or her, and as such, I was interested in learning about what motivated the men in this study to attempt change.

\subsubsection{A good family}

The most prominent theme referred to as a motivation for change was the idea of a good family. All men knew that these families existed, and that this was something desirable.

\footnotetext{
${ }^{27}$ The definition of a social drinker varies, but for this purpose I refer to a social drink as a person who drinks alcohol in moderation with no negative consequences attached to it.
} 
I asked Bart what a good family meant to him, and he said:

Sapos em i gat kross insait long femili, vailens em i no answer. Paitim meri bilong mi em i no answer. Paitim ol pikinini bilong mi em i no answer. Em i gat gutpela rot, mi inap long wokim. Long stopim. Sapos mi paitim ol pikinini na meri bilong mi, ol pikinini no inap kamap gut... mi laik traim halivim ol pikinini bilong mi kamap gud behain.

[If there is anger in the family, violence is not the answer. To fight/hit my wife, this is not the answer. To fight/hit my children, this is not the answer, instead I can help them on their way. If I fight/hit my children or wife, the children will not have a positive future...I want to try and help the children to have a good future.]

Albert said that he had "always tried...to be a good guy, a good adult, a good father" and the model for a "good life" was found through the church. Albert said:

It wasn't so much the church itself, but what they taught about family life. How each person should live their life. And as I saw these things from my past I wanted to be on the good side. It doesn't mean that I was good all the time, but it was a guide.

Eric said that although his wife was "more religious" than him, "the preacher talk about family issues in church and this is where I get my ideas and ways to deal to or tackle my personal and family issues".

Cedric was motivated by doing something different to what he had experienced as a child. About his own upbringing, he said "it was a chaos family", where his father had been abusive, and because of this he "wanted something better, a good family".

Yet, a good family was not limited to the absence of violence between a husband and a wife; all participants made special references to their children. Their children motivated their change.

David, who felt "lost" and that his abusive behaviour had damaged his family started to look for "meaning in life". Aware of the impact of the abuse on his children, David said "I realised I was unfair to my children and I felt sorry for them".

Bart wished that he could undo the fear his children had developed of him as a consequence of his violent outbursts against their mother. Although Bart's own father had been violent 
towards his mother for a short period during his upbringing, he said that they were "good role models" who had helped in shaping his "gudpela tingting" [good way of thinking]. Bart's parents, his mother in particular, had always reassured him that he did not need to worry about the violence in the house, and that knowledge had freed him from fear.

Eric also wanted a better future for his children than what he had put them through. He said he felt motivated to change for the love of his children "I don't want my children to go through the type of upbringing that I went through... I want to try to be the best father to my children and better husband to my wife".

\subsubsection{Encouragement from others}

The second theme emerging from the male participants' motivation was the encouragement from others to change. How this encouragement was presented and the preferred ways of being approached is discussed in the next part of this chapter, yet in this part it is important to point out that other people's involvement had made a difference. The male participants expressed motivation to create a good family, away from violence, yet without other people's encouragement it is unclear to what extent the pursuit of a good family would have been realised.

I have chosen the word encouragement as it implies a non-demanding prompting. It is exempt from expectations and a person will not lose face if they chose not to abide by it. If you are encouraged, the decision is yours. For the men in this study, being in charge of the future of the relationship was important.

All male participants reported that there had been one or more person in their lives who had encouraged them to make changes. Bart said that it was his father that had talked to him. I asked him how this had unfolded and Bart said:

Mi save harim papa bilong mi. Em save stap taim mi paitim missis. Em save tok tok. Mi save harim tasol em i go. Tasol taim mi stap mi yet, mi remembering tok tok bilong em. Mi save lukim tru tok tok bilong em. I had a good papa and mama.

[I listened to my father. He was staying with us when I was fighting/hitting my wife. He is good at talking. I listened, but I didn't pay attention. But when I was alone I remembered what he had said. I thought that he was right. I had a good dad and mum.] 
Cedric who has a strong Christian faith had been encouraged by the pastor at his church. This encouragement was necessary for him to want to change.

The primary encouragement to change for Albert and Eric came from their wives. From the beginning of the abuse, their wives had encouraged them to be responsible for the sake of the family. Both men expressed gratitude for their wives' patience and commitment to help them change.

Also, David said that "mature friends", for whom he had respect, had encouraged him to try and think of other solutions when he experienced problems. David used to think about what they had said long after a conversation had ended.

\subsection{How to Make the Change?}

This part of the chapter shifts from presenting the motivations for change, to how to go about making that change. From working at the FSC and through this research, I understand that there is a big gap between the two and all too often, not changing appears to be the easier option. I acknowledge the persistent efforts by the men in this study to end the violence against their wives (and family), knowing that it was never going to be easy, yet they did not give up.

\subsubsection{Making a decision}

Ending violence did not just happen for any of the male participants. In fact, none of the men ended their violence without relapses. Making the decision to stop was a necessary step.

David, encouraged by his mature friends, "made a contract" with himself to stop his physical violence towards his wife. Although he occasionally breached this contract, it formed the foundation for a violence-free relationship. Eric wanted to change a number of behaviours and "promised" his wife to change on consecutive Mothers' Days. Driven by a fear of losing her, he first promised to quit smoking, and the following year to quit alcohol. Eric said that these promises "kick started the changes that are happening in our marriage and family life" and his own decision to change, formed the promise. Similarly, Albert decided that "enough is enough". Fed up by his own behaviour he decided to stop the violence. He said "I stopped and then I started to look for avenues to help myself". Bart, 
who was still struggling with the idea of never "finding an answer" to the question of his wife's fidelity decided to stop his abuse so trust could be re-established. He said "em i no gudpela marit" [it is not good for the marriage] and he was the one who had to change, "mi yet save stap" [I am the one who has to stop].

\subsubsection{Maturity}

In Bougainville, being mature is not necessarily linked with age; rather the interviews suggested that it summarises behaviours of people who act in particular ways, and who exclude violence from their lives.

David's story (above) on how the encouragement from "mature people" helped to increase his motivation for change echoed Albert's story that pointed out that in order to enable change, acting maturely was important. To him this meant to "think before making a decision", and not react to whatever would normally have upset him. Attending activities arranged by the church was a fitting setting for Albert to meet mature people. Seeking these types of friends was not a passive process, but something Eric actively engaged in with support from his wife. Eric explained that certain neighbours and colleagues were "mature people" who attended church and did not endorse violence; spending time with them helped him want to change.

\subsubsection{Non-confrontation}

Cedric spoke highly of a pastor who had helped him make changes. He said "his approach was right, he only spoke to me", as opposed to challenging him. Cedric also pointed out that it had been important that the pastor "picked the right time" when he was feeling "open" to listen, well after the latest violence had ended. David spoke in a similar vein to Cedric. He said that his new "mature" friends used to speak to him after the abuse had "quieted down", to "sit with" him and to talk. He said "a good way to talk is important, condemning you is not the way". Through these non-challenging conversations David also learnt about the difference between "assertiveness and being aggressive", a difference he doubts most Bougainville men understand, yet he thinks would benefit them.

I asked Bart what had worked for him, and he said:

B: $\quad$ Planti taim mi go tokim uncle bilong mi na tokim "uncle mi no hamamas, asde mi paitim meri no gut tru again". But ol i no save kam directly long mi na tokim "no ken paitim meri". 
[Often I go and talk to my uncle and say "Uncle I am not happy, yesterday I fought/beat my wife badly again". But he did not come to me directly to say "You can't fight/beat your wife".]

V: $\quad$ So sometimes you go to your Uncle's [house] to talk to them to say that "Ah what have I done?". Did they give you some good advice, challenge you, or was it just a good place to express your feelings?

B: $\quad$ Planti taim em i tok tok planti gudpela samting. Mi save harim tok tok bilong em. Em i no tok "yu wrong or you right", em i save harim mi tasol. Em i gud way.

[Often he says good things. I listen to what he is saying. He doesn't say "You are wrong or you are right", he just listens to me. It's a good way.]

Similarly for Eric, whose wife was his greatest influence, her way of speaking to him was non-confrontational. Eric said:

One of the things that amazed me and inspired the change was the realisation that despite all the abuses that she went through, she continued to be faithful and carried out her duties as a wife and mother to our children... She is a very patient, loving, faithful and a wise woman...she is my greatest influence.

Albert's wife was also supportive, yet he acknowledged that "she really needed change". For Albert, change was encouraged through communication, he said "communication is vital" and so was a "common understanding between couples". I asked Albert how he and his wife ensured that they have a "common understanding", and he said "We really talk, not just talk, really talk about issues affecting married life. Because when it is good in the family, the outside will be okay".

\subsubsection{Education}

The shift to a violence-free marriage demanded a new approach to deal with problems. The men in the study had been open to change, consistently being in charge of when and how this happened, and some had actively sought education for help.

David decided to learn more about "healthy relationships" and acquired a number of books that he read many times over. He said that he always carried a book about "strong relationships" with him and that he had found it helpful to read. At the same time he had started to write a journal. This journal was about his life, and how his behaviour was affecting the family. He said this was educational for him, as he realised 
how he was treating his family. David said "I was not in charge of my own life", but selfeducation played a part in regaining control.

Eric said that books had taught him better ways of dealing with problems. He explained:

My wife, she bought books on subjects relating to anger management and marriage, and we both read together. There was one titled 'How to make your wife happy' that she bought and presented to me as a Fathers' Day present.

Albert referred to the Internet as a source of learning more about positive relationships and found it particularly useful to read about different types of "guilt" as this was something he could relate to. I asked about other major influences to which he answered:

There were trainings done by NGOs...that really helped me to work with the people...to develop themselves in the village and their community...this training really helped me...I have a booklet that I got from them...If I am okay, I want my family to be okay. I want my neighbours to be okay.

Albert sounded elevated when he explained about these courses he had attended and the ways he had implemented what he had learnt. To me, it sounded like education had supported his confidence.

\subsubsection{Appreciation; time and understanding}

The most appropriate way to begin this part is to acknowledge the wives of the men in this study. All five wives stayed with their husbands through times which I imagine must have been extremely testing. Even some of the men in the study marvelled at their wife's ongoing support. It is important to recognise the hardship these women went through; and that they kept on supporting their husbands whilst also trying to keep themselves and their children safe. The next chapter discusses the influence of discourse on these women's supportive actions.

Appreciation is defined as the "recognition and enjoyment of the good qualities of someone or something" (Oxford Dictionary, 2014, p. 1). For the male participants, appreciation of their wives was minimal for a long time. Yet, in the process of change, some of the men spoke of how they began to appreciate their wives and how this in turn reinforced their relationship, reduced the violence and increased wellbeing. 
Cedric, after 20 years of marriage said that he "realised what a woman is". This realisation helped him to become a better husband and start appreciating his wife. He said "women are the best administrators of the house; they are hard-working, they get firewood, cook, help the children, and are the last one to go to bed". Although Cedric never accepted his wife "telling him off", he said that "women are stronger than men", referring to women's role as "house administrators". Cedric further said that he had had many good conversations with his wife in the bedroom, and that these conversations had brought him closer to her and he began to appreciate what she was doing for the family.

David also spoke of a growing sense of appreciation for his wife which strengthened their relationship. They stopped making "demands" on one another and he intentionally decided to stop feeling suspicious. "Suspicion kills you from the inside", he said. Instead he began to appreciate his wife; her cooking, her motherly duties and her role as a wife. As a result, the way they interacted with one another became "more enjoyable", the relationship with the children improved and even their sex-life got better.

Eric, Albert and Bart all said that their marriages had improved as a result of spending more time with their families, doing activities together. The process to end violence was far from linear, however; it is likely that small positive gestures encouraged more family time which in turn encouraged more positive gestures. Eric said that he enjoys going to church with his wife nowadays and that he had realised that his wife "possesses qualities that other men longed for in a woman". Bart had a smile on his face when he described the beautiful white beach near where he lives with his wife, and about the walks they take there. Previously, Bart would only go to the beach with his friends, but now the entire family goes. And Albert, who had always been close to his children, spoke of his closeness to his wife. He said "almost every night, me and my wife sit up late, after everyone has gone to sleep. We sit down and talk". Albert, who admitted that jealousy had been a big problem for him in the past, said that he had stopped being jealous, and that talking to his wife helped clarify so many misunderstandings. Nowadays, Albert said, he appreciates his wife; "I understand her work, what she does...we really talk". 


\subsection{The End of Violence}

\subsubsection{Remorse and belief systems}

All of the men in the study recognised that violence was a poor way of solving problems, yet only Albert and David articulated a deep sense of remorse. David said "I was very remorseful...after almost killing my wife", and Albert spoke of regretting his abusive behaviour and the importance of forgiveness.

Albert said that in order to leave arguments behind "you must offer forgiveness straight after, or it may roll on for days". This offer of forgiveness should be received with acceptance and then a joint willingness established to move on. Albert's stories of guilt and forgiveness were not limited to his marriage, but he also spoke in abstract terms. For example:

Guilt...makes you realise what went wrong...you realise what you have done and you manage to resolve it, to forgive one another on that issue...that makes us reflect, that makes us realise that I am wrong and that I have to say sorry to whomever and then we resolve it once and for all.

These men were rightfully proud for using alternatives to physical violence when solving family problems. Despite behavioural changes however, little in what they said suggested a change in value-systems concerning gender-equality. Although David and Cedric both referred to a new sense of "appreciation of women", the meaning attached to this appreciation did not seem to reflect an intrinsic value of women, but rather it reflected their wives' commitment to the running of the households. There was no mentioning of trying to even out the work balance in the home, or an acknowledgement of the many heavy tasks and expectations on women and wives. In actual fact, the male participants' expectations of their wives did not change; women's position in the household seemed inflexible.

\subsubsection{The process}

The men and women in this study shared one major similarity; the lengthy process of becoming free from intimate partner violence. Although taking the decision to end the abuse was a pre-requisite for change for the male participants, the enactment of the decision was fraught with relapses. None of the men appeared distressed about occasionally falling back into previously abusive behaviour, the end-goal of eventually becoming violence-free, seemed sufficient. Albert for example said, "I always tried my best...but there were 
influences that made me engage in some quarrels with my wife. But after that, I had to try and rebuild that friendship we had again". For the men, becoming violence-free, or ending the abuse, primarily referred to the end of physical violence. Stories about ending other forms of intimate partner violence, such as psychological abuse, were absent. To what extent these other forms of violence had played a part in their relationships and were terminated was not described explicitly and may not necessarily have been recognised as abuse.

\section{Conclusion}

What is evident in the men's stories is that stopping violence in an intimate partner relationship is neither linear nor easy. All men told stories of relapses into violence supported by dominant discourses of male dominance in all spheres of life. The process of change was supported when the men could continue to feel in charge of their decisions and marriages. Change happened in ways that suited them and when they were ready. The male participants' understanding of gender-based violence was not made explicit. The interviews did however implicitly suggest that it was primarily physical violence that had ended. 


\section{Chapter 7: Analysis}

A critique is not a matter of saying that things are not right as they are. It is a matter of pointing out on what kinds of assumptions, what kinds of familiar, unchallenged, unconsidered modes of thought the practices that we accept rest. (Foucault, 1981, as cited in Rabinow \& Rose, 2003, p. 1)

\section{Introduction}

This analysis pays attention to two of the most dominant discourses in this study. It is clear that gender-inequalities are presently extensive in Bougainville as they were repeatedly expressed by both men and women in this study. Through noticing what language the participants' used to describe events and belief systems, as well as what was not said, I explore how these discourses enabled and restricted possibilities for change.

The first discourse is male dominance in all areas of life ${ }^{28}$ Even though positive changes took place, the discourse of male dominance continued to exert its presence. The second discourse I examine is concerned with the expected behaviours of a wife and is the discourse a good woman looks after the family. There were an infinite number of other, smaller, discourses that also formed part of the participants' lives, however; I have chosen to incorporate them into the more encompassing discourses discussed here. Where relevant I bring forward examples of contradictions and conflicting discourses as expressed by the participants. I find comfort in knowing that even Foucault's analysis of discourse often conflicted itself and jumped in unexpected ways (Rabinow \& Rose, 2003). In order to avoid repetition, I refer to particular events as relating to one primary discourse although I acknowledge that the examples I use can sometimes fit within both.

In honouring the process of reflexivity and my contextual subjectivity, I do not claim that the participants' stories are reproducible. They represent a snapshot of events as seen through my choice of theoretical lens. Also, I recognise that my analysis may not always represent the voices of the interviewees because of my preference for a gendered analysis which in turn is anchored in a context vastly different to the participants. I do however hope that I have done the stories and the participants' justice by using their stories to draw a link between gender-based violence and dominant belief systems; something I believe is a starting point for change. By interweaving all relevant voices in this Foucauldian-inspired

\footnotetext{
${ }^{28}$ For ease of reading I will occasionally refer to this discourse as only 'male dominance'.
} 
discourse analysis, the results form a complex picture which opens up further explorations of this topic in Chapter 8.

\subsection{Male Dominance in All Areas of Life}

This heading runs a real risk of committing a Foucauldian faux pas unless accompanied with an explanation. Male dominance in all areas of life is a bold discourse that is easy to contest and indeed, later in this chapter I show that it is neither fixed nor absolute. Yet this discourse echoed loudly in all of the interviews and supporting documents, hence not addressing it would be inappropriate. I am not suggesting that Bougainville men possess abilities to exert power (positive or negative) in ways that women cannot. However, the current social framework, by which men and women relate, provides a platform for inequalities which in turn allows for overall male dominance. In adopting a bottom-up perspective of analysis I believe that power relations at the micro-level (e.g. intimate relationships and within families) enable macro-level forms of domination, such as institutionally endorsed patriarchal practices (Sawicki, 1991). To persist, hence what happens within a relationship or within a family ultimately has an effect on the wider society, which in turn influences the thoughts and actions of individuals. This interlinked way of thinking was illustrated in the conceptual framework (Chapter 2) which highlighted the complexities of cause and effect.

\subsubsection{Intimate partner relationships and language}

The discourse of male dominance refers to a wide range of discursive practices as described by the interviewee. Discursive practices are defined as a:

Historically and culturally specific set of rules for organising and producing different forms of knowledge. It is not a matter of external determinations being imposed on people's thought, rather it is a matter of rules which, a bit like the grammar of a language, allow certain statements to be made. (O'Farrell, 2007, para. 18)

Some of the discursive practices in this study were highlighted by men's explicit language which reinforced their belief of legitimate authority within a marriage. For example, language such as "allowing wives" particular modest actions, such as doing "women things" suggested that the husband believed that he had the right to dictate his wife's actions. One of the men said that he did not like it when his wife "hassled him" about his abuse of her, whilst another did not approve of his wife "correcting" him. These examples, spoken casually, were vocal signs of a belief system that normalises male dominance in marriage. 
Yet the normalisation was not limited to the stories of the men; women also used language that signified a belief in gender inequality. For example, one woman explained that she had "confessed" to her husband; an act suggesting his superiority. I also recall the many conversations I have had with Bougainville women living on Buka Island who casually refer to their husband as "boss bilong mi" [my boss], ${ }^{29}$ a phrase influenced by and perpetuated by this discourse. In turn, I have never heard a man refer to his wife in similar terms, most likely because this is not an option readily available to him and it would be abnormal to refer to her as such. The current discourse leaves no space for a woman being the boss.

So how can we understand this choice of language? Social constructionists explain that there is no world out there that language can reflect as true; rather, language is a product of a cultural and historical experience and understanding of the world. Jørgensen and Phillips (2002) explain:

Language is not seen as a channel that transparently communicates a pre-existing psychological reality which is the basis for experience; rather, subjective psychological realities are constituted through discourse, defined as situated language use or language use in everyday texts and talk. [emphasis in original] (Shotter 1993; Wetherell \& Potter 1992, as cited in Jørgensen \& Phillips, 2002, p. 103)

The language of the participants further alerted me to unspoken rules relating to their marriages. None of the men, although acknowledging that they had had alcohol-relatedproblems, spoke of their drinking as an issue per se. Rather, it was the violent outbursts connected to the drinking that were viewed as a problem. For the sole woman who said that she had drunk alcohol, she did so after the marriage had encountered problems and pointed out that she had never had a drink before. The difference between the men's and the woman's stories of alcohol use is that the woman felt a need to explain her drinking, as this was considered to be breaking an unspoken rule, whilst none of the men suggested that the act of drinking alcohol per se was a problem.

A second rule illustrating the discourse concerns decision-making. Two of the clearest examples were voiced by the two women who were separated at the time of the interview. Both women wanted their husbands to decide if they were to remain married, or divorce. Although both of these women were disappointed with their husbands' extramarital affairs

\footnotetext{
29 'Boss' refers to a senior person and has more weight than its casual, often joking, use in New Zealand.
} 
and physical abuse, they said that it was up to the husband to decide what would happen next. In asking the women if this was a decision she could make, both answered elusively as though this was not an option available to them. This corresponds with Doty who affirms that "subjects... can be thought of as positions within particular discourses, intelligible only with reference to a specific set of categories, concepts, and practices" (Doty, 1993, p. 303). The specific concept available to these women focused on male dominance through their suitability to make decisions and any deviation from this practice would have been considered abnormal.

The discourse is further enabled by the idea that a woman needs a husband for her safety and protection, and that being an unmarried woman is viewed negatively. One of the women said that, "it is not good for a woman to be alone", which fits with my observations at the FSC where clients suggested that being single and an adult woman was undesirable as people would think something was wrong with her. On the other hand, none of the interviewees suggested that a man needs a wife other than to carry out daily chores, e.g. one man married a young woman based on how she "worked in the house". Men take a wife in order to cook and carry out other tasks they believe are not in their domain (as shown by the newspaper article from Chapter 2 about a man who summoned his wife to court after he burnt his fingers cooking food; a job he expected her to perform despite the fact she had left him five years prior. It should be noted that the court urged the woman to return as "it is not proper for a married woman to stay in her own village for that long").

It is not suggested here that wives and husbands ought to share all household tasks or even the amount of work. What is suggested, however, is that the discourse of male dominance encourages women to be dependent on a husband (by the use of words such as "need" and "protect"), which in turn renders them open to vulnerabilities. Foucault's suggestion that power is constantly negotiated between parties becomes largely restricted in practice as the room for negotiation is stunted by unequal marriage expectations that are difficult to challenge (Sawicki, 1991) .

In contrast, not all language throughout all interviews suggested male dominance. Some of the language, in particular the women's, suggested resistance. For example, one woman exclaimed that her husband is now doing the cooking whilst she can sleep in, clearly revelling in shared responsibilities. Another woman said that she had rejected her husband's pleas for 
a continuation of their marriage, whilst other women spoke of financial independence which removed the reliance on a husband and thus assisted in rejecting the influence of this discourse.

Contradictions to discourse are not a sign of its weakness and deficit, rather they serve the purpose of bringing richness to a critique (Jørgensen \& Phillips, 2002). Hook explains that "if we are to successfully identify discourse, and to gauge it in the fullness of its various capacities, then we need a notion that can join together an ensemble of discourse's various components, despite their diversity" (2001, p. 24). By exposing contradicting and alternative discourses, hegemonic practices can be challenged, which in turn leaves space for the development of new knowledge and alternative truths.

Foucault said "where there is power, there is resistance and yet, or rather consequently, this resistance is never in a position of exteriority in relation to power" (Foucault \& Hurley, 1990, p. 95). In other words, power and its resistance go together. This discourse is evident in all areas of Bougainville life, male and female. Women can only resist violence in ways that are possible to them at a given time. In the women's stories chapter there were several examples of resistance such as speaking out against the violence, relocating when possible and for some women, even initiating a divorce.

This affirms Foucault's suggestion that power and resistance are connected. This resistance formed a basis for alternative discourses to become possible.

\subsubsection{Family and village systems}

All participants shared stories about their families; stories of love and support, as well as stories of disappointment and distance. As I described in Chapter 3, Bougainville is largely a traditional society where people live close to their family of origin, usually on the land of the woman's family, and where family obligations are coloured by customary expectations. The family and place of birth are central to an individual's identity, and opinions and advice ${ }^{30}$ from those around matter highly.

The discourse of male dominance, as described by the participants' stories, was reinforced by family members on both the woman's and the man's side.

\footnotetext{
${ }^{30}$ In Bougainville it is common to give 'advice' to someone. In my experience, advice is similar to guidance and there is an expectation that the person receiving the advice should act on it.
} 
The most obvious actions that reflected and perpetuated the continuation of this discourse were the comments and demands by family members, in particular mothers. Several mothers asked their daughters to remain in a relationship, even though they were aware of the abuse. I did not ask how many of the mothers of the female participants had experienced abuse themselves, yet it is likely that several of them had, which corresponds with a cycle of violence. This perpetuation of violence is not limited to recurring abuse within an intimate partnership, but it has been described as an "inter-generational pathway of maltreatment" (WHO, 2007, p. 8). This also parallels the male participants' accounts of violence in their childhood homes, as all of them told stories of how their mothers had survived gender-based violence or other family problems.

It should not be assumed that the mothers (and other family members) who encouraged their daughters to stay in an abusive relationship did not care for them, as I am yet to meet a Bougainville mother who does not care for and love her children. Rather, discourses determine what is possible for any person and what is outside their scope (McEwan, 2008). If some form of violence within the marriage is the norm, then deviating from this becomes difficult. Of course, the meaning of the word violence is likely to be different between families and different again from the definition I use. ${ }^{31}$ Foucault argues that the truth available to a person is "embedded in, and produced by, systems of power" (Jørgensen \& Phillips, 2002, p. 14), which in turn is "a network of boundaries that delimit, for all, the field of what is socially possible" (Hayward, 2000, p. 4). In light of this, those mothers who encouraged their daughters to stay in an abusive relationship would have been influenced by their tolerance of abuse and the surrounding social and customary constructs.

Divorce or separation, although legitimised through legislation, is not readily accessible to women in Bougainville. In conversation with gender-based violence (GBV) professionals in Buka I noted an absence of a discussion regarding divorce for women survivors of violence. Only in extreme circumstances, concerning immediate safety, would this option be talked about in earnest. The apparent reluctance to consider all options available is a consequence of an absence of alternative discourses, such as a woman's right to make her own decision.

\footnotetext{
${ }^{31} \mathrm{GBV}$ is an umbrella term for any harm perpetuated against a person's will. It includes physical, sexual, financial or psychological harm or suffering (most often but not exclusively, to women), including threats of such acts, coercion or arbitrary deprivations of liberty whether occurring in public or private life (EIGE, 2014).
} 
When speaking with the participants it became clear that it was not customarily appropriate to challenge a husband's authority over his family. Some women articulated this inappropriateness to challenge, whereas others did not even suggest that their family could have challenged him or asked him to change. When female family members had been supportive (according to the participant), the women had all provided quiet forms of support: offering food, a place to stay and sometimes money. In these situations, female family members showed no direct authority in deciding the next course of action for the woman. Thus, the silences and absence of initiatives indirectly supported male dominance.

Male family members, on the other hand, although rarely challenging the abusive husband, provided an escape route for their sisters or daughters, by going to stay with them, or by bringing the women into their homes, or even encouraging them to leave the abusive relationship. The male family members displayed an authority that provided a life-line in times of need. Yet the discourse of male dominance remained untouched. For those family members who actively helped the woman to escape the abuse, it was only a male family member who had the authority to do so. Equally, during those few instances when family members took a stance against their own abusive relative, it was a male member who took the stance. Consistently, female family members' rights to challenge the discourse of male dominance were absent. This is not to suggest that the female family members should have known how to change this situation, or even should have attempted to do so. In contrast to Foucault's reluctance to locate domination, including in relation to gender, I agree with Hartsock (1990) who is concerned that this reluctance may lead to victim blaming and failure to see high level power structures.

There are two apparent points to make here; first, the link between custom and discourse, and second, seemingly contradictory, ways of using custom to resist the discourse. Customary practices are bound to time and place, and thus fit within the social constructivist framework. As mentioned previously, custom in Bougainville is strong and influential. In many ways, a custom, just as a discourse, stipulates what is possible, and what is not. Deviations from customary expectation can lead to stigmatisation, similar to deviations from dominant discourses (Clarke, 2008). The customary inappropriateness of challenging a married man in Bougainville today is an expression of male dominance, which has emerged 
over time. ${ }^{32}$ Women's historical capacity to negotiate egalitarian power-relationships (often based on land) has been overwhelmed by current discourses privileging men (Helen Hakena, personal communication, November 2013). A genealogical analysis, favoured by Foucault and feminist writers (Sawicki, 1991) would have explored the historical context of current customary expectations. Yet for now, I acknowledge that there is more to the story and that the current discourse of male dominance continues to be strengthened by the inaction and silence of those who do not speak out as a result of their power and authority being overlooked (Willig \& Stainton-Rogers, 2007).

Again, I finish by looking to see where resistance to the discourse is occurring. It is important to understand that custom is not stagnant or fixed, but fluid and changes over time. For example, today young girls are encouraged to attend school, which would not have been as common some generations back. And just as resistance to discourse is possible, so too is challenging custom, although doing so is likely to have both negative and positive consequences. In Bougainville, I have noted how particular women challenge the norm regularly, yet at select times. These women generally either work with issues concerning gender-equality or are women with personal experiences of violence who are invited to speak out at events that bluntly challenge the negative consequences of male dominance (such as during the International Day of Peace). These speeches are often appreciated by all who listen. As such, challenging male dominance has become a possibility in certain situations. At these, sometimes minor events, the challenge is not personal but rather a form of encouragement aimed at the family level. From my observation, the encouragement is best received when delivered from a local person who understands custom and therefore knows how to address such sensitive issues.

Within an intimate partner relationship resistance was also possible, although since this challenge was personal, it was received less positively than when women speak out at generic forums. All of the women in this study tried, in ways possible to them, to resist the violence. Some asked for help from relatives and employers, where as others relocated with work, and even initiated divorce when it was clear that the husband was unlikely to change.

\footnotetext{
${ }^{32}$ The disruption to traditional ways of living and making meaning of life was imposed by missionaries in the early $20^{\text {th }}$ century. Later, the 10 -year long Crisis revolving around the foreign operated Panguna mine tore the region apart, impacting on social relationships and expectations of all. This was followed by the current reliance on aid to 'get Bougainville up on its feet' again, with support from the international community. These events have all had, and continue to have, an impact on gender relationships.
} 


\subsubsection{Key Institutions: The Church}

It is not enough to focus on the micro-workings of social relations such as language and actions used between married partners and within family units. To ensure a comprehensive analysis it is important to include wider societal factors that influence power and control (Willig \& Stainton-Rogers, 2007).

Derrida has written extensively on the role of institutions in peoples' lives and claims that "in an institution, individuals are distributed across a hierarchised, institutional spacing, a play of places, which define in advance the role, the power, and the voices of the individual, something that is embodied in expressions" (Derrida, 1997, p. 104).

To understand how key institutions shaped the participants' stories, I first focus on the church and later, in relation to the discourse of a good woman, on the influence of two government agencies. I recognise that my personal subjectivities concerning the church are different to most of the participants and that it is my voice that is heard in this instance. Yet, I respect the belief systems expressed in various ways by the participants.

Jørgensen and Phillips reminded me of the importance of providing an understanding of how we all contribute to the rules of our lives through daily practices and how these are "shaped by social structures and power relations that people are often not aware of" $(2002$, p. 66). This is not a criticism of people, rather what is suggested is that it is impossible to be aware of, and understand, the entire web of connections that people have with their surroundings.

In Bougainville, the amalgamation of church and customary influences is evident. For example, many of my Bougainville friends believe in both the teachings of the Bible, and in some forms of sorcery, although the latter is not as obvious. ${ }^{33}$ Still, it is clear that people are proud to hold strong Christian beliefs and the church and its activities permeate most people's lives.

In this study, the discourse of male dominance was expressed by the unequal relationship the participants had to the expectations regarding forgiveness. ${ }^{34}$ Although asking for forgiveness is not limited to personal grievances (but stretches further to organisations,

\footnotetext{
${ }^{33}$ Although many Bougainvillean's publically reject sorcery in an attempt to stamp it out, I have noticed that people are still cautious of doing anything that could have others condemning you and ultimately accuse you of sorcery. Also, it is not unusual to hear people, half jokingly, half seriously, suggesting that an 'unexplainable' event such as an unforeseen decision or illness may have been sorcery-induced.

${ }^{34}$ The significance of reconciliation and forgiveness has been discussed in various chapters, in various contexts.
} 
nation states and so forth) (Derrida, 2001), its link to Biblical verses and confession is apparent: to be a good Christian you ought to forgive those around you. ${ }^{35}$

Bible verse, in Matthew 6:14-15: "For if you forgive men when they sin against you, your heavenly Father will also forgive you. But if you do not forgive men their sins, your Father will not forgive your sins" (Bible Study Tools, 2014, para. 1).

Most women in this study implicitly suggested that they had an obligation to accept their husbands' regular apologies in an absence of other choices (e.g. make demands on him before accepting). Other women verbalised their obligation to forgive on religious and/or customary grounds. For the one woman who had asked her husband to forgive her for wrongdoing, he had responded with further violence, suggesting he felt no obligation to offer forgiveness. Despite this woman explaining that her husband was strict in his faith, the discourse of male dominance and its associated practices appeared to have greater influence on him than the church and the religious discourse of forgiveness.

Worthington (2011), in drawing from the work of Derrida (2001) challenges the "common understanding" that forgiveness is a pre-requisite for "moving on". He states:

Forgiveness might suture a wound, enabling healing and reconciliation, but its closure also ushers in, if not forgetting, an attenuation or weakening of the suffering of victims of unforgiveable crime and the silencing or appropriation of their voice. (Worthington, 2011, para. abstract)

The silencing of voices in this case relates to the women in this study. Not only did the men fail to make changes after their apologies, but the apology itself appeared as a tool of manipulation. For the female participants, their ability to re-negotiate the expressions of power within their marriage was reduced because of their fear of further violence and because of the knowledge that forgiving is what a good Christian should do. This places women in a difficult situation; either you forgive and continue to be abused, or you do not forgive and face further consequences from both the husband and the church.

However, forgiveness does not only work in adverse ways for women. For some women in this study, forgiveness seemed to be a necessity for being able to move on with their lives. Some of the women appeared strengthened by this option of forgiving, or not forgiving, as

\footnotetext{
35 There are numerous verses on forgiveness in the Bible depending on interpretation.
} 
though this helped with regaining agency. One of the women initiated the forgiveness of her former husband's mistress by contacting her and telling her that she forgave her. This appeared to assist this woman with renegotiating the power relationship with her former husband.

The church further strengthened the discourse of male dominance by teaching that divorce is not to be considered. In theory, this is not gender discrimination, but in reality women are over-represented in GBV statistics, thus this issue is more relevant to them (Fulu et al., 2013). Discouraging options for women who are experiencing violence is an indirect form of support for those who abuse. Knowing that violence is unlikely to result in a divorce (or in an arrest), abusive behaviours can continue to flourish. For those Bougainville women who did choose to divorce, some expressed internalised guilt for taking this course of action, evident in their language and actions of continued support for their husband.

In addition, the church pastors in Bougainville are all men and neither are they exempt from influences and attitudes of male dominance. Many women experienced the embodiment of these attitudes as a lack of support from the church, which kept them from seeking help there. One woman told of how her pastor had walked away as he witnessed physical abuse towards her, and did not contact the police or other family members.

In contrast, a critique of the influence of the church is not solely a negative one and presenting it as such is misleading. Whilst particular pastors showed little support for the women experiencing violence, for those men who wanted to make change, the church was a source of guidance. Individual pastors offered personal support, whilst the positive pictures of families painted during church services inspired change in men. Instead of taking explicit action to reject the discourse of male dominance, the church contributed to change through positive family ideals and individual support.

The church only influenced the men's abusive behaviours, without providing any support for the women or challenging the discourse of male dominance. Chapter 6 showed that the male participants responded approvingly to those who did not confront them and who did not demand a change. The timing and tact of the people who spoke with them was important. As such, the pastors acted within the bounds of custom by supporting the men 
and thus, indirectly, their wives, without influencing the structures underpinning the violence.

\subsection{A Good Woman Looks After Her Family}

The dominant discourse of a good woman looks after her family is a discourse that is easy to contest. ${ }^{36}$ Indeed, over half of the women in this study ended their marriage with a divorce, which could be considered the ultimate rejection of this discourse. However, the analysis will show that even those women who ended their relationship felt the weight of this often smothering discourse.

The expectations of men and women in marriage are different. In the men's chapter the participants expressed a desire for a good family, and their contribution to this aspiration was centred on the absence of violence. This idea was supported by Mr Sam Kauona, a respected former BRA general (from the Conflict), who challenged husbands and boys to be "true gentlemen and not beat up their wives" (Masiu, 2013, p. 23). The women, on the other hand, had greater expectations of their husbands, which included protection and practical support. In addition, the expectations on women were more complex and demanding and were supported by men and women and the discourse of what constitutes a good woman.

\subsubsection{Binary oppositions}

Binary oppositions such as male/female, good/bad, rational/emotional have a long history, where self is defined in relation to other and where binaries help define what is considered normal and right (by privileging one position over the other) (McEwan, 2008). In Bougainville, primarily the church has influenced people to think in binary terms; the Bible does not offer nuances. Also, increasing influences from other parts of the world, paint ideas and practices as good or bad. In thinking about the other in relation to this study, I found the work of McEwan (2008) useful in considering how power is exercised through discourses of binary thinking.

The name of this discourse was deliberately chosen as an example of binary language denoting the good/bad paradigm. I pay special attention to how binary thinking favours men whilst rendering woman negatively, ${ }^{37}$ an analytical focus Foucault paid no special attention

\footnotetext{
${ }^{36}$ For ease of reading I will often refer to the discourse of 'a good woman looks after her family' as only 'a good woman'.

${ }^{37}$ I am also aware that binaries discriminate against people of colour, non-heterosexual people, disabled people and more, but for the purpose of this analysis I focus on the effect on women.
} 
to (Hartsock, 1990). Derrida (1997) claimed that both parts of a binary opposition are dependent on one another, which means that shifting the focus to the other end would only feed the same oppressive rule and fail to create change. Instead, it is important to rethink how we can expose the positions of fixed identities (as noted in text, institutional processes, belief systems and more) as products of a complex yet socially constructed system that favours binary thinking and which ultimately has effects on both sides. To expose the construction of realities, Derrida famously developed the concept of deconstruction. Defining deconstruction is difficult, as the very act of locking in a belief system based on opposing definitional work, would in fact be misleading. Derrida, in answering a request of explaining "deconstruction in a nutshell" said, "deconstruction, in a nutshell, the very idea!" (Derrida, 1997, p. 30).

However, in an attempt to utilise deconstruction in this thesis I carefully read the transcripts for definitional binaries and taken-for-granted knowledge and noted an abundance of examples that suggested a good woman ought to look after the family. However, deconstruction as a technique requires more than only exposing binary thinking and its link to knowledge production and meaning, to have an effect on social change. Instead of focusing on the binary opposition to the privileged as a means to bring on change, deconstruction seeks to create new terms of making meaning that stop perpetuating inequalities.

Using binary language is not only the domain of men (or other privileged binary positions), but it forms part of discourse from which no one is exempt. The discourse of a good woman looks after her family was implicitly suggested by all participants. Challenging a man's behaviour, not caring for his safety, prioritising own and children's wellbeing, smoking, texting and drinking were all painted as the opposite to good. These were undesirable behaviours of a wife, unspoken expectations embedded in common sense and influenced the meaning people made of events.

To be more specific, the binary of a good/bad woman in relation to alcohol was clear; a woman who drinks alcohol is bluntly considered a bad wife (and not for example, a woman who likes a laugh or a strong woman), whilst men's alcohol consumption was judged less harshly. Another case refers to the male participants' understanding of a good family. A good family was one without violence, whilst a bad family was one with violence. There were 
few references to nuances of family life, but rather the good/bad paradigm was spoken about as a generalised truth.

However, neither is this discourse without contradictions and I recall a former Bougainville colleague who rejected the binary idea of women and alcohol. This female friend, a middle aged woman, occasionally drank beer with her husband, and once when at a lunchtime picnic, she also had a drink. These actions are nothing dramatic, however; I remember thinking how unusual her confident actions were, and that on top of it all she felt no need to apologise or give excuses for having an alcoholic drink. Her husband did not seem to mind either.

Finally, I highlight the participants' references to shame. The issue of bringing shame to one's family primarily related to the act of a wife wanting to leave her husband. Even though he was abusive it was considered inappropriate behaviour for a good woman to initiate a separation. Instead, appropriate customary processes included village meetings and/or fatherly/brotherly approval, as separation was not a decision the woman easily should take herself unless she was willing to bring shame on the family. This finding corresponds with my experience from the FSC; the issue of shame represses the options available to a woman and once again colours her as good or bad; as a woman of shame or a woman of pride. For some women, I believe the thought of bringing shame to those around them seems even more painful than enduring GBV, hence they avoid such contemplation.

Finally, one could argue that the same binary rule of good/bad, right/wrong also applies to men, but this research has shown that expectations are lower and fewer for men; hence the binary opposition is less striking or even absent.

\subsubsection{Marital expectations}

Women should shut their mouth. It is the women's mouth and action that invites violence. We are all humans and cannot be loyal to these laws protecting women. To stop violence and defend men to cause reasoning and counselling and that will amend the law from occurrence there must be a law to limit what women say to men [sic]. (Kamkuus, 2013, p. 17)

The above quote is an excerpt from the reader's letters in the Post Courier newspaper. Its position, although extreme, points to discourses of women-blaming and marital expectations of women based on inferiority. I do not believe that most men in Bougainville 
agree with Mr Kamkuus. However, the newspaper chose to publish this comment, without a response, and as such reinforced the belief that at the very least men and women are different and that women somehow bring violence upon themselves.

The discourse of a good woman includes the expectation that women should stay with their husband no matter what. Several men in this study commended their wives in the interviews for continuing to be "patient", "committed", "faithful", "loving", "wise", "fulfilling duties as a mother and wife" and so on, despite the abuse. Looking after the family then (from the man's standpoint), suggests prioritising the husband's wellbeing above the children or the woman herself. No men made reference to their wives ever trying to leave, calling the police or resisting the violence other than through asking him to stop. Instead, her endurance during the time of the abuse was praised as attributes of a good wife.

The discourse does not only create truths and expectations for men, but women themselves are affected. For example, in response to her husband's abuse, one woman said in a matter of fact way, "If he wasn't happy with me as a wife he should leave and find someone who could match him". This comment implies that the violence somehow was her fault and since she could not make him happy he should find another wife. Other women continued to cook food and take it to their husbands after the separation, suggesting that the discourse of a good woman is not limited to the bonds of marriage, but expands beyond and into separation. The female participants' expectations of protection by their husbands were not fulfilled; on the contrary, several of the women took on the role of protecting the family, including the husband. This largely went unnoticed by the men.

Sawicki referred to power relations as containing both "possibilities of liberation and domination" (1991, p. 56) and the interviews offered several examples of how the participants had resisted dominant belief systems. The clearest example of this is the seven women in this study who had divorced. Six of the divorces were initiated by the wife. Although the social constructions around them were reluctant to consider divorce as a solution to marital violence, these women rejected that expectation to remain. Several of these women further asserted their decision by relocating their place of work in an attempt to gain distance from their (former) husband. At this point it is good to remember that those women who left did so only after exploring a number of other possibilities, and that those 
who divorced had on average been married for 13 years and endured the violence over a very long time.

Absent from all 18 interviews is any positive reference to having left an abusive spouse. The discourse of a good woman was so prevalent that it prevented alternative expressions for the women, such as pride or even joy for having safeguarded themselves and their children. In addition, many women took on the responsibility for the failure of their marriage as expressed through internalised guilt and occasionally remorse for having left. For example, one woman suggested that she had abused her children by taking them with her when she left their abusive father. This places women in a complicated predicament; either you prioritise the safety of your children and yourself, which paints you negatively, or you stay in the abusive relationship jeopardising your own health and safety.

This particular discourse was slippery to define as the participants' stories were expressed as a hegemonic discourse. We all live within our own framework of common sense and takenfor-granted knowledge. It is our way of understanding how the world works and dictates what we do (Willig \& Stainton-Rogers, 2007). I recall several incidents whilst living in Bougainville when common sense practices clashed. One example is when my partner ${ }^{38}$ (male Caucasian) and I (female Caucasian) agreed to have local male friends stay with us for a few nights as they had travelled from afar. Our expectation was that we should share some of the domestic responsibilities during these days as my partner and I were also working fulltime. This was a foreign idea to our friends. We were expected to cook all meals (including hot breakfasts), clean after everyone and provide company at all times. As this did not fit with our expectations of having friends to stay (indeed we needed to go to work) we spoke about it with our friends and ended up having a laugh at our differing backgrounds.

In hindsight, it was the contrast between our dominant discourses (of what constitutes a good host) that highlighted our expectations as different and thus socially contextualised. I am not suggesting that laughing things off is a particularly useful or even available option to those in this study. For us, however, the negotiating of power (e.g. as expressed through whose discourse of domestic expectation was prioritised) was relatively easy. Yet in this case

\footnotetext{
${ }^{38}$ My partner Mark joined me in Bougainville after I had spent $2 \frac{1}{2}$ years there in total, hence I had already made friends who had respect for me, and who I respected in return. In preparation for Mark's arrival, and when local male friends introduced him to other Bougainvilleans, Mark was referred to as masta bilong Vicki [Vicki's master].
} 
it was not only gender that impacted on the ability to negotiate accepted processes; educational levels and possibly ethnicity also played a role. ${ }^{39}$

In addition to resistance of the discourse, it does allow women some authority over the family's wellbeing. For all of the women, both those who divorced and those who remained married, the wellbeing of their children was paramount. Despite the burden of the family's welfare primarily resting on the woman, this responsibility also encouraged action. Thus this discourse includes an allowance for women to take some authority to initiate change.

\subsubsection{Key Institutions: The Police and Child Protection}

If it is accepted that institutions are part of, and perpetuating discourse, then it is of interest to consider what effect this has on staff working at these institutions. Where do personal beliefs versus institutional beliefs meet, and what does this mean for the public?

Two key institutions that played a part in shaping the discourse of a good woman were the police and child protection services.

\section{The police}

In Chapter $5 \mathrm{I}$ told the story of a woman who had been severely beaten by her partner in a restaurant when two male police officers walked in for lunch. This horrific experience, for which the partner was never charged, emphasises two areas of interest. Firstly, the abuse took place in front of two police officers and not one. The acceptance of the violence was not the case of a single officer's poor judgment, but endorsed by two police colleagues. If one of the officers had acted on the crime committed in front of them, the outcome would have changed immediately, but they did not. I should add, since I am familiar with Buka, that this restaurant is situated approximately 500 metres from the police station so if the police officers would have required help, help could be found nearby. Secondly, the beating happened in a public restaurant where the police officers knew other people were watching. They chose not to arrest the man perpetuating the violence, but asked him about his relationship to the woman he was beating up, and on learning they were married, suggested mediation. As such, the two male police officers made their belief system of male dominance and the importance of a husband and wife staying together known to anyone watching. They did not suggest the wife went and stayed with a relative or friend because

\footnotetext{
${ }^{39}$ Discrimination because of gender, ethnicity, and educational levels are only some of the external factors that impact on people's ability to negotiate power within relationships (Amnesty International, 2014a).
} 
the idea of separating the couple was not readily available to them. Foucault holds that "the individual is the arbitrary construct of a social formation [and that] society gives us the values and practices by which we live" (Bevir, 1999, p. 4). This does not exclude anyone, even the police.

Both discourses of male dominance and a good woman were illustrated by the normalising actions of the police. The system of power and knowledge that allowed for the construction of the female subject to be unworthy of police protection, operated within a network of social constructs i.e. what is possible and what is not, what deserves attention and what does not.

I agree with poststructural writers who believe that power is fluid and in a constant flux because this ultimately has the capacity to allow the voices and realities of others to be heard and considered true (McEwan, 2008; Willig, 2007). In the absence of further investigation of the historical context of Bougainville women's restricted and subjugated knowledges, it is sufficient to assert that current social beliefs such as "community rights are...more important than a woman's rights" (Wainetti, 2013, p. 1) currently influence the actions of everyone living within the community. No one is exempt from the enabling and constraining effects of the power-knowledge paradigm (Rabinow \& Rose, 2003).

In addition to the theoretical position of the fluidity of power, that I firmly believe is the only way to hold on to hope for change, I agree with Hayward. Hayward develops the position further by stating that "power relations that warrant criticism...are those defined by practices and institutions that severely restrict participants' social capacities to participate in their making and re-making" (2000, p. 4).

In reading and re-reading the transcripts of the male participants, I noted an absence of references to the police. Despite some of the men admitting to nearly killing their wives and others made it clear that their violence had been well-known in the community, no one made reference to the police, either as a deterrent or even as a form of support. The absence of pressures by the police fit within the findings above; the context of the abuse took place while neither family members nor the police took action to deter its continuation.

Despite stern criticism of the Papua New Guinean police force for misusing their institutional powers, this does not form a complete picture of the current situation (Human rights watch, 
2014). Although not mentioned, possibly because the participants were required to be violence-free for at least a year before the interview, recent developments within the police force have created some changes. The macro-level institutional decision to establish a family and sexual violence unit (FSVU) at the police station is a pragmatic vision which indirectly rejects dominant discourses supporting abuse. Since opening in Bougainville in 2013, I noted a small yet positive change driven by a few dedicated staff.

\section{Child protection}

The following discussion is not an attempt to point fingers at particular child protection staff, ${ }^{40}$ but to show how this key institution participated in, and reflected the discourse of a good woman. I recognise there are other influencing factors that contributed to the experiences of the participants. However, dominant regimes of "power/knowledge" (Bevir, 1999, p. 3) regarding gender played a part in the creation of truths that marginalised the women in this study.

The regimes of the power/knowledge nexus (Foucault, 1980, 1984), refer to how the subject is a function of this nexus, and how her/his choices are based on her/his social context and not destined to a set outcome or behaviour (Bevir, 1999). Nearly all women in this study had chosen not to involve child protection services, ${ }^{41}$ except the youngest participant who had tried multiple times. This woman had at first been encouraged to mediate with the abusive partner and later she was asked if she wanted to reconcile with him. Whilst firmly declining both suggestions, none of her child custody requests were processed and subsequently her child is not in her care at present.

The actions of various child protection officers, despite being agents of a government division, acted according to what made sense to them. By not adhering to the wishes of their client they endorsed the belief of how a good woman should behave: staying with her husband. In doing this, they failed to fulfil their statutory obligations of ensuring the wellbeing of the child (Unicef, 2014). Clearly, the officers are not the government division per se, but they are representatives who reflect a broader system of thought. There is a gap

\footnotetext{
${ }^{40}$ The division of community development governs the child protection office, previously known as the welfare office and still often referred to as such. Amongst other obligations, they are mandated to assist with child maintenance arrangements including payments, and child protection.

${ }^{41}$ I believe this is for customary reasons as this type of 'service' is relatively new (in concept and in reality) and unknown, and in my experience external and internal issues prohibit the child protection office from offering a constant and successful service.
} 
between the role and expectations of government workers and their actions. In this study, their discursive practices seem more influenced by social norms than legal mandates.

Likewise, in my experience, people attending GBV services are often given personal opinions rather than impartial advice. For example, at the FSC we needed to continuously remind security staff at the hospital not to show their disapproval of survivors of physical and sexual violence, but to inform them of our location. The security staff, all men, agreed to our reminders but often expressed a personal disapproval of these clients as they believed they had brought the sexual and/or physical violence on themselves. As security guards they also believed they had the right to voice their opinion to these women. When those you seek help from suggest that your place is with your husband, and that you somehow contributed to the violence, it is understandable that you would take on discriminatory discourses as truth.

\section{Conclusion}

The two dominant discourses analysed in this chapter are products of hegemonic belief systems concerning male dominance, and can be located at all tiers of the conceptual model from Chapter 2. The four tiers, from personal abilities to broader institutional and societal influences, help clarify the interlinked nature of dominant discourses. In this instance, the discourses were concerned with men's and husband's privilege of being considered leaders of the family unit.

Legislation and policies that aim to improve gender relationships (see Chapter 1 ) were absent from the participants' stories, and therefore the analysis. The gap between high level decisions and the day to day actions of people is large and discussions regarding the impact of this discrepancy are largely absent. What was clear in this chapter is that Individual people who make up institutions are guided by their own belief systems, based on religious and customary preferences, and not by legislative mandates and this caused grievances for several women in this study.

The space for counter discourses to have an impact, beyond individual families, was made difficult because of the enormous influence of the church and custom, both which encourage male dominance. With that said, dominant discourses were challenged and resisted, although this appeared to have little impact beyond the family unit. 
This chapter also highlighted the distinction between resistance to violence and resistance to discourse. The former was mainly possible when issues of safety were a concern, while resistance to discourses that underpin violence were largely missing. 


\section{Chapter 8:}

\section{Conclusion and Discussion}

\subsection{Thesis review}

This qualitative study was guided by feminist poststructural epistemology. It brings together feminist theories of gender and power with poststructuralist insights into language, subjectivity and the function of institutions to explore how discourses work to perpetuate and resist gender inequalities. Gender-based violence (GBV) is embedded in broader patterns of social control and coercion, some being subtle, and others much clearer (DeShong, 2013). Feminists across disciplines share a joint commitment to point out and name those ideas and practices that perpetuate women's subordination.

In the first chapter I made the link between GBV and development studies explicit by referring to GBV as a human rights breach that disproportionally affects women and girls. In Chapter 2 I presented the socio-ecological model, a conceptual framework upon which the literature review, themes and analysis rest. This four-tiered framework illustrated how various influences in life affect our ideas about equality and violence, and subsequently how interventions need to reflect these different layers. Following the ecological model, I pointed out that Papua New Guinea (PNG) has a long way to go before achieving their own goal of improved gender equality. In Chapter 3 I took the reader on a whirlwind tour through Bougainville's domestic structures, and whilst it is important to acknowledge the many aspects of daily life that work well, I noted how the incidences of violence, including sexual violence, are very high. In Chapter 4 I described how feminist poststructural epistemology guided me through the field work and analysis. Foucault's Discourse Analysis (DA) helped draw out dominant discriminatory discourses. In Chapters 5 and 6 I presented the participants' stories by grouping the findings into themes. These themes highlighted discourses that supported violence and its resistance. In Chapter 7 I focused on two discourses that both enabled and resisted the perpetuation of GBV; male dominance and expectations of a good woman.

\subsubsection{Revisit research questions}

The study set out to explore what methods support and sustain positive change in Bougainville in intimate-partner relationships previously affected by gender-based violence. 
I also had two further questions:

What were the experiences of the male and female participants as former perpetrators and survivors of violence?

How can the participants' experiences of gender-based violence help inform policy development and improved professional practice?

To answer these, I engaged former perpetrators and survivors of GBV to learn from their experiences. My three years of living in Bougainville also strengthened the work. This is the first qualitative study of this kind in Bougainville, that I am aware of, that has drawn from both unstructured interviews and observation to inform recommendations with an aim of influencing policy and practice.

\subsection{Key findings and Implications}

The findings are all interrelated, and should not be read in isolation. I am reluctant to recommend possible interventions without prior consultation and participation from relevant local organisations. I believe that any initiative should be supported and preferably driven by local actors well versed with the customs of Bougainville.

This study has revealed several themes, some specifically answering the research questions, others extend further to help paint a picture of the broader issue of gender discrimination. In this section I outline the most important themes that have implications for policy, practice and future research. The key themes are presented as per the ecological framework; beginning with individual factors and working outwards to wider society. I acknowledge that most themes cross-over tiers, however; for ease of reading, I link each theme to the most relevant part of the framework.

Note that it is only the themes that are presented according to the framework, whilst the implications of the themes stretch across tiers. For clarity, I include the socio-ecological model again below. 


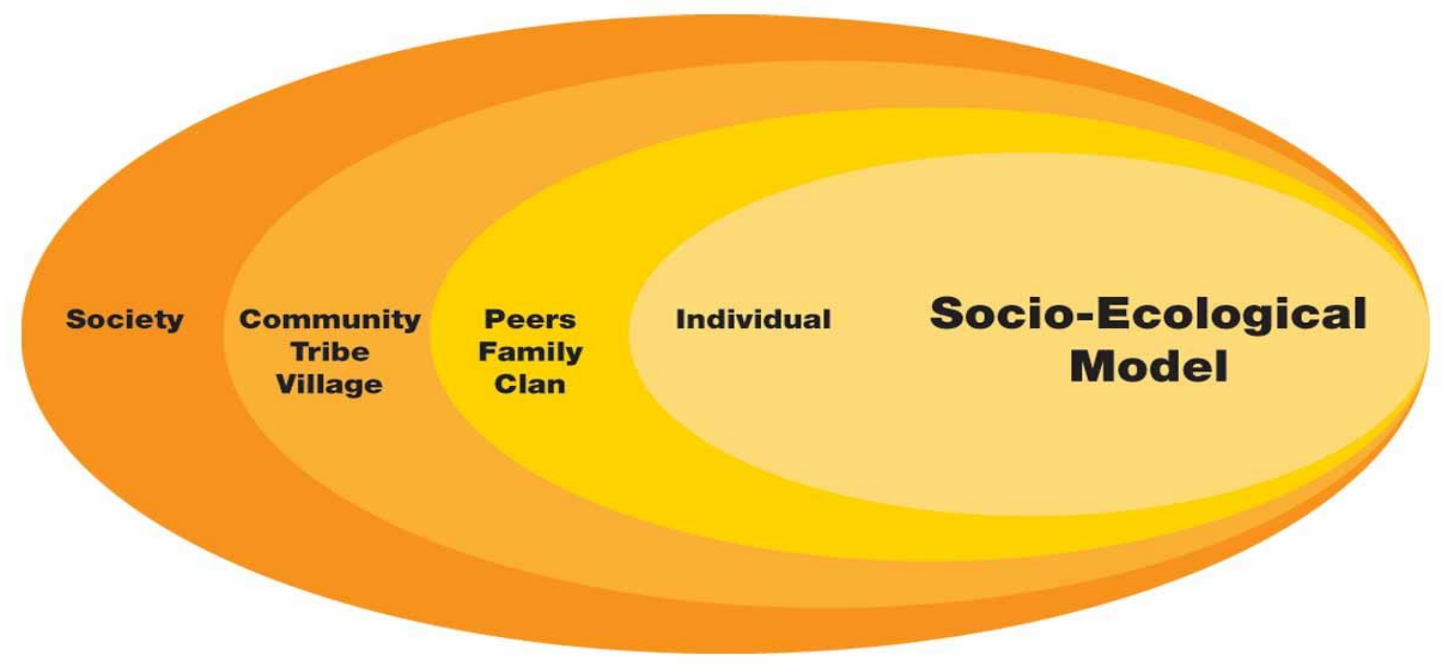

\begin{tabular}{|c|c|}
\hline Individual & Implications \\
\hline $\begin{array}{l}\text { All women in the study resisted violence in } \\
\text { different ways depending on what was } \\
\text { available to them. } \\
\text { Some of the men acknowledged their wives' } \\
\text { resistance and made positive changes as a } \\
\text { result. }\end{array}$ & $\begin{array}{l}\text { Individual counselling for men by trained } \\
\text { male counsellors to help develop better } \\
\text { ways of solving family problems. } \\
\text { Campaigns that encourage men to seek help } \\
\text { for mental health issues, and alcohol and } \\
\text { drug abuse. }\end{array}$ \\
\hline $\begin{array}{l}\text { All female participants had an education, } \\
\text { often tertiary, and held paid employment } \\
\text { which aided financial independence. }\end{array}$ & $\begin{array}{l}\text { Greater focus on the implementation of } \\
\text { policies that support women's economic } \\
\text { opportunities such as vocational and tertiary } \\
\text { education, and on retaining girls in school } \\
\text { after childbirth. } \\
\text { Advocate for paid parental leave and } \\
\text { strengthened policies that support women's } \\
\text { economic empowerment and leadership. }\end{array}$ \\
\hline $\begin{array}{l}\text { The male participants wanted to feel in } \\
\text { control of their decisions hence the process } \\
\text { of change was driven by them. } \\
\text { Informal education and access to } \\
\text { information supported the men in the } \\
\text { process of change. }\end{array}$ & $\begin{array}{l}\text { Create resource hubs in the main centres, } \\
\text { aimed at educating boys and men in } \\
\text { fostering healthy relationships and good } \\
\text { families. } \\
\text { Support school-based and village-based } \\
\text { educational interventions that work with } \\
\text { boys and men to promote non-violent } \\
\text { gender identities. } \\
\text { Engage local male leaders to act as spoke } \\
\text { persons for gender-equal relationships. }\end{array}$ \\
\hline
\end{tabular}




\begin{tabular}{|c|c|}
\hline $\begin{array}{l}\text { For all participants the process of becoming } \\
\text { violence-free took several years and relapse } \\
\text { was common. }\end{array}$ & $\begin{array}{l}\text { Work with village leaders to develop a zero } \\
\text { tolerance for abuse in their village and } \\
\text { develop strategies for dealing with domestic } \\
\text { violence when it happens. }\end{array}$ \\
\hline Family-Relationships & Implications \\
\hline $\begin{array}{l}\text { Supportive employers opened up more } \\
\text { options for women experiencing abuse. }\end{array}$ & $\begin{array}{l}\text { Raise awareness around the injustice of the } \\
\text { survivor of violence having to relocate, } \\
\text { whilst the perpetrator is allowed to stay. } \\
\text { Review policy that currently penalises } \\
\text { women for taking sick-days when away after } \\
\text { domestic violence. }\end{array}$ \\
\hline $\begin{array}{l}\text { The more satisfied the female participant } \\
\text { was with the support from her family, the } \\
\text { more likely she was to initiate a divorce. }\end{array}$ & $\begin{array}{l}\text { Ensure women are fully informed of all } \\
\text { options available to them, including divorce. } \\
\text { Public discussions on the shame versus } \\
\text { safety paradigm. Encourage families to } \\
\text { prioritise safety and rights, over } \\
\text { discriminatory practices. }\end{array}$ \\
\hline $\begin{array}{l}\text { Customary protocols restricted families' } \\
\text { ability to challenge an abusive husband. }\end{array}$ & $\begin{array}{l}\text { Work with entire communities to promote } \\
\text { mutually respectful relationships. }\end{array}$ \\
\hline $\begin{array}{l}\text { A desire to keep children safe was central to } \\
\text { initiating positive change for both male and } \\
\text { female participants. }\end{array}$ & $\begin{array}{l}\text { Encourage both men and women to take } \\
\text { responsibility for pro-active family planning. } \\
\text { Ensure families are fully informed on issues } \\
\text { relating to spacing, timing and number of } \\
\text { children. } \\
\text { Discourage families from using harsh } \\
\text { punishments that hinder young people from } \\
\text { communicating openly and which } \\
\text { perpetuate the cycle of violence. } \\
\text { Offer parenting programmes that provide } \\
\text { skills, tools, resources and support to foster } \\
\text { healthy and non-violent discipline. } \\
\text { Support public campaigns that address the } \\
\text { impact of violence on children and promote } \\
\text { good families. } \\
\text { Couple and individual counselling }\end{array}$ \\
\hline
\end{tabular}




\begin{tabular}{|c|c|}
\hline & $\begin{array}{l}\text { programmes aimed at strengthen } \\
\text { relationships and improving communication. }\end{array}$ \\
\hline Community-Village & Implications \\
\hline $\begin{array}{l}\text { The church and individual pastors influenced } \\
\text { the male participants to create a violence- } \\
\text { free family life based on a vision of a good } \\
\text { family. } \\
\text { The female participants reported } \\
\text { significantly less support from the church } \\
\text { and individual pastors. }\end{array}$ & $\begin{array}{l}\text { Engage with church leaders to propose } \\
\text { training on human rights, including GBV. } \\
\text { Encourage church leaders to network with } \\
\text { professional services and to refer people as } \\
\text { and when needed. }\end{array}$ \\
\hline $\begin{array}{l}\text { Violence against women was considered } \\
\text { private and not a public issue. }\end{array}$ & $\begin{array}{l}\text { Encourage public discussion on how GBV is a } \\
\text { loss to the entire society and not only to the } \\
\text { individual family. } \\
\text { Raise awareness of FSVU, FSC and the Family } \\
\text { Help Desk at the court house. These are not } \\
\text { only emergency services, but clients are } \\
\text { welcome at any point. } \\
\text { Campaign to show the legal steps to end one } \\
\text { marriage before beginning another. Should } \\
\text { go with open discussions on the effect on } \\
\text { families of infidelity and polygamy. }\end{array}$ \\
\hline Society & Implications \\
\hline $\begin{array}{l}\text { Child protection services, the police and the } \\
\text { court had nil or negative effect on the } \\
\text { participants in the process of change. }\end{array}$ & $\begin{array}{l}\text { Prioritise gender sensitisation schemes for } \\
\text { government officials and staff of ABG } \\
\text { Divisions, in particular Local Level } \\
\text { Government and Council of Elders that both } \\
\text { have links to inaccessible areas. } \\
\text { Work alongside ABG Divisions to strengthen } \\
\text { staff capacity to develop gender-specific } \\
\text { policies. }\end{array}$ \\
\hline $\begin{array}{l}\text { Legislation criminalising violence did not } \\
\text { make a difference to the participants' lives. }\end{array}$ & $\begin{array}{l}\text { To work alongside CoEs and village elders to } \\
\text { educate them on the consequences of child } \\
\text { sexual abuse and incest and the need to } \\
\text { report such cases to the police. }\end{array}$ \\
\hline
\end{tabular}




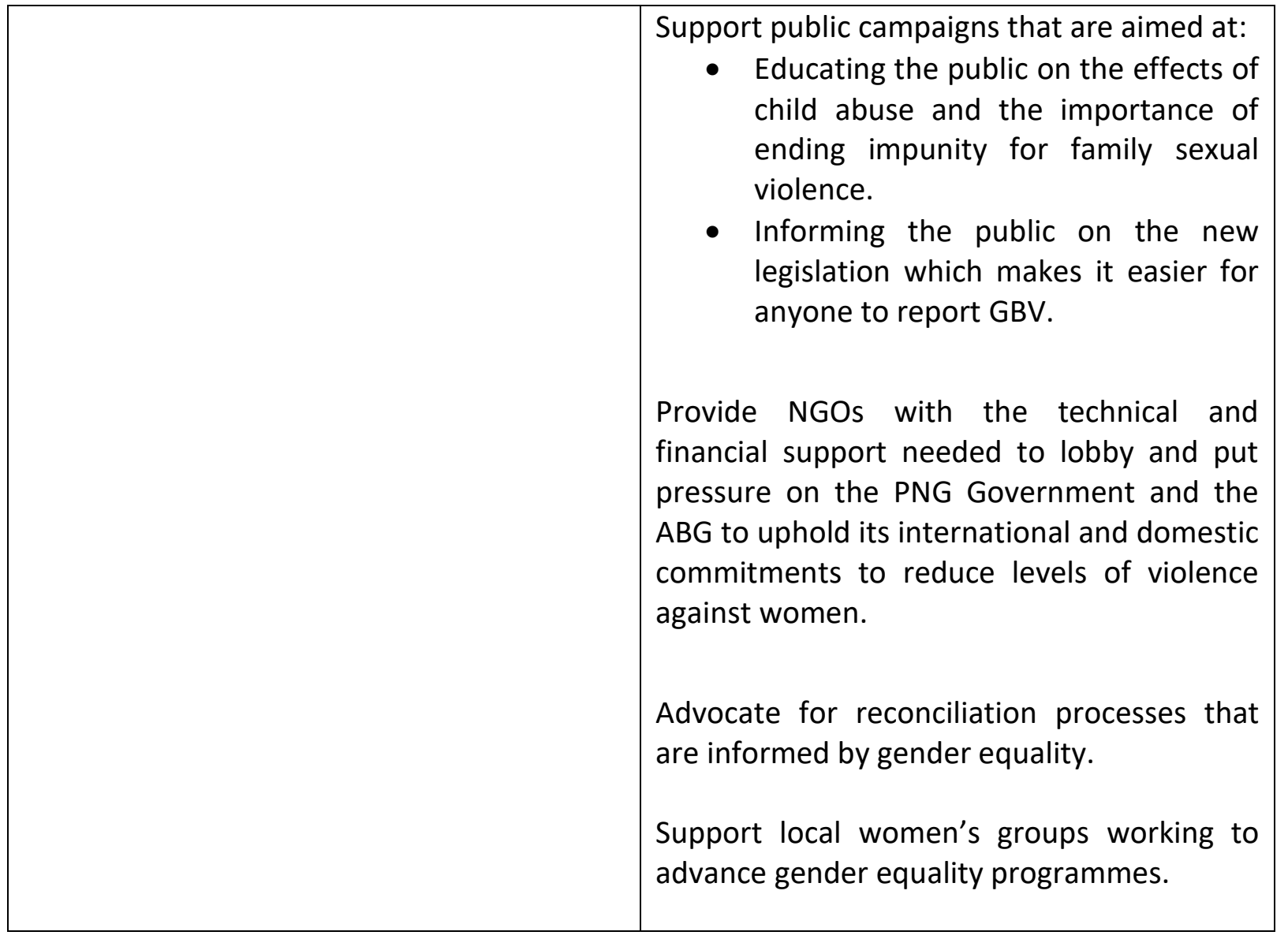

\subsection{Future Research Possibilities}

This study has pointed to numerous gaps in knowledge on the subject of GBV in Bougainville. Below are some possible research areas that would contribute to the overall understanding of violence against women, and gender equality.

- There is a disparity between women's position as landowners and men's overt dominance over the family. How is this possible and what can be done to change this?

- What are the barriers to accessing public services?

- How can young men in Bougainville express themselves in ways that are socially acceptable without including references to violence and physical strength?

- Are the new public services in Bougainville, such as the FSC and the FSVU having a positive effect on clients and the communities?

- This study suggests that the general public's understanding of GBV differs to the definition used by international development actors'. Further research into this gap 
of understanding would target future interventions and ultimately the publics' understanding of GBV, including sexual consent.

- Several female participants' mentioned events that happened during the Conflict. Further research would help develop a better understanding of what effects the Conflict has on current gender relationships.

- What customary practices can strengthen gender relationships, including within marriages?

\subsection{Limitations}

Although I did not aim to generalise the findings it is worth noting that the participants' were all educated and nearly all held paid employment. This is not representative of the general Bougainville population where an estimated 30 per cent of people never attend primary school and where unemployment is high. The findings may have looked different if people with less education had fit the criteria and volunteered their time.

There were also some language limitations as I preferred to conduct the interviews in English. Although most people living and working in urban areas (i.e. Buka Town) speak English, I believe a majority felt better rehearsed speaking Pidgin English. As such, I may have excluded some potential participants. Additionally, I may have inadvertently given preference to those with an education, as they were more likely to speak English. Also, with the one participant which I communicated with through email, I am aware that I may have missed out on specific sayings, tones and pauses, that only face to face interviews can provide.

Bougainville is mainly a matrilineal society which means that women are the landowners and that land is inherited through the mother's side. However, information about women's day to day ability to make decisions and their actual powers is often incomplete or contradictory. This research, although not specifically analysing the complexities of the matrilineal system today, acknowledges that this particular area could provide an untapped possibility for future interventions.

I am aware that my hopes and dreams for an egalitarian Bougainville (indeed world) may not be the same as the hopes and dreams of many Bougainvilleans. My hopes are based on a 
feminist preference linked to my personal history which is different to the circumstances present in Bougainville. Although all of those I spoke with believe that GBV is wrong, my understanding of equality is very different from those I met.

\subsection{Value}

I hope that the findings in this thesis will be of use to the Buka Family Support Centre (FSC), and ultimately those who attend their service for support. The FSC has much flexibility with regard to designing its activities, so will be able to utilise the findings as they see fit. The FSC also has the ability to influence stakeholders through network meetings, attendance at conferences and in partnership with donors. In addition, other agencies in the wider Pacific who are working to address gender inequality may find parts of this thesis to be of interest.

This research is unique in Bougainville. No studies have been done on what actually constitutes change from the perspective of those who have had personal experience of violence. Other studies concerning the motivations, extent (Baines, 2012; Fulu et al., 2013) and impact on health and wellbeing (Ganster-Breidler, 2010) of GBV in Bougainville and PNG have been researched and published. However, thus far, no study has included the voices of survivors, nor from men who have made positive changes.

I believe that my dual role of researcher and FSC worker were of real benefit to this study. By spending an entire year immersed in the topic of GBV and change, and by working closely with NGOs and government professionals, I feel that I am starting to understand what a complex issue this is and what it means to local people. Naturally, as mentioned many times throughout this study, I will never fully understand the multifaceted matter of intimate partner violence in Bougainville, but now I believe that I have something valuable to contribute to the discussion.

Having worked with hospital management and staff for a year, through a well-respected agency (VSA) I hope that I have gained some trust among the people and so the findings of this thesis will be likewise trusted and able to influence and improve the work of the FSC.

\subsection{Discussion}

The dominant discourse of male dominance is stagnant and widely embedded in social approval. There is a general acceptance of men as heads of households and community leaders, which leaves little room for women to share power and challenge the status quo. 
Despite political commitments for two decades to end violence against women, the PNG Government has stated that "the overall approach to gender-based violence issues has been unstructured and uncoordinated". I would like to add that the overall approach has been handled like a hot potato where no Government agency has wanted to take charge of it, but rather passed it on. The will to create change has been limited to pockets of organisational and individual resistance.

The study found that even though physical violence had ended, the attitudes and belief systems underpinning it remained unchanged. Authoritarian-male grooming began early in life and was difficult to shake. Resistance was focused on ending VAW and not on resisting the discourse of male dominance.

Encouraging changes to discriminatory customary practices is a hugely sensitive topic and needs to be addressed with tact by the right people. The intention of this study is not to place blame or even to pinpoint ultimate causes for violence; it is about identifying workable solutions, and solutions in Bougainville need to fit within custom. It is evident that custom has changed over time and will continue to change. Therefore solutions should include greater gender equality in customary practices.

Bougainville's primarily matrilineal system is a source of strength and pride. It is often implicitly suggested that this system equates to greater gender equality and respect for women than the largely patrilineal PNG allows. Yet, I am concerned that such suggestions and beliefs often serve to evade the issue of GBV. Donor agencies have traditionally focused on high level implementations of policy and legislation aimed at curbing violence against women, yet the findings suggest that such efforts have minor impact on the day to day experiences of women.

Instead it is mainly local development agencies, well versed with their own customs that have been driving discussions about the inherent strength of the matrilineal system and how it can be used for the greater purpose of ending violence against women. However, these agencies often work against dominant male structures and discourses and from which they themselves are not exempt.

The need to understand local Bougainville custom, as far down as individual districts, is crucial for effective development practice. It is not enough to have had some experience of a 
custom, rather local people should be involved in any intervention. Involving local people serves two purposes; to ensure interventions are fitting within customary protocols and for enduring approval from the local community.

CoEs are the link between people and local level government and fill a customary function. CoEs have the ability to reach those who live outside of main centres where services are scarcer and where regular communication tools such as radio and newspapers do not reach. As such, CoEs have the potential to influence rural people to a greater extent than national and provincial governments.

What this study has shown is that positive change is relative. All participants claimed to fit the research criteria of having lived free from GBV for a minimum of one year. However, with the unfolding of conversations it became increasingly clear to me that this primarily meant only the end of physical violence. Both the male and female participants told many stories of how life had changed for the better, but I continued to identify several of the stories as still being affected by psychological abuse. The definition of GBV in Bougainville appears much narrower than within the broader field of development work. It was not my position or will to point out these personal reflections, but it made me aware of the different perceptions of GBV.

It is clear that the road to becoming violence-free is never easy. The participants used a range of methods, in a variety of combinations, to reach the stage where they felt violencefree. Previous to this study, influenced by knowledge of the cycle of violence ${ }^{42}$ and fear for safety, I would have urged anyone extreme caution in staying with a partner who is violent. Of course, this standpoint, if oversimplified, was anchored to a Swedish nuclear-family upbringing and an adult life driven by individual wants. Today I still urge the same caution, yet I think the solutions are complex and vary with peoples' circumstances. For some people, leaving a partner is most certainly necessary for personal and offspring's safety. For others, where leaving is not possible there may be other solutions that can ensure their wellbeing. I am reminded that amongst those female participants who stayed and those who left, both took deliberate decisions that they felt content with while considering themselves as living

\footnotetext{
${ }^{42}$ Referring to the repetitive phases of domestic violence that usually escalates over time (National Network of Stopping Violence, 2014)
} 
free from violence. The long term goals of ensuring equality for all ought not to be at the cost of an individual's wellbeing.

The conceptual model provides a variety of possible interventions. It is clear that education for both sexes, and at all tiers of the model, is central to furthering gender equality.

\subsection{Final Thoughts}

This study, although centred on Bougainville, has wider implications. Violence against women is not only a serious concern in PNG, but throughout the world women are disproportionally affected by gender-based violence. Interventions to address violence need to build on the unique systems and way of life in each particular country. For example, Sweden, my country of birth, also reports high rates of domestic violence. However, Swedish interventions should look different to the interventions needed in the Pacific where community plays a much greater role in influencing people's behaviours.

The key themes and implications show that a long-term commitment to end GBV in Bougainville is needed. Interventions should address immediate safety while taking a longterm approach to changing discriminatory systems. Investing in preventative actions and policies, and improving the capacity of local organisations to implement support services are two major strategies that should run concurrently.

Additionally it is important to hold governments accountable to international agreements that focus on ending violence against women, while also increasing the support to those countries that struggle to achieve their goals. There are lessons to be learnt from the many goals and targets that have not been met, such as the Millennium Development Goals in PNG. These lessons should be seen as opportunities to improve policy development and help mitigate risks to future strategies. However, it is not enough to write detailed policies addressing gender equality, there must be a greater focus on implementing them in effective ways. This would ultimately improve women's ability to exercise their rights, to gain access to economic progress and better overall health, while ensuring men are part of the process.

This study has shown that people in all circumstances have the capacity for change, and for those working within the broader field of development, it is a good reminder that change can, and does happen. 


\section{Appendices}

\section{Appendix A: Participant Information Sheet}

\section{INFORMATION SHEET FOR RESEARCH}

\section{RESEARCHER: VIKTORIA DEGERMAN \\ TITLE: GENDER-BASED VIOLENCE IN BOUGAINVILLE: STORIES OF CHANGE}

I am a Masters student in Development Studies at Victoria University of Wellington, New Zealand. As part of this degree I am undertaking a research project leading to a thesis. The project is focusing on how to reduce violence in intimate relationships in Bougainville. By learning from your experience, what led to and sustains a life free from violence, this project can contribute to the knowledge and practice aimed at supporting men and women currently experiencing gender based violence in Bougainville.

\section{BACKGROUND}

Gender-based violence (GBV) has become an umbrella term for any harm that is perpetuated against a person's will. This includes physical, sexual, psychological and economic harm or suffering (most often, but not exclusively, to women) including threats of such acts, coercion or arbitrary deprivations of liberty, whether occurring in public or in private life. Bougainville has a poor record of GBV with many individuals and families being negatively affected, however, there are several initiatives in Bougainville that are committed to improving the situation. This particular research may act as a resource for the Buka General Hospital's Family Support Centre to help in its initiatives to improve gender relationships.

\section{EXPECTED RESULTS}

This research will identify what drives positive change. It will include both men and women, from the perspectives of those who used to abuse their partners in the past, and those who were abused, but are now living free from violence and abuse. The interviews will lead to an analysis which will help to understand 'what works' when addressing gender based violence. By speaking with those who have personal knowledge of the complexities of GBV, the research will be specific and anchored in local custom. The results will be available for Buka General Hospital as well as for an overseas audience in the form of presentations and journal publications as per the consent form.

\section{INTERVIEW FORMAT}

Each interview will take approximately one hour and be held in English. It will be audio recorded if you consent to this. If you choose not to be audio recorded, I will take detailed notes during our conversation instead. The exact nature of the interview is not pre-determined but will depend on how the conversation unfolds. However, the point is to learn about your personal experiences of intimate partner violence, whether you are a survivor of abuse or someone who used abuse in their relationship in the past. What made change possible? What supported/s you to live a life free from violence? Feel assured that no judgment will be passed onto you, instead I appreciate your honesty and self reflection. Should you feel uncomfortable or prefer not to answer any question asked, you are welcome to decline to answer. The interview will take place at the Family Support Centre at Buka Hospital. To make sure that I have understood our conversation correctly I suggest that we meet twice, the first time for the interview itself and the second time to ensure that the information I gathered is correct. 


\section{CONFIDENTIALITY}

All information gathered in the interview is confidential and will only be seen by myself and my supervisor Dr Sara Kindon who is living in New Zealand. Your participation is voluntary and you can retract or change any statements that you have made before April 2014. You can do this by contacting me on any of the details below or during my second meeting with you. This will not have any disadvantage to yourself. The recording of our conversation will be stored at Victoria University in a password-protected computer for two years after completion of the project which is expected to be October 2014.

\section{ETHICAL APPROVAL}

This study has been reviewed and approved by the Ethics Committee of the Victoria University of Wellington in New Zealand.

\section{DATA USE AND STORAGE}

The data collected will be securely stored in such a way that only myself and my academic supervisor will be able to gain access to it. This data will be securely stored for two years after completion of the project for the purpose of accessing the information for additional studies and presentations. If the data is used for additional purposes than the thesis, no information that will identify you will be included.

The completed thesis will be submitted for marking to the School of Geography, Environment and Earth Sciences and deposited in the University library. It is intended that the findings will be presented to Buka General Hospital, and be of particular interest to the Family Support Centre. One or more articles may be submitted to scholarly journals and the research may form the basis of conference presentations. If you wish to receive a report of the findings you may do so by indicating your interest in the consent form (or by verbal recorded consent). This report will be in English.

If you have any questions or would like to receive further information about the project, please contact Sr. Essah Barnabas at Buka Family Support Centre (Buka General Hospital) on essahbarnabas@outlook.com or 7188 4796. You are also welcome to contact myself. See my contact details below. In addition, please contact the Family Support Centre if you experience any unwanted negative effects from the interview and would like support.

Thank you for considering taking part.

\section{Viktoria Degerman}

Email: viktoriadegerman@hotmail.co.nz

Phone: 70442470 (PNG)

+ 64221034125 (NZ) 


\section{Appendix B: Participant Consent Form}

\section{CONSENT FORM}

Title of Project: Gender-Based Violence in Bougainville: Stories of Change

a) I have read and understood the information sheet and I understand that I can request more information at any stage either from Viktoria or Sr. Essah Barnabas

\section{YES/ NO (please circle)}

b) I confirm that I am currently living free from violence and have done so for a minimum of one year

\section{YES/ NO (please circle)}

c) I consent to being audio recorded during the interview YES/ NO (please circle)

d) If I choose not to be audio recorded, I consent to being recorded through written note taking YES/ NO (please circle)

e) With this consent form I have been given an outline of the themes that will be talked about during the interview

\section{YES/ NO (please circle)}

f) I understand that the information I give will not be used for any other purposes than those listed in the information sheet without my consent and that any information attributed to me will remain confidential

\section{YES/NO (please circle)}

g) I consent to participate in an interview about my past experience of gender based violence and what supported positive change. I am aware that my participation is voluntary and that I can withdraw at any time, refuse to answer any questions, or retract any statements before the April 2014 without disadvantage

\section{YES/ NO (please circle)}

h) I would like to receive an executive summary in English of the findings at the conclusion of the research

YES / NO (please circle)

This is where I would like it sent to: 
i) I would also like to add that:

I, .

consent to being interviewed by Viktoria Degerman for the purposes of completing a Master's thesis, producing journal articles, presenting at conferences and to add to the knowledge of Buka General Hospital's Family Support Centre whom are serving clients from all over of Bougainville.

\section{THANK YOU}

Signed:

(or verbally recorded)

Date: 


\section{Appendix C: Interview Themes}

\section{For survivors of violence}

\section{Interview Guide}

- Factual information such as where he/she is from, length of marriage/partnership (or since divorce/separation if appropriate), other cultural particulars if the participant finds it important i.e. clan area, village status, land rights

- Current living situation i.e. children, other family/non family members

- Educational background and employment (formal or informal)

- $\quad$ Living context whilst experiencing abuse

- What type of GBV were they experiencing (this will not include questions of what happened, and examples of the abuse they endured, but I will cautiously ask if they experienced physical, sexual, psychological or financial abuse, or a combination)

- Context of change: what and/ or who influenced change to happen? What made it possible?

- Was the change gradual or sudden? Any particular determining factor?

- Participant input: What did the participant do (if anything) him/herself during the period of change?

- What has sustained a life free from abuse? People? New knowledge? Support? Or anything else.

- In what way (if relevant) is their relationship different today than whilst experiencing abuse from an intimate partner?

\section{For former perpetuators of violence}

- Factual information such as where he/she is from, length of marriage/partnership (or since divorce/separation if appropriate), other cultural particulars if the participant finds it important i.e. clan area, village status, land rights

- Current living situation i.e. intimate partner, children, other family/non family members

- Educational background and employment (formal or informal)

- Living context whilst abusive

- Form(s) of gender-based violence within the relationship (again, this will not include questions of what happened exactly and examples of abuse they used against their partner. This enquiry will cautiously ask about if the person used physical, sexual, psychological or financial abuse, or a combination).

- Context of change: what and/ or who influenced change to happen? What made it possible? Gradual or sudden change? Any particular determining factor?

- Participant input: How did the participant himself (or herself) contribute towards making this positive change?

- What has sustained a life (relationship) free from abuse? People? New knowledge? Support? Or anything else.

- In what way (if relevant) is their relationship different today than it when abuse was present? 


\section{Appendix D: Interview Questions (for one email-based interview)}

\section{Structured Email Questions:}

1. What year are you born?

2. Where are you from? (Province)

3. How many brothers and sisters do you have?

4. What year did you get married?

5. I understand that you have sometimes acted in abusive ways in the past, but that this has now changed and that you are enjoying your family in positive ways today. That's great. What was the biggest contributing factor for you to want to stop using some form of abuse with your wife? (I.e. internal belief system, organisational input, family pressure, police pressure or anything else)

6. Who was living with you at the time of the violence?

7. Did any organisation influence you to want to make positive changes? If so which?

8. Were there any particular people that helped you wanting to make changes? Who? What did they say and how did they say it (i.e. they said it in a non-confronting way)

9. Did your work influence you or not really?

10. What about any spiritual influence, like the church? If you felt positively influenced by the church, what part of their influence was particularly good?

11. Did your family or anyone in the village say or does anything that made you want to make these good changes? What did they say if so? (i.e. an elder or a close family member?

12. Anything or anyone else that have supported you to live a more peaceful life? (i.e. your wife)

13. Anything else you would like to add? 


\section{References}

It contains many omissions and inconsistencies, especially concerning capitalisation, place of publication, page numbers, volume numbers and citations to media. It appears to have been put together very hurriedly.

Bougainville Inward Investment Bureau (2013). Retrieved July 4, 2014, from http://www.investbougainville.com/About-Bougainville

Adultery and Enticement Act. (1988). Papua New Guinea Human Rights Library. Retrieved from https://archive.org/details/AdulteryAndEnticementAct1988.

Amnesty International. (2006a). Papua New Guinea: Culture and resources no excuse for violence against women [Press release]

Amnesty International. (2006b). Papua New Guinea: Violence against women - Not inevitable, never acceptable [Press release]. Retrieved from http://www.amnesty.org.au/svaw/comments/2352/

Amnesty International. (2013). Papua New Guinea repeals Sorcery Act while moving closer to executions. Retrieved June 12, 2014, from http://www.amnesty.org/en/news/papua-newguinea-repeals-sorcery-act-while-moving-closer-executions-2013-05-28

Amnesty International. (2014a). Discrimination. Human Rights. Retrieved October 9, 2014, , from http://www.amnesty.org/en/discrimination

Amnesty International. (2014b). Sexual and Gender-based Violence in the Pacific. Retrieved October 10, 2014, from http://www.amnesty.org.nz/our-work/stop-violence-against-women/sexualand-gender-based-violence-pacific

Anderson, E. (2012). Feminist Epistemology and Philosophy of Science. In E. N. Zalta (Ed.), The Stanford Encyclopedia of Philosophy (Fall 2012 ed.). Stanford, CA: Stanford University

Baines, L. (2012). Gender-Based Violence in Papua New Guinea: Trends and Challenges. Burgmann Journal(1).

Banks, G. (2008). Understanding 'resource'conflicts in Papua New Guinea. Asia Pacific Viewpoint, 49(1), 23-34.

Bevir, M. (1999). Foucault and critique: Deploying agency against autonomy. Political Theory, 65-84.

Bible Study Tools. (2014). Forgiveness Bible Verses. Retrieved October 1, 2014, from http://www.biblestudytools.com/topical-verses/forgiveness-bible-verses/

Boege, V. (2009). Peacebuilding and State Formation in Post-Conflict Bougainville. Peace Review, 21(1), 29-37.

Boege, V. (2013). Addressing legitimacy issues in fragile post-conflict situations to advance conflict transformation and peacebuilding In B. Foundation (Ed.), (pp. 84). Brisbane: The University of Queensland.

Boyd, N. M., \& Bright, D. S. (2007). Appreciative Inquiry as a mode of action research for community psychology. Journal of Community Psychology, 35(8), 1019-1036.

Braithwaite, J. (2010). Reconciliation and architectures of commitment: sequencing peace in Bougainville: ANU E Press.

Bre, H. (2006). The Real Cost of Bride Price. Melanesian Journal of Theology, 22(2), 8-18.

Burr, V. (1995). An Introduction to Social Constructionism: Routledge.

Cassell, C., \& Symon, G. (2004). Essential Guide to Qualitative Methods in Organizational Research (C. Cassell \& G. Symon Eds.). UK: Sage Publications Ltd.

Clarke, S. (2008). Culture and identity. The SAGE Handbook of Cultural Analysis, 510-529.

CLGFP. (2013). Women's Leadership Stories-Bougainville Stories of inspiration from women in local government (pp. 29). Fiji: Commonwealth Local Government Forum Pacific (CLGFP).

Conciliation Resources. (2002). Weaving consensus: the Papua new guinea-Bougainville peace process. In A. Carl \& L. Garasu (Eds.), Women building peace. UK.

Connect. (2014). Community-Based Approach of Our Suicide Prevention Program Model. Training Professionals and Communities in Suicice Prevention Strategies. Retrieved November 10, 
2014, from http://www.theconnectprogram.org/about-connect/community-basedapproach-our-suicide-prevention-program-model

Cooperrider, D. L., \& Whitney, D. (2005). Appreciative Inquiry: A Positive Revolution in Change (1st ed.). California: Berrett-Koehler Publishers, Inc.

Derrida, J. (1997). Deconstruction in a nutshell: A conversation with Jacques Derrida: Fordham Univ Press.

Derrida, J. (2001). On cosmopolitanism and forgiveness: Psychology Press.

DeShong, H. A. (2013). Policing femininity, affirming masculinity: relationship violence, control and spatial limitation. Journal of Gender Studies(ahead-of-print), 1-19.

DFAT. (2014). Papua New Guinea country brief. Department of Foreign Affairs and Trade,: Retrieved from https://www.dfat.gov.au/geo/png/png brief.html.

Dinnen, S. (2001). Law and order in a weak state: Crime and politics in Papua New Guinea. USA: University of Hawaii Press.

Dinnen, S., \& Thompson, E. (2004). Gender and small arms violence in Papua New Guinea. Made available in DSpace on 2011-01-05T08: 55: 592 (GMT). No. of bitstreams: 4

04_08_dp_dinnenthompson. pdf. jpg: 4203 bytes, checksum:

29c04d5ec86c962a644da1ea15a6b29a (MD5) 04_08_dp_dinnenthompson. pdf: 480630 bytes, checksum: 79b5678eba2fd51a6bc8797a9c584ded (MD5) 2984- NO. XSH: 368 bytes, checksum: 347c88aacd12c431cd575a80d923376e (MD5) 04_08_dp_dinnenthompson. pdf. txt: 79461 bytes, checksum: 386a0bc51f44c2e59c6b0d16122ade28 (MD5) Previous issue date: 2005-03-10.

Doty, R. L. (1993). Foreign policy as social construction: A post-positivist analysis of US counterinsurgency policy in the Philippines. International Studies Quarterly, 297-320.

Dr B. Matanu (2013, November 21st, 2013). [Womens Rights Workshop].

EIGE. (2014). What is gender-based violence? Retrieved October 10, 2014, from http://eige.europa.eu/content/what-is-gender-based-violence

Evenhuis, M. (2013, October 8th, 2013). [Sorcery in Bougainville].

Eves, R. (2012). Christinaity, masculinity and gender violence in Papua New Guinea. In s. a. g. i. M. p. The state (Ed.). Australian National University: Australian National University.

Fetterman, D. M. (2010). Ethnography: Step-by-Step (3rd ed.). US: SAGE Publications, Inc.

Fletcher, J., Parkhill, F., Fa'afoi, A., \& Morton, M. (2006). Poto He Anga: collaboration and Consultation in Pasifika research. Qualitative Research Journal, 6(1), 36-50.

Fonow, M. M., \& Cook, J. A. (1991). Back to the future: A look at the second wave of feminist epistemology and methodology. In J. A. C. Mary Margaret Fonow (Ed.), Beyond Methodology: Feminist Scholarship as lived research. USA: Indiana University Press.

Foucault, M. (1979). Michel Foucault: power, truth, strategy (Vol. 2): Feral Publications.

Foucault, M. (1980). Power/knowledge: Selected interviews and other writings, 1972-1977: Random House LLC.

Foucault, M. (1984). Space, knowledge and power. The Foucault Reader, 239, 256.

Foucault, M., \& Hurley, R. (1990). An introduction. Vol. 1 of The history of sexuality. Trans. Robert Hurley. New York: Vintage-Random.

Fulu, E., Warner, X., Miedema, S., Jewkes, R., Roselli, T., \& Lang, J. (2013). Why Do Some Men Use Violence Against Women and How Can We Prevent It? Quantitative Findings from the United Nations Multi-country Study on Men and Violence in Asia and the Pacific. Bangkok: UNDP, UNFPA, UN Women and UNV.

Ganster-Breidler, M. (2010). Gender-Based Violence and the Impact on Women's Health and WellBeing in Papua New Guinea. Contemporary PNG Studies, 13.

Gaventa, J. (2003). Foucault: Power is everywhere. Retrieved September 24, 2014, from http://www.powercube.net/other-forms-of-power/foucault-power-is-everywhere/

Gaventa, J., \& Cornwall, A. (2001). Handbook of action research: Participative inquiry and practice. In P. Reason \& H. Bradbury (Eds.): Sage. 
Gavey, N. (1989). Feminist Poststructuralism and Discourse Analysis. Psychology of Women Quarterly, 13, 459-475.

Geology (Cartographer). (2008). Papua New Guinea Map - Papua New Guinea Satellite Image. Retrieved from http://geology.com/world/papua-new-guinea-satellite-image.shtml

Goodland, R. (2012). Responsible mining: the key to profitable resource development. Sustainability, $4(9), 2099-2126$.

Graham, L. J. (2005). Discourse analysis and the critical use of Foucault.

Graham, L. J., \& Slee, R. (2008). An illusory interiority: Interrogating the discourse/s of inclusion. Educational Philosophy and Theory, 40(2), 277-293.

Gregory, D., Johnston, R., Pratt, G., Watts, M., \& Whatmore, S. (Eds.). (2011) The Dictionary of Human Geography (5th ed.). United Kingdom: Blackwell Publishers Ltd.

Greig, A., Basnyat, A., \& Lang, J. (n.d.). Men and the Prevention of Gender-based Violence A Conceptual Framework for Policy Change. Partners for Prevention: Working with Boys and Men to Prevent Gender-based Violence. Discussion Paper. UN Asia Pacific Regional Programme. UN Asia Pacific Regional Programme

United Nations. Retrieved from file:///C:/Users/viktoria/Downloads/policy_change\%20(2).pdf GUIDE, A. P. (2005). Researching violence against women.

Hakena, H. (2002). Interview with Helen Hakena, Leitana Nehan Women's Development Agency. In C. Richards (Ed.), Peace Women. Peace Women.

Hakena, H., Ninnes, P., \& Jenkins, B. (2006). NGOs and post conflict recovery M. May (Ed.) The Leitana Nehan Women's Development Agency (pp. 182).

Haraway, D. (1988). Situated Knowledges: The Science Question in Feminism and the Privilege or Partial Perspective. Feminist Studies, 14(3), 575-599.

Harding, S. (1988). Introduction: Is there a Feminist method? In S. Harding (Ed.), Feminism and Methodology: Social Science Issues (pp. 208). Bloomington and Indianapolis: Indiana University Press.

Hartsock, N. (1990). Foucault on power: a theory for women? Feminism/postmodernism, 162.

Hayward, C. R. (2000). De-facing power: Cambridge University Press.

Heise, L. L. (1998). Violence against women an integrated, ecological framework. Violence against women, 4(3), 262-290.

Herbert, S. (2000). For Ethnography. Progress in Human Geography, 24(4), 550-568.

Hesse-Biber, S. N. (2012). Exploring, Interrogating, and Transforming the Interconnections of Epistemology, Methodology, and Method. In S. N. Hesse-Bibe (Ed.), Handbook of Feminist Research Theory and Praxis (2nd ed., pp. 792). Boston College: SAGE Publications Inc.

Hook, D. (2001). Discourse, Knowledge, Materiality, History Foucault and Discourse Analysis. Theory \& Psychology, 11(4), 521-547.

Howley, P. (2004). The Melanesian way: Law and justice before the arrival of the white man. Contemporary PNG Studies, 1, 69.

Howley, P. (2005a). A marriage of Melanesian custom law and Westminster. Contemporary PNG Studies, 2, 103.

Howley, P. (2005b). Rescue mission for village courts: Mediation on non payment of allowances to village courts. Contemporary PNG Studies, 3, 47.

Human rights watch. (2014). Papua New Guinea: Address police brutality. World report. Retrieved September 24, 2014, , from http://www.hrw.org/news/2014/01/21/papua-new-guineaaddress-police-brutality

Ipp, O. (2013). Bougainville Stability Desk Study (U. S. A. f. I. Development, Trans.) Development Transformations (pp. 29). USA: United States Agency for International Development.

Islands Business. (2013). PNG Family Protection Bill passed. Retrieved June 12, 2014, from http://www.islandsbusiness.com/news/papua-new-guinea/2953/png-family-protection-billpassed/ 
Jacobs, S. (2012). Seeking optimism: Westminster in PNG. Policy: A Journal of Public Policy and Ideas, 28(4), 30.

Jayaratne, T. E., \& Stewart, A. J. (2008). Just Methods: An Interdisciplinary Feminist Reader (A. M. Jaggar Ed.). CO: Paradigm.

Jessep, O. (1992). De Facto relationships and the law in Papua New Guinea. International and Comparative Law Quarterly, 460-472.

Jolly, M., Stewart, C., \& Brewer, C. (2012). Engendering Violence in Papua New Guinea: ANU E Press.

Jørgensen, M. W., \& Phillips, L. J. (2002). Discourse analysis as theory and method: Sage.

Kamkuus, M. (2013, December 2, 2013). Shut up ladies, Post Courier.

Kay, B., \& Russell, R. (2013). Mosquito Eradication: The Story of Killing Campto: CSIRO PUBLISHING.

Kirkman, A. (2013, 3/08/2013). [Revisions required to your Human Ethics application].

Kopi, M. (2010). Violence and Insecurity in the Southern Highlands of Papua New Guinea: Oxfam.

Krug, E. G., Mercy, J. A., Dahlberg, L. L., \& Zwi, A. B. (2002). The world report on violence and health. The lancet, 360(9339), 1083-1088.

Kua, K. (2013). Papua New Guinea parliament repeals Sorcery Act, reinstates execution. In J. Tahana (Ed.), Pacific News (pp. 1).

Map of Bougainville (2010). Retrieved from http://commons.wikimedia.org/wiki/File:Bougainville map.png

Masiu, R. (2013, Nov 27, 2013). Violence against women on rise, Post Courier.

McEwan, C. (2008). Postcolonialism and development: Routledge.

Miller, T., Mauthner, M., Birch, M., \& Jessop, J. (2012). Ethics in Qualitative Research (2nd ed.). London, UK: SAGE Publications

Mills, S. (2007). Geography, gender and power. In J. W. Crampton \& S. Elden (Eds.), Space, knowledge and power: Foucault and geography: Ashgate Publishing, Ltd.

Momis, J. (2013). Bougainville president furious at "flawed report" on gender violence. In D. Wiseman (Ed.), Dateline Pacific. Radio NZ: Radio NZ.

Morriss, C. (2006). 'Women of War, Women of Peace: Politics, Empowerment and Women in Postconflict Bougainville' Paper presented at the Australasian Political Studies Association Conference, University of Newcastle.

Moss, P. (2001). Taking on, Thinking about, and Doing Feminist Research in Geography. In P. Moss (Ed.), Feminist Geography in Practice: Research and Methods (pp. 288): Wiley-Blackwell.

Nanau, G. L. (2011). The Wantok System as a Socio-economic and Political Network in Melanesia. The Journal of Multicultural Society, 2(1), 31-55.

National Department of Health. (2009). Ministerial Taskforce on Maternal Health in Papua New Guinea (N. D. o. Health, Trans.). Port Moresby: National Department of Health.

National Network of Stopping Violence. (2014). Who's Affected. Retrieved September 24, 2014, , from http://www.nnsvs.org.nz/whos-affected/women

National Research Institute. (2010). Papua New Guinea District and Provincial Profiles National Research Institute.

National Strategic Plan Taskforce. (2009). Papua New Guinea Vision 2050: National Strategic Plan Taskforce. PNG: Retrieved from http://www.actnowpng.org/sites/default/files/png\%20version\%202050.pdf.

Nations, U. (2012). Towards freedom from fear and want: Human rights in the post-2015 agenda Thematic Think Piece. 13. http://www.un.org/millenniumgoals/pdf/Think\%20Pieces/9 human rights.pdf

NZ Aid Programme. (2012). New Zealand Partnerships For International Development: Consultation Paper. New Zealand.

O'Farrell, C. (2007). Michael Foucault-Key Concepts. Retrieved October 3, 2014, from http://www.michel-foucault.com/concepts/ 
OECD. (n.d.-a). OECD Principles for Public Governance of Public-Private Partnerships. Retrieved June 6, 2014, from http://www.oecd.org/governance/oecdprinciplesforpublicgovernanceofpublicprivatepartnerships.htm

OECD. (n.d.-b). Partnering with Civil Society: 12 Lessons from DAC Peer Reviews. Retrieved June 6, 2014, from http://www.oecd.org/dac/peer-reviews/partneringwithcivilsociety.htm

Orkii. (2013). Papua New Guinea Fertility rate, total (births per woman). Retrieved from: http://www.orkii.com/papua-new-guinea/fertility-rate-total

Oxfam. (2014). Escaping Violence. Retrieved May 30, 2014, from http://www.oxfam.org.nz/whatwe-do/where-we-work/papua-new-guinea/gender-justice/escaping-violence

Oxfam. (n.d.). Protecting the accused: Sorcery in PNG. Retrieved June 3, 2014, from http://www.oxfam.org.nz/what-we-do/where-we-work/papua-new-guinea/genderjustice/confronting-sorcery

Oxford Dictionary. (2014). Appreciation Oxford Dictionaries language matters. Oxford University Press: Oxford University Press.

Pearson, D. (2010, 18-19 November). Matrilineal System in Bougainville; The cultural solution to Land Tenure and Security for women. Paper presented at the Indigenous Women, Climate Change \& Reducing Emissions From Deforestation \& Forest Degradation (Redd+), Philippines.

PIFS. (2013). 2013 Pacific Regional MDG's Tracking Report (pp. 112): Pacific Island Forum Secretariat. PNG Government. (2004). Millenium Development Goals: Progress report for PNG (P. Government \& U. N. i. PNG, Trans.). In N. E. Council (Ed.), (pp. 50).

PNG Government. (2009). Report on the Status of Women in Papua New Guinea and the Autonomous Region of Bougainville 2008 Papua New Guinea.

PNG Government. (2010a). National Health Plan 2011-2020 Transforming our health system towards Health Vision 2050 (Vol. Volume 1, pp. 70). National Department of Health: PNG Government.

PNG Government. (2010b). Papua New Guinea Medium Term Development Plan 2011-2015. Port Moresby, PNG: Department of Planning and Monitoring.

Pollard, S. (2014). Economic growth - can inclusive policies overcome exclusive practices? . Retrieved from http://devpolicy.org/

Rabinow, P., \& Rose, N. (2003). Foucault today. P. Rabinow \& N. Rose (Eds.(2003) The essential Foucault (1954-1984).

Radio New Zealand. (2013). PNG sorcery-related killings described as 'silent epidemic'. Dateline Pacific.

http://www.radionz.co.nz/international/programmes/datelinepacific/audio/2579875/pngsorcery-related-killings-described-as-'silent-epidemic'

Radio New Zealand. (2014a). Bougainville police detain woman accused of using black magic. Dateline Pacific. http://103-14-3-

6.rev.rnz.net.nz/international/programmes/datelinepacific/audio/2596257/bougainvillepolice-detain-woman-accused-of-using-black-magic

Radio New Zealand. (2014b). Six killed in sorcery-related attack in PNG. Retrieved from Radio New Zealand website: http://www.radionz.co.nz/international/pacific-news/241881/six-killed-insorcery-related-attack-in-png

Reddy, P. (2008). Reconciliation in Bougainville: Civil war, peacekeeping and restorative justice. Contemporary Justice Review, 11(2), 117-130.

Regan, A. (1998). Causes and course of the Bougainville conflict. The Journal of Pacific History, 33(3), 269-285.

Regan, A. (2002). Bougainville: Beyond Survival. Melanesia: The future of tradition. Retrieved July 3 , 2014, from https://www.culturalsurvival.org/ourpublications/csq/article/bougainvillebeyond-survival

Reilly, B. (2008). Ethnic Conflict in Papua New Guinea. Asia Pacific Viewpoint, 49(1), 12-22.

Sawicki, J. (1991). Disciplining Foucault: Feminism, power, and the body: Psychology Press. 
Secretariat of the Pacific Community. (n.d.). Revised Pacific Platform For Action On Advancement Of Women And Gender Equality (RPPA) (pp. 4). Fiji.

Silverman, D. (2006). Interpreting Qualitative Data (3 ed.): Sage Publications Ltd.

Sirivi, J. T., \& Havini, M. T. (2004). As Mothers of the Land: The Birth of the Bougainville Women for Peace and Freedom. Austraian National University: Pandanus Books.

Slatter, C. (2012). Gender and custom in the south pacific. Yearbook of New Zealand Jurisprudence, $13,89$.

Smith, P. D. (1987). Education and colonial control in Papua New Guinea: A documentary history: Longman Cheshire.

Stuart, K., \& Barnett, J. (2012). Localising peace: The young men of Bougainville's 'Crisis generation'. Political Geography, 31(1), 34-43.

Swain, P. (2005). Rebuilding Bougainville. In VSA (Ed.), VSA Case Study Series (pp. 68). Wellington New Zealand: VSA.

Thomson, M. (2012). Integrating Gender-based Violence: The post- 2015 agenda Addressing Inequalities The Heart of the Post-2015 Development Agenda and the Future We Want for All (pp. 39). The Irish Consortium on Gender-based Violence The Irish Consortium on Genderbased Violence

Thrift, N. (2008). Non-representational theory: J. Urry (Ed.) Space, Politics, Affect Retrieved from http://www.cmecc.com/uploads/\%E8\%AF\%BE\%E6\%9C\%AC\%E5\%92\%8C\%E8\%AE\%BA\%E6\%9 6\%87/\%E7\%A9\%BA\%E9\%97\%B4\%E7\%A4\%BE\%E4\%BC\%9A\%E6\%96\%87\%E5\%8C\%96/\%5B39 \%5D\%5B\%E7\%A9\%BA\%E9\%97\%B4\%E7\%A4\%BE\%E4\%BC\%9A\%E6\%96\%87\%E5\%8C\%96\%5D.T hrift,N(2008).Non-Representational. Theory .Space, politics, affect.pdf

UN. (1996). Women and violence. Retrieved October 14, 2014, from http://www.un.org/rights/dpi1772e.htm

UN Data. (2014). Papua New Guinea [Electronic]. Retrieved from: https://data.un.org/CountryProfile.aspx?crName=Papua\%20New\%20Guinea

UNICEF. (2013). At a glance: Papua New Guinea Statistics (December 27th, 2013 ed.). USA: UNICEF.

Unicef. (2014). Lukautim pikinini module 10 child protection laws and policies. Retrieved October 22, 2014, , from http://www.unicef.org/png/FBO Manual Part 4.pdf

United Nations. (1979). Convention on the Elimination of All Forms of Discrimination against Women. United Nations Entity for Gender Equality and the Empowerment of Women. Retrieved June 10, 2014, from http://www.un.org/womenwatch/daw/cedaw/cedaw.htm

United Nations. (2000). Goal 2: Achieve Universal Primary Education. Retrieved June 28, 2014, from http://www.un.org/millenniumgoals/education.shtml

United Nations. (2013). Promote Gender Equality and Empower Women We can end poverty: Millenium Development Goals and Beyond 2015. Retrieved June 2, 2014, from http://www.un.org/millenniumgoals/gender.shtml

US Government. (2013). The Social-Ecological Model: A Framework for Violence Prevention. USA: USA Government Retrieved from http://www.cdc.gov/violenceprevention/pdf/sem framewrk-a.pdf.

Vaioleti, T. M. (2006). Talanoa Research Methodology: A developing position on Pacific Research. Waikato Journal of Education(12).

Vilosi, D. J. (2014). Arawa Health Center Restoration: Saving Lives. In EMTV (Ed.), EMTV. PNG: EMTV.

Wainetti, U. (2013). Extreme violence against PNG women on the rise. The Queensland Nurse, 32(4), 22.

Weiner, J., McLeod, A., \& Yala, C. (2002). Aspects of conflict in the contemporary Papua New Guinea Highlands. State Society and Governance in Melanesia, 16.

WHO. (2007). The cycles of violence. Violence and Injury Prevention Programme Retrieved September 30, 2014, from http://www.euro.who.int/ data/assets/pdf file/0008/98783/E90619.pdf

WHO. (2012). Health Service Delivery Profile Papua New Guinea 2012 In WHO \& P. N. G. National Department of Health (Eds.), (pp. 12): WHO 
National Department of Health, Papua New Guinea.

WHO. (2013). A quarter of all women in the WHO European Region experience physical and/or sexual violence by an intimate partner [Press release]. Retrieved from http://www.euro.who.int/en/media-centre/sections/press-releases/2013/11/a-quarter-ofall-women-in-the-who-european-region-experience-physical-andor-sexual-violence-by-anintimate-partner

WHO. (2014a). The ecological framework Violence Prevention Alliance. Global campaign for violence prevention. Retrieved June 30, 2014, from http://www.who.int/violenceprevention/approach/ecology/en/

WHO. (2014b). What do we mean by "sex" and "gender"? Gender, women and health. Retrieved November 11, 2014, from http://www.who.int/gender/whatisgender/en/

WHO. (2014c). What do we mean by "sex" and "gender"? Gender, women and health Retrieved October 14, 2014, from http://www.who.int/gender/whatisgender/en/

Willig, C. (2007). Discourse Analysis. In J. A. Smith (Ed.), Qualitative Psychology: A Practical Guide to Research Methods (2 ed., pp. 288): SAGE.

Willig, C., \& Stainton-Rogers, W. (2007). The SAGE handbook of qualitative research in psychology: Sage.

World Vision. (2014). Bougainville. Retrieved June 28, 2014, from http://www.worldvision.org.nz/our-work/where-we-work/papua-newguinea/bougainville.aspx

Worthington, K. L. (2011). Suturing the Wound: Derrida's "on Forgiveness" and Schlink's The Reader. Comparative Literature, 63(2), 203-224.

Yin, R. K. (2003). Case study research: design and methods (3rd ed.). California, US: SAGE Publications Inc.

Zocca, F. (2010). Gender and Accusations of Malevolent Sorcery and Witchcraft in Papua New Guinea. Catalyst, 40(2), 192. 